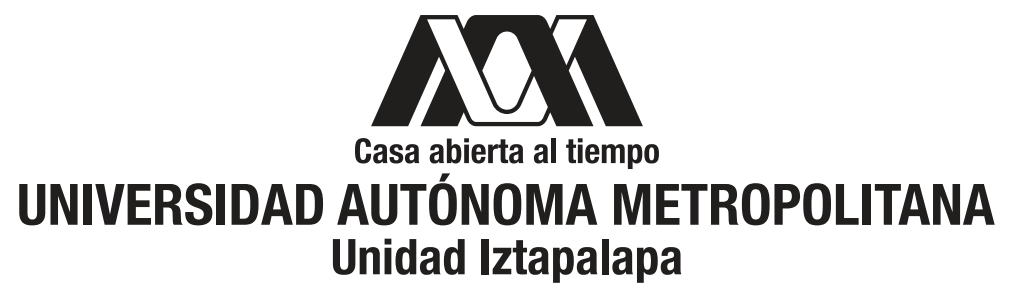

DIVISIÓN DE CIENCIAS BÁSICAS E INGENIERÍA

POSGRADO EN MATEMÁTICAS APLICADAS E INDUSTRIALES

\title{
Estimación computacional de la distribución interna de dosis absorbida en un tumor sólido a partir de imágenes tomográficas
}

\author{
$\begin{array}{lllll}\mathbf{T} & \mathbf{E} & \mathrm{S} & \mathrm{I} & \mathrm{S}\end{array}$ \\ que para optar al grado de: \\ Maestro en Ciencias (Matemáticas Aplicadas e Industriales) \\ presenta: \\ Fís. Sirio Bolaños Puchet
}

$\begin{array}{ll}\text { Asesores: } & \text { Dr. José Héctor Morales Bárcenas } \\ & \text { Dr. Luis Alberto Medina Velázquez }\end{array}$

Jurado calificador:

Presidente: $\quad$ Dr. Luis Alberto Medina Velázquez

Secretario: $\quad$ Dr. Mario Gerardo Medina Valdez

Vocal: $\quad$ Dr. José Héctor Morales Bárcenas

Vocal: $\quad$ Dr. Carlos Juárez Osornio 

Mariel y Amelia

姉妹 



\section{Agradecimientos}

A mis asesores, Héctor y Luis Alberto. Al primero por darme la oportunidad de hacer mi trabajo de tesis en un tema con sentido de utilidad que aplica las matemáticas a la vida; al segundo por recibirme con los

brazos abiertos en su laboratorio y realizar los experimentos junto conmigo. A ambos por sus consejos.

A los colegas y compañeros del Laboratorio de Física Médica e Imagen Molecular, por su apoyo en la realización de los experimentos; por las discusiones, las bromas y las risas. En especial a Irene, por crecer el modelo tumoral y enseñarme a preparar la agarosa; a Josefina y Vanessa, por cuidar de los ratones; a Omar, por facilitarnos las dosis de lutecio y a Roberto, por asistirme en la realización de los experimentos.

A los ingenieros Abel Orero y Emilio Giménez de Oncovision, por su ayuda poniendo en marcha el equipo y realizando la cuantificación de las imágenes.

Al M. en C. Miguel Rodríguez, por su apoyo en la calibración de las películas de tinte radiocrómico.

A los miembros del comité sinodal, por sus comentarios y observaciones.

A mis profesores de la maestría, en especial a Patricia Saavedra y Héctor Juárez, por sus enseñanzas.

A Mariel, por todo su amor y su apoyo; porque hemos vencido juntos una tesis más.

A Javier, porque en el proceso de explicarle lo que hacía, pude entenderlo yo mejor.

A mis padres, por darme la vida y permitirme disfrutarla. 



\section{ÍNDICE}

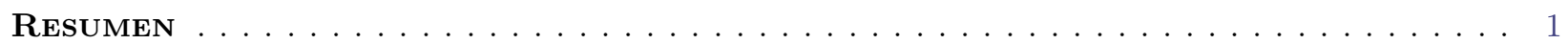

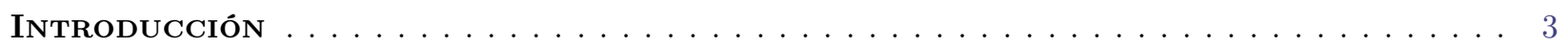

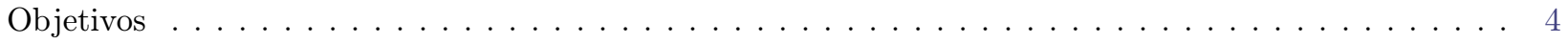

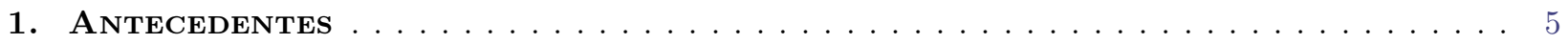

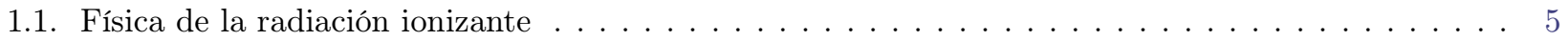

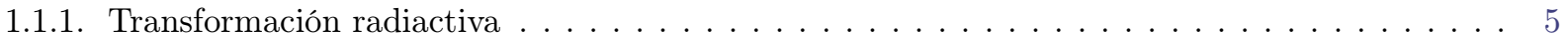

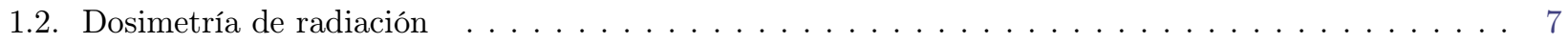

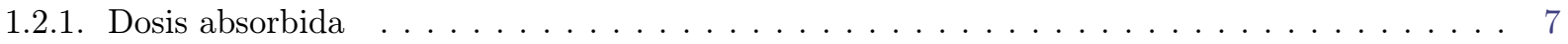

1.2.2. Estimación de la dosis absorbida: el formalismo MIRD $\ldots \ldots \ldots \ldots \ldots \ldots \ldots \ldots \ldots$

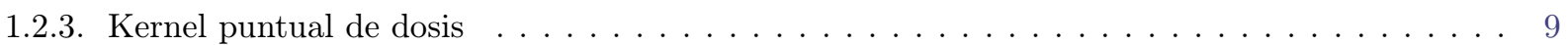

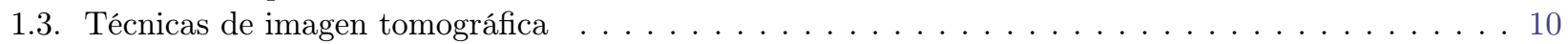

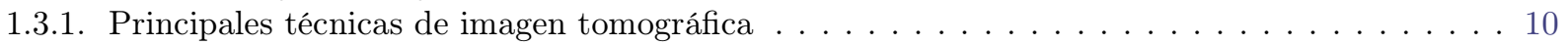

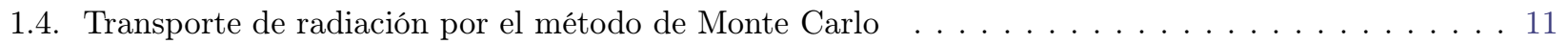

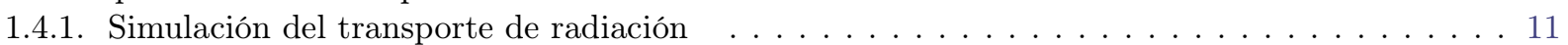

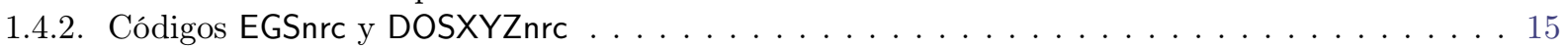

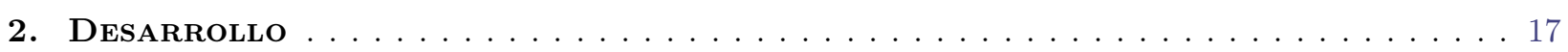

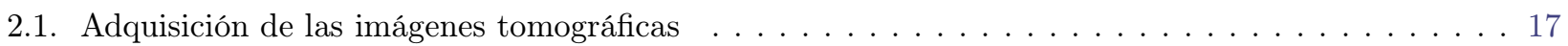

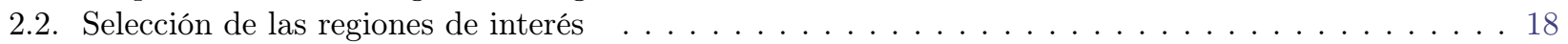

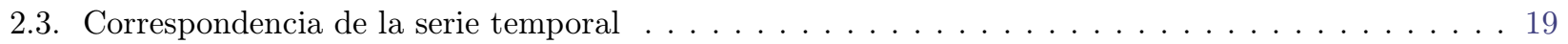

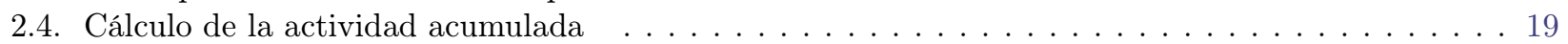

2.5. Cálculo del kernel de dosis por voxel _ . . . . . . . . . . . . . . . . . . . . . . . 20

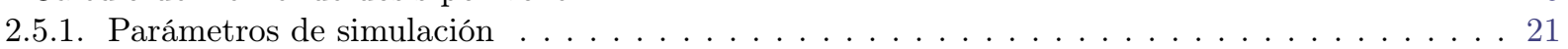

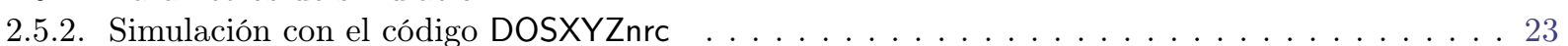

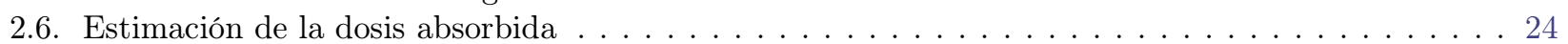

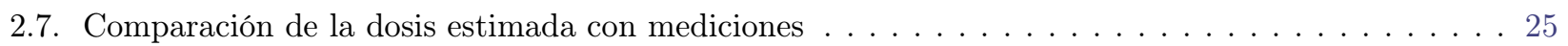

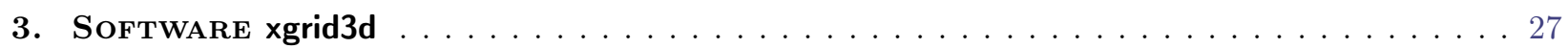

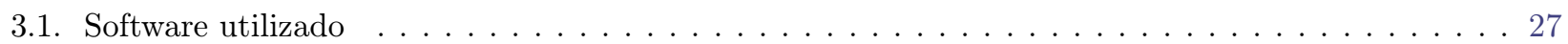

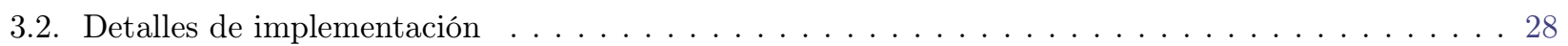

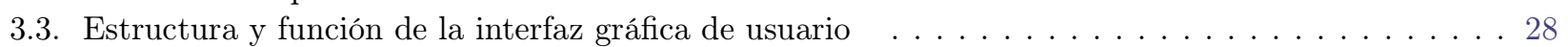

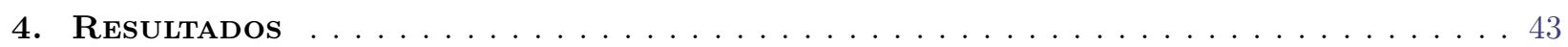

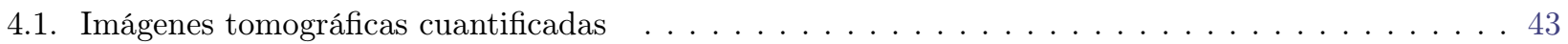

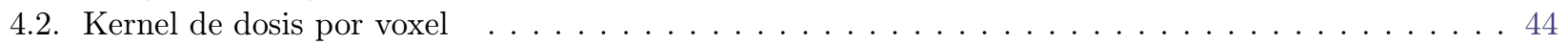

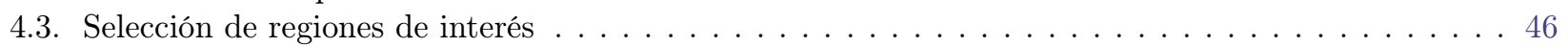

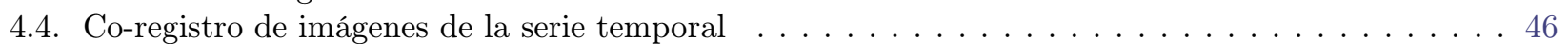

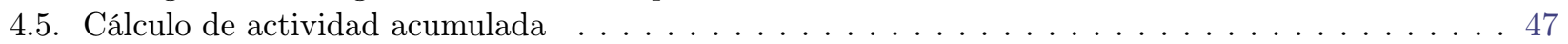

4.6. Estimación de dosis . . . . . . . . . . . . . . . . . . . . . . . . . . . . . . . 49

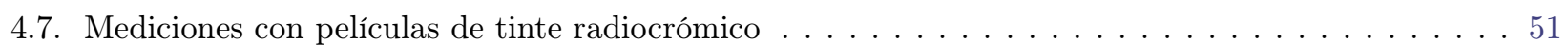




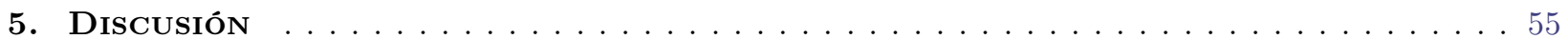

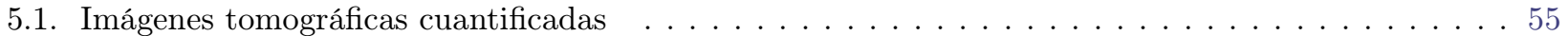

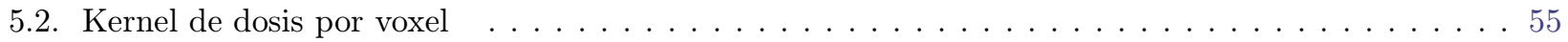

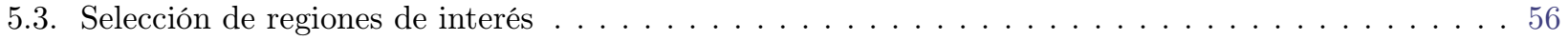

5.4. Co-registro de imágenes de la serie temporal $\ldots \ldots \ldots \ldots \ldots \ldots \ldots \ldots \ldots \ldots$

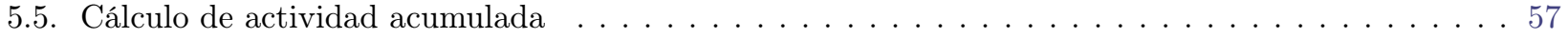

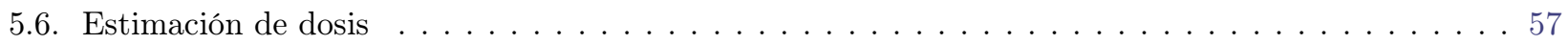

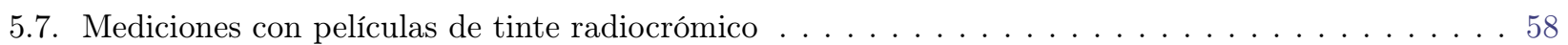

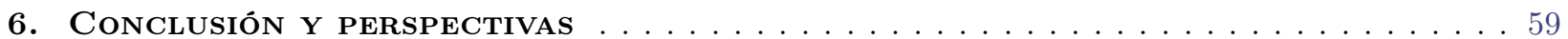

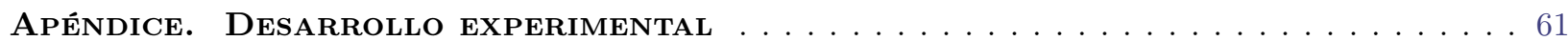

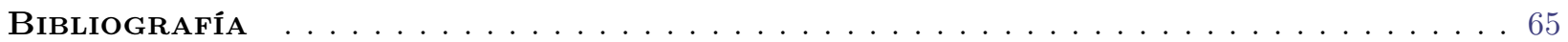




\section{RESUMEN}

En este trabajo se propone una metodología de cálculo para estimar la distribución de dosis absorbida al interior de un tumor sólido. El enfoque seguido utiliza la información de una serie de imágenes tomográficas de la distribución de actividad de un radionúclido emisor beta-gamma para calcular la distribución de actividad acumulada; a partir de ésta, se obtiene la distribución de dosis absorbida por convolución con un kernel de dosis por voxel, el cuál se genera mediante la simulación computacional del transporte de radiación por el método de Monte Carlo. Para auxiliar en la implementación de la metodología se desarrolló el software xgrid3d, el cuál se describe a detalle. A partir de los resultados de la prueba de concepto realizada con un modelo tumoral, se identificaron algunas dificultades y limitaciones de la metodología. Se concluye que, si bien se ha desarrollado e implementado con éxito la metodología, hace falta realizar más pruebas y contar con una estimación del error para dar confiabilidad a los resultados. Este trabajo es un primer paso hacia el desarrollo de la dosimetría Monte Carlo personalizada. 



\section{INTRODUCCIÓN}

En esta tesis de matemáticas aplicadas se propone una metodología de cálculo para estimar la dosimetría interna de un radionúclido emisor beta-gamma en un tumor sólido, a partir de datos tomográficos. Es un trabajo multidisciplinario e interinstitucional, vinculado al sector salud en el ámbito de la investigación de nuevas terapias contra el cáncer.

De acuerdo con la Organización Mundial de la Salud ${ }^{[1]}$ :

«Cáncer» es un término genérico que designa un amplio grupo de enfermedades que pueden afectar a cualquier parte del organismo; también se habla de «tumores malignos»o «neoplasias malignas». Una característica definitoria del cáncer es la multiplicación rápida de células anormales que se extienden más allá de sus límites habituales y pueden invadir partes adyacentes del cuerpo o propagarse a otros órganos, un proceso que se denomina «metástasis». Las metástasis son la principal causa de muerte por cáncer.

Muchos tipos de cáncer, como los sarcomas, carcinomas y linfomas, forman tumores sólidos, es decir, masas anormales de tejido que no contienen quistes ni regiones con líquido ${ }^{[2]}$. Otros tipos de cáncer, como las leucemias, por lo general no forman tumores sólidos.

El cáncer es la segunda causa de muerte a nivel mundial, acarreando 8.8 millones de defunciones en $2015^{[1]}$. En México, si se agrupan todas las defunciones ocurridas en 2013 como consecuencia de algún tipo de cáncer, éste se ubica como la segunda causa de muerte en mujeres y la tercera en hombres ${ }^{[3]}$. Debido a varios factores, entre ellos las limitaciones de las tres modalidades convencionales de terapia (cirugía, radioterapia y quimioterapia) y el gran número de pacientes que mueren actualmente (más del $50 \%$ de los casos a nivel mundial en $2012^{[4]}$ ), la investigación de nuevos tratamientos para el cáncer es un área de mucha actividad e importancia hoy día.

La participación de las matemáticas aplicadas, junto con las ciencias físicas, en esta área de investigación es de particular importancia. En las últimas décadas, ha habido avances dramáticos en las tecnologías de la formación de imágenes y el diagnóstico médico se ha beneficiado de la incorporación de mejores algoritmos de reconstrucción en las distintas técnicas de imagen, como son la tomografía computarizada de rayos X o las tomografías por emisión (PET y SPECT).

Este trabajo está guiado por datos experimentales, por lo que se buscó profundizar en la comprensión de los datos al participar de manera directa en su proceso de adquisición. El trabajo experimental se llevó a cabo en el Laboratorio de Física Médica e Imagen Molecular de la Unidad de Investigación Biomédica en Cáncer (INCan/UNAM), en el Instituto Nacional de Cancerología; en este laboratorio se trabaja en un sistema de liberación de fármacos a nanoescala por medio de liposomas, que permita el transporte selectivo de fármacos citotóxicos al tejido tumoral, utilizando un anticuerpo monoclonal para mejorar la especificidad por las células tumorales y un radionúclido para fines de imagen y terapia, con el que se podría ofrecer un tratamiento combinado que aumente la eficacia terapéutica y disminuya los efectos secundarios adversos de las terapias convencionales ${ }^{[5]}$.

Los liposomas son vesículas de dimensiones nanométricas formadas por una doble capa de fosfolípidos que encierran un espacio acuoso. Existen algunos estudios dosimétricos tanto teóricos ${ }^{[6,7]}$ como experimen$\operatorname{tales}^{[8,9]}$, así como algunos estudios preclínicos ${ }^{[10,11]}$ que analizan el uso de complejos liposoma-radionúclido con fines terapéuticos, administrados por vía intravenosa o intratumoral en tumores sólidos. En el caso intratumoral, se ha encontrado que es ventajoso el mayor grado de localización y fijación obtenido mediante la inyección directa en el tumor de los liposomas radiactivos, lo que se traduce en una dosis de radiación mayor en el tumor y menor en los tejidos sanos, así como una relajación del requisito de una distribución homogénea en todo el tumor debido al efecto de fuego cruzado de la radiación $\beta^{[12]}$; a pesar de esto, la correcta determinación de la biodistribución de los liposomas radiactivos dentro del tejido tumoral sigue siendo un factor preponderante en la determinación de la distribución espacial de la dosis ${ }^{[8]}$. 
Un radionúclido de mucho interés en este campo es el Renio-188 $\left({ }^{188} \mathrm{Re}\right)$. El empleo de este radionúclido es atractivo debido a sus características físicas y químicas, así como su disponibilidad a costo razonable mediante un generador in situ de Tungsteno-188/Renio-188 con una vida útil de 6 a 8 meses ${ }^{[13,14]}$. Entre las propiedades físicas favorables del Renio- 188 se encuentran ${ }^{[15]}$ : una vida media relativamente corta $(17 \mathrm{~h})$, lo que favorece su manejo radiológico, una emisión gamma de baja intensidad (155 keV, 15.6\%) con energía en el rango idóneo para su detección mediante una cámara gamma y una emisión beta de alta energía (764 keV promedio, $2.12 \mathrm{MeV}$ máxima) para propósitos terapéuticos.

El empleo de un emisor beta-gamma como el Renio-188, hace posible la determinación de manera no invasiva - mediante una técnica de imagen - de la biodistribución del agente terapéutico, lo que abre las puertas a la evaluación dosimétrica y a la planeación terapéutica personalizadas. Mediante la simulación computacional del transporte de radiación por el método de Monte Carlo, además de una serie temporal de imágenes tomográficas de la distribución de radiactividad inyectada al paciente (en una dosis diagnóstica), y con la ayuda de la modelación farmacocinética, es posible obtener una predicción de la dosimetría del tejido tumoral y de los órganos sanos de interés previo a la terapia ${ }^{[16,17]}$. Con esta información puede, en principio, evaluarse la viabilidad y efectividad de la terapia en términos del balance entre el efecto terapéutico potencial y los efectos secundarios nocivos, así como optimizar la terapia considerando la dosis recibida por el tumor en relación a los tejidos sanos, e incluso con ayuda de la modelación radiobiológica es posible hacer una predicción - aunque con bastantes reservas - del efecto terapéutico de la radiación sobre el tejido tumoral afectado.

Este trabajo se propone desarrollar una metodología de cálculo que permita realizar la dosimetría interna de los radionúclidos emisores beta-gamma bajo consideración para la terapia liposomal, la cuál pueda utilizarse como herramienta en el ámbito de la investigación preclínica con modelos animales y que sirva como base para la eventual aplicación clínica.

La estructura de esta tesis es la siguiente. En el primer capítulo se incluyen los antecedentes conceptuales que sirven como sustento. El segundo capítulo plantea la metodología de estimación de dosis y es el capítulo más importante de esta tesis, pues en él se describen a detalle los pasos que llevan desde la adquisición de las imágenes tomográficas hasta la estimación de la distribución de dosis. En el capítulo tres se describe el software xgrid3d, desarrollado como auxiliar para la implementación de la metodología. En el cuarto capítulo se presentan los resultados de la prueba de concepto realizada para evaluar la viabilidad y utilidad de la metodología, mientras que el quinto capítulo aborda la discusión de éstos. Por último, en el capítulo seis se enuncia la conclusión y algunas perspectivas de trabajo futuro. En el apéndice se describe el desarrollo experimental que acompaña a la prueba de concepto realizada.

\section{OBJETIVOS}

\section{Objetivo general.}

Estimar mediante un algoritmo computacional la distribución interna de dosis absorbida en un tumor sólido, utilizando información sobre la distribución de actividad acumulada de un radionúclido emisor beta-gamma obtenida a partir de imágenes tomográficas en la modalidad SPECT.

\section{Objetivos particulares.}

1. Desarrollar una metodología para estimar la dosis absorbida en una matriz tridimensional de imagen tomográfica, a partir de una distribución de actividad como función del tiempo.

2. Calcular un kernel de dosis por voxel para el radionúclido emisor beta-gamma de interés, mediante la simulación computacional del transporte de radiación por el método de Monte Carlo.

3. Estimar la dosis absorbida mediante la convolución por transformada de Fourier entre la distribución de actividad acumulada y el kernel de dosis.

4. Evaluar la metodología a través de una prueba de concepto con un modelo tumoral. 


\section{CAPÍtulo 1}

\section{ANTECEDENTES}

Para abordar este trabajo de tesis es necesario revisar conceptos relativos a la física de la radiación ionizante, la dosimetría de radiación, las técnicas de imagen tomográfica y la simulación del transporte de radiación por el método de Monte Carlo. Debido a la amplitud de estos temas, sólo se presentan los fundamentos necesarios que sustentan el presente trabajo.

\subsection{FÍSICA DE LA RADIACIÓN IONIZANTE}

El término radiación se refiere a energía en tránsito. La radiación ionizante es aquella que tiene la capacidad de expulsar electrones de los átomos con los que interactúa ${ }^{[18,19]}$, lo que se denomina ionización.

La radiación ionizante puede clasificarse en dos grandes categorías:

Radiación Directamente Ionizante - Considera las partículas cargadas, que depositan su energía en la materia a través de múltiples interacciones de tipo Coulombiano con los electrones del medio a lo largo de su trayectoria.

Radiación Indirectamente Ionizante - Considera las partículas neutras, que depositan su energía en la materia mediante un proceso de dos etapas: primero transfieren su energía a las partículas cargadas del medio a través de un número relativamente pequeño de interacciones fuertes, y después estas partículas cargadas depositan su energía como en el caso directamente ionizante.

Algunos tipos de radiación ionizante de interés son:

Rayos $\gamma$. Radiación electromagnética (fotones) emitida durante las transiciones nucleares o la reacción de aniquilación entre materia y antimateria.

Rayos X. Radiación electromagnética (fotones) emitida por las partículas cargadas al cambiar de nivel de energía atómico (rayos X característicos o de fluorescencia) o al ser frenadas en el campo de interacción Coulombiana del núcleo (rayos X continuos o Bremsstrahlung).

Electrones. Partículas con carga unitaria negativa.

\subsubsection{Transformación radiactiva}

La transformación radiactiva es el proceso mediante el cuál un núcleo inestable se transforma en uno más estable y siempre va acompañado de una liberación de energía, ya sea como radiación electromagnética o como energía cinética de las partículas emitidas, o una combinación de ambas; cuando el núcleo producto es a su vez inestable, el proceso continúa a lo largo de una cadena de transformación hasta alcanzar una configuración nuclear estable. La transformación radiactiva es un fenómeno estocástico y espontáneo, pues no es posible predecir el momento en que ocurre y no es afectado de manera significativa por el ambiente externo del núcleo. 
Algunos modos de transformación radiactiva de interés son ${ }^{[20]}$ :

\section{Decaimiento $\boldsymbol{\beta}^{-}$.}

Consiste en la conversión de un neutrón en un protón con la subsecuente liberación de un electrón y un neutrino, los cuáles comparten la energía liberada en la transformación dando lugar a una distribución o espectro para la energía cinética del electrón, que se extiende desde cero hasta una energía máxima.

\section{Emisión $\gamma$.}

Cuando un núcleo está en un estado excitado puede emitir espontáneamente un fotón - denominado rayo $\gamma-$ y pasar a un estado de menor energía, ya sea en un sólo paso o a través de una cascada de emisiones sucesivas; la energía de cada fotón así emitido es igual a la diferencia de energía entre los estados involucrados.

\section{Conversión interna.}

Consiste en la emisión directa de un electrón atómico — denominado electrón de conversión - usualmente desde una capa interna, dando lugar a una cascada de relajación para ocupar la vacancia electrónica.

\section{Descripción matemática del decaimiento radiactivo.}

Empíricamente se observa que el número de átomos radiactivos en una muestra disminuye con el tiempo. La disminución en el número de átomos radiactivos $d N(t)$ durante un intervalo de tiempo $d t$ es proporcional a este intervalo y al número actual de átomos radiactivos $N(t)$, dando lugar a la siguiente ecuación diferencial:

$$
d N(t)=-\lambda N(t) d t
$$

cuya solución se conoce como la ley de decaimiento radiactivo:

$$
N(t)=N_{0} \mathrm{e}^{-\lambda t},
$$

donde $N_{0}=N(0)$ es el número inicial de átomos radiactivos y $\lambda$ es la constante de decaimiento total, con valor $\lambda=1 / \tau$ donde $\tau$ es la vida promedio de un núcleo radiactivo en la muestra. La principal característica de esta ley de decrecimiento exponencial es que a intervalos iguales de tiempo, el número de átomos radiactivos disminuye en la proporción constante dictada por $\lambda$.

Al número promedio de transformaciones radiactivas por unidad de tiempo se le conoce como la actividad de la muestra:

$$
A(t)=\lambda N(t),
$$

y tiene unidades de transformaciones nucleares o decaimientos radiactivos por segundo, lo que en el Sistema Internacional de Unidades se denomina un Becquerel (Bq).

La vida media de un radionúclido se define como el tiempo promedio necesario para que el número de átomos radiactivos en una muestra disminuya a la mitad:

$$
\tau_{1 / 2}=\frac{\ln 2}{\lambda}
$$

y es una propiedad que puede medirse experimentalmente, a diferencia de la constante de decaimiento. 


\subsection{Dosimetría DE RADiACIÓN}

La dosimetría de radiación se refiere a la determinación, ya sea mediante el cálculo o la medición, de la cantidad y distribución espacial y temporal de la energía depositada por la radiación ionizante al interactuar con la materia. La dosimetría interna de radionúclidos trata específicamente del depósito de energía en los tejidos debido a la radiación emitida por radionúclidos dentro del cuerpo, y tiene aplicación tanto en cuestiones de radioprotección como de medicina nuclear diagnóstica y terapéutica ${ }^{[21]}$.

\subsubsection{Dosis absorbida}

La dosis absorbida es una cantidad relevante para todos los tipos de radiación ionizante ${ }^{[18]}$. Se define como el valor esperado de la energía depositada por unidad de masa en un punto:

$$
D=\frac{d \bar{E}}{d m}
$$

y sus unidades son $\mathrm{J} \cdot \mathrm{kg}^{-1}$, lo que en el contexto de la dosimetría de radiación se denomina Gray (Gy).

Esta cantidad representa la energía por unidad de masa que se transfiere a la materia para producir cualquier efecto atribuible a la radiación. Algunos efectos son proporcionales a $D$, mientras que otros varían con $D$ de maneras más complicadas. Sin embargo, si $D=0$ la radiación no puede tener ningún efecto; es por esto que la dosis absorbida es la cantidad más importante para propósitos de determinar el efecto de la radiación sobre la materia.

La tasa de dosis absorbida se define como la derivada temporal de la dosis absorbida:

$$
\dot{D}=\frac{d D}{d t}
$$

y sirve para describir la variación temporal de la dosis absorbida, la cuál se debe al carácter dinámico de la radiactividad y a la farmacocinética del radiofármaco introducido al paciente.

Las experiencias in vivo e in vitro realizadas en el campo de la radiobiología han contribuido a identificar los principales parámetros que influyen sobre la respuesta biológica de los tejidos a la irradiación; estos incluyen —más allá de la dosis absorbida total — la tasa de dosis absorbida y el grado de heterogeneidad de la distribución de dosis absorbida ${ }^{[17]}$.

La dosis de radiación no puede medirse directamente de manera no invasiva, por lo que es necesario recurrir a las técnicas de imagen médica para obtener información a partir de la cual pueda realizarse una estimación de la dosis absorbida o la tasa de dosis y de su distribución espacial en el paciente. El propósito de esta estimación puede ser para monitorear la dosis de radiación durante la terapia, o bien para predecir la dosis de radiación durante la terapia a partir de una evaluación previa conocida como planificación del tratamiento.

\subsubsection{Estimación de la dosis absorbida: el formalismo MIRD}

La estimación de la dosis absorbida depende de varios factores, como son la actividad administrada, la distribución espacial y temporal de la actividad en el cuerpo del paciente, la anatomía del paciente y las características (tipo y energía) de las radiaciones emitidas ${ }^{[22]}$.

El esquema de cálculo establecido por el Comité Médico de Dosis de Radiación Interna (MIRD), de la Sociedad de Medicina Nuclear e Imagen Molecular (SNMMI), tiene el objetivo de estimar la dosis absorbida antes de la administración de un radiofármaco y es el enfoque más utilizado en el campo de la dosimetría interna. 
La ecuación que propone el formalismo MIRD para calcular la dosis absorbida en el caso independiente del tiempo puede escribirse de las siguientes formas ${ }^{[23]}$ :

$$
\begin{aligned}
\bar{D}\left(r_{k} \leftarrow r_{h}\right) & =\tilde{A}_{h} \sum_{i} \Delta_{i} \phi_{i}\left(r_{k} \leftarrow r_{h}\right) / m_{k} \\
& =\tilde{A}_{h} \sum_{i} \Delta_{i} \Phi_{i}\left(r_{k} \leftarrow r_{h}\right) \\
& =\tilde{A}_{h} S\left(r_{k} \leftarrow r_{h}\right)
\end{aligned}
$$

donde $\bar{D}\left(r_{k} \leftarrow r_{h}\right)$ es la dosis absorbida promedio en la región objetivo $r_{k}$ debido a la actividad en la región fuente $r_{h}$ y la suma en las dos primeras formas es sobre las emisiones en la región fuente. Los demás términos se explican a continuación:

$\tilde{A}_{\boldsymbol{h}}$ - es la actividad acumulada, que representa el número total de transformaciones nucleares que ocurren en la región fuente $r_{h}$ durante el tiempo de interés y se calcula integrando la actividad en tal región como función del tiempo sobre el intervalo de interés, lo que involucra tomar en cuenta tanto la disminución en la actividad del radionúclido con el tiempo como el proceso de eliminación del radiofármaco del cuerpo;

$\boldsymbol{\Delta}_{\boldsymbol{i}}$ - es la energía promedio por transición nuclear para la emisión $i$ y se calcula como $n_{i} \bar{E}_{i}$, donde $\bar{E}_{i}$ es la energía promedio por partícula y $n_{i}$ es el número de partículas emitidas por transición;

$\phi_{\boldsymbol{i}}\left(\boldsymbol{r}_{\boldsymbol{k}} \leftarrow \boldsymbol{r}_{\boldsymbol{h}}\right)$ - es la fracción absorbida, que representa la fracción de la energía emitida en la región fuente $r_{h}$ que es absorbida en la región objetivo $r_{k}$. Varía con el tipo y energía de la radiación, el material que atraviesa la radiación y la configuración geométrica y composición de las regiones objetivo y fuente. Por el principio de reciprocidad se cumple que $\phi_{i}\left(r_{k} \leftarrow r_{h}\right)=\phi_{i}\left(r_{h} \leftarrow r_{k}\right)$. Matemáticamente, esta función cumple el papel de la función de Green ${ }^{[24]}$ de un operador autoadjunto, pues satisface la relación de simetría antes enunciada; esta propiedad significa que la respuesta del sistema, causada por una perturbación puntual, es indistinta a la localización de la perturbación;

$\boldsymbol{m}_{\boldsymbol{k}}$ - es la masa de la región objetivo $r_{k}$;

$\boldsymbol{\Phi}_{\boldsymbol{i}}\left(\boldsymbol{r}_{\boldsymbol{k}} \leftarrow \boldsymbol{r}_{\boldsymbol{h}}\right)$ - es la fracción absorbida específica, y es igual a $\phi_{i}\left(r_{k} \leftarrow r_{h}\right) / m_{k}$;

$\boldsymbol{S}\left(\boldsymbol{r}_{\boldsymbol{k}} \leftarrow \boldsymbol{r}_{\boldsymbol{h}}\right)$ - es el valor $S$ para las regiones $r_{k}$ y $r_{h}$, que representa la dosis absorbida promedio por unidad de actividad acumulada para una configuración dada de regiones objetivo y fuente, y se calcula como $\sum_{i} \Delta_{i} \Phi_{i}\left(r_{k} \leftarrow r_{h}\right)$.

Para obtener la dosis promedio total en la región objetivo $r_{k}$, se suman simplemente las contribuciones de todas las regiones fuente $r_{h}$ :

$$
\bar{D}\left(r_{k}\right)=\sum_{h} \bar{D}\left(r_{k} \leftarrow r_{h}\right)
$$

En el caso dependiente del tiempo se considera que tanto la masa de la región objetivo como las fracciones absorbidas pueden cambiar con el tiempo, por lo que se utiliza la siguiente expresión:

$$
\dot{D}\left(r_{k}, t\right)=\sum_{h} A\left(r_{h}, t\right) S\left(r_{k} \leftarrow r_{h}, t\right)
$$

donde $\dot{D}\left(r_{k}, t\right)$ es la tasa de dosis promedio total en la región objetivo $r_{k}, A\left(r_{h}, t\right)$ es la actividad en la región fuente $r_{h}$ y $S\left(r_{k} \leftarrow r_{h}, t\right)$ es el correspondiente valor $S$, todos al tiempo $t$; integrando esta expresión sobre el intervalo de irradiación se obtiene la dosis promedio total. 
Desde sus inicios este esquema se ha basado en el uso de maniquíes antropomórficos (modelos matemáticos de la anatomía humana) que representan una geometría promedio de los órganos del cuerpo para rangos de edad específicos en ambos géneros y también para casos especiales como los bebés y las mujeres embarazadas. El Comité MIRD ha publicado tablas de fracciones absorbidas obtenidas mediante simulaciones del transporte de radiación dentro de estas geometrías al nivel de órganos ${ }^{[25]}$. Sin embargo, no hay nada intrínseco en el esquema MIRD que impida su extensión a regiones de cualquier tamaño y posición relativa, para las que se considere que la actividad se distribuye uniformemente en cada región fuente y se obtenga la dosis promedio para cada región objetivo.

La escala mínima para la definición de una región fuente en un modelo dosimétrico usualmente se basa en la escala espacial a la que es posible cuantificar de manera precisa la actividad de un radiofármaco ${ }^{[26]}$. La dosimetría por voxel o a nivel de voxel se define como el cálculo de la dosis absorbida en regiones de tejido con dimensiones que van desde unos pocos centímetros hasta cientos de micrómetros. Como su nombre lo indica, la dosimetría por voxel se asocia generalmente con las técnicas de imagen tomográfica para la cuantificación de la actividad.

\subsubsection{Kernel puntual de dosis}

Un kernel puntual de dosis representa la distribución radial de tasa de dosis alrededor de una fuente de radiación puntual e isotrópica en un medio infinito y homogéneo, ya sea para una emisión monoenergética o para un espectro de emisión ${ }^{[27]}$. Esta distribución radial puede expresarse de varias maneras, ya sea como fracción absorbida específica o como dosis absorbida por unidad de actividad, en función de la distancia $\boldsymbol{r}$ desde la fuente puntual. Otro enfoque utiliza una malla cartesiana y considera un voxel como fuente, describiendo la distribución de dosis dentro de la propia matriz, lo que da lugar al denominado kernel de dosis por voxel; este enfoque se emplea cuando se trabaja con imágenes tomográficas.

La idea del kernel puntual se basa en considerar que toda región fuente puede descomponerse en un conjunto de fuentes puntuales, y que por lo tanto la dosis debido a la actividad total en tal región puede verse como una superposición lineal de las contribuciones de cada fuente puntual. En términos matemáticos esto se expresa mediante una integral de convolución ${ }^{[28]}$ en tres dimensiones:

$$
\dot{D}(\boldsymbol{r}, t)=\int_{\Omega^{\prime}} A\left(\boldsymbol{r}^{\prime}, t\right) k\left(\boldsymbol{r}-\boldsymbol{r}^{\prime}\right) d \Omega^{\prime}
$$

donde $\dot{D}(\boldsymbol{r}, t)$ es la tasa de dosis absorbida en la posición $\boldsymbol{r}$ dentro de la región objetivo al tiempo $t, A\left(\boldsymbol{r}^{\prime}, t\right)$ es la actividad radiactiva en la posición $\boldsymbol{r}^{\prime}$ dentro de la región fuente $\Omega^{\prime}$ al tiempo $t$ y $k\left(\boldsymbol{r}-\boldsymbol{r}^{\prime}\right)$ es el valor del kernel puntual centrado en $\boldsymbol{r}^{\prime}$ y evaluado en $\boldsymbol{r}$; el kernel $k$ es función solamente de la distancia $\left\|\boldsymbol{r}-\boldsymbol{r}^{\prime}\right\|$ y cumple con propiedades matemáticas análogas a la fracción absorbida $\phi$ del esquema MIRD, en la página anterior. Si en lugar de la actividad, se utiliza la actividad acumulada dentro de la región fuente:

$$
\tilde{A}\left(\boldsymbol{r}^{\prime}\right)=\int A\left(\boldsymbol{r}^{\prime}, t\right) d t,
$$

se obtiene la dosis absorbida en la región objetivo.

Los principales inconvenientes de este enfoque son que el kernel puntual es válido solamente en el caso de un medio homogéneo, lo que puede ser problemático cuando se busca aplicarlo en regiones inhomogéneas del cuerpo (como las interfases con los huesos o los pulmones), y que usualmente se calcula para la distribución de dosis promedio, por lo que no considera las fluctuaciones estadísticas propias de la transformación radiactiva al nivel de átomos individuales y se coloca en el dominio de la macrodosimetría.

En los casos donde esto es irrelevante, el kernel puntual es un método muy práctico, pues solamente requiere calcularse una vez y posteriormente se aplica, mediante un algoritmo rápido de convolución - como puede ser la transformada rápida de Fourier - a cualquier distribución de actividad. Sin embargo, si las inhomogeneidades en la composición del medio son de importancia, debe abandonarse este enfoque y realizarse la simulación directa del transporte de radiación en el tejido o región de interés. 


\subsection{TÉCNICAS DE IMAGEN TOMOGRÁFICA}

Las técnicas de imagen tomográfica médica permiten obtener información del interior del cuerpo de manera no invasiva, en la forma de un conjunto de planos o cortes que abarcan una porción del volumen del cuerpo. El tipo de información que puede obtenerse es de tipo anatómico, mostrando las estructuras internas del cuerpo, o funcional, mostrando las condiciones fisiológicas del paciente, y puede obtenerse de forma estática o dinámica, según si se toma una sola imagen o un conjunto de imágenes en una serie temporal. La principal característica de las técnicas de imagen tomográfica es que permiten obtener una distribución tridimensional de las estructuras bajo estudio, lo que mejora considerablemente la localización anatómica respecto a la imagen plana — pues evita la ofuscación por el traslape de estructuras superpuestas - contribuyendo así a mejorar la calidad del diagnóstico ${ }^{[29,30]}$.

La formación de una imagen tomográfica ${ }^{1.1}$ involucra el registro de información desde un gran número de ángulos alrededor del objetivo, lo que da lugar a un conjunto de proyecciones a partir de las cuales puede realizarse la reconstrucción - mediante un algoritmo matemático - de un corte o sección del mismo; debido a esto, los sistemas de imagen tomográfica médica utilizan un sistema de detectores que rota en un anillo fijo alrededor del paciente, el cuál es trasladado a su vez a lo largo del eje de rotación para abarcar el volumen bajo estudio. Cada corte así obtenido se halla subdividido en una malla rectangular de elementos de imagen (pixeles), cada uno de los cuales corresponde a un elemento de volumen (voxel) con dimensiones - dentro del plano del corte y a lo largo del eje de rotación - dictadas por el arreglo de detectores y la modalidad de detección utilizados. De este modo, el resultado de un estudio de imagen tomográfica es una descomposición del volumen de interés en una matriz tridimensional de voxeles, cada uno de los cuales tiene asociado un valor numérico que representa alguna información relacionada con esa ubicación.

Las técnicas de imagen tomográfica médica utilizan fotones suficientemente energéticos como para poder penetrar el cuerpo del paciente. Cuando se detectan las emisiones provenientes de una fuente en el interior del cuerpo se habla de tomografía por emisión, mientras que cuando se registran las emisiones de una fuente externa tras atravesar el cuerpo se habla de tomografía por transmisión.

\subsubsection{Principales técnicas de imagen tomográfica}

\section{Tomografía computarizada de rayos X (CT).}

Conocida simplemente como tomografía computarizada ${ }^{1.2}$, es una técnica de tomografía por transmisión que utiliza como fuente un tubo de rayos $\mathrm{X}$ y permite observar de manera no invasiva las estructuras anatómicas al interior del cuerpo en tres dimensiones.

\section{Tomografía computarizada por emisión de fotón único (SPECT).}

Forma parte de las técnicas de imagen nuclear, cuyo propósito es obtener una imagen de la distribución de una sustancia radiactiva al interior del cuerpo. Es una técnica de tomografía por emisión que se emplea con radionúclidos que emiten rayos $\gamma$ únicos o múltiples (sin correlación angular), usualmente en el rango de energía entre 80 y $300 \mathrm{keV}$ y de manera óptima en el rango entre 100 y $200 \mathrm{keV}$. Debido a que la distribución de un radiofármaco en el cuerpo está asociada a procesos fisiológicos o metabólicos, esta modalidad de imagen permite obtener información funcional, pero no anatómica.

Para conocer de manera precisa la ubicación de los procesos fisiológicos o metabólicos registrados por la SPECT, es necesario complementarla con información anatómica derivada de una CT. Con este fin se han desarrollado sistemas de imagen multimodal SPECT/CT que integran ambas modalidades de imagen en un mismo aparato, lo que permite realizar ambos estudios en rápida sucesión, asegurando así una buena correspondencia espacial y temporal.

1.1. En matemáticas este es un tipo de problema inverso, ver [31].

1.2. También se conoce como transformada de Radón en matemáticas, ver [32]. 


\subsection{Transporte de radiación por el método de Monte Carlo}

El método de Monte Carlo es una técnica matemática que simula un proceso estocástico a través del muestreo de las distribuciones de probabilidad de las variables aleatorias asociadas, con el objeto de obtener información estadística sobre el proceso tras un gran número de realizaciones. En el ámbito de la física, se utiliza para obtener soluciones a sistemas macroscópicos a través de la simulación de sus interacciones microscópicas, y representa un intento por modelar la naturaleza mediante la simulación directa de la dinámica esencial del sistema en cuestión; de este modo, permite verificar las implicaciones de una teoría y comparar con los resultados de un experimento ${ }^{[21,33-36]}$.

Los principales componentes del método de Monte Carlo aplicado a la simulación de un proceso físico son:

i. Un conjunto de distribuciones de probabilidad que describen las interacciones del sistema físico.

ii. Un generador de números aleatorios distribuidos de manera uniforme en el intervalo unitario.

iii. Un conjunto de reglas de muestreo para generar muestras de las distribuciones de probabilidad.

iv. Un esquema de registro y acumulación de resultados.

v. Una o más técnicas de reducción de varianza que disminuyen el tiempo de cómputo.

La idea general es que, a partir de la simulación de un gran número de eventos individuales — denominados historias - que obedecen las interacciones del sistema, puede obtenerse información sobre el comportamiento promedio de éste, bajo la forma de una estimación numérica del valor esperado de cualquier propiedad considerada en la simulación.

De manera específica, cada historia consiste de una serie de interacciones, cada una de las cuales se modela sorteando valores de las distribuciones de probabilidad correspondientes a través de las reglas de muestreo, las cuales utilizan números aleatorios uniformes. El registro de resultados puede consistir en la historia completa, una cantidad asociada a cada historia o una cantidad acumulada sobre las historias realizadas, de acuerdo con lo que se desee calcular o con el uso posterior que se quiera dar a los resultados. Las técnicas de reducción de varianza son métodos que priorizan el subconjunto del espacio de búsqueda del problema que es relevante para una situación dada, con el objeto disminuir el tiempo de cómputo requerido para obtener un resultado con cierta varianza. La estimación del error es un aspecto fundamental del método de Monte Carlo, pues al tratarse de un proceso estadístico es imprescindible evaluar la variabilidad en los resultados para que tengan validez y sean comparables.

\subsubsection{Simulación del transporte de radiación}

El transporte de radiación se refiere al tránsito de la radiación ionizante por la materia. La simulación de este proceso involucra considerar el comportamiento de cada partícula — ya sea neutra o cargada - desde su aparición hasta su desaparición, conforme atraviesa un medio o una geometría de interés ${ }^{[21,37]}$. La exposición de esta sección está tomada de [33].

El aspecto más básico del transporte de partículas se refiere al tipo de operaciones matemáticas involucradas en el desplazamiento de las partículas por el espacio. Si se considera que una partícula está caracterizada solamente en términos de su posición $\boldsymbol{x}$ y su dirección $\mathbf{u}$ (en relación a un sistema de coordenadas fijo), entonces el transporte de la partícula consiste simplemente en una serie de traslaciones y rotaciones que alteran estas variables de acuerdo con los parámetros asociados a cada operación: longitud de arco $s$ en el caso de la traslación y ángulos polar $\theta$ y azimutal $\phi$ en el caso de la rotación. 
En notación de operadores (traslación $\mathcal{T}$ y rotación $\mathcal{R}$ ) esto puede expresarse como:

$$
\begin{aligned}
\mathcal{T}\left(\left\{\boldsymbol{x}_{0}, \boldsymbol{u}_{0}\right\}, s\right) & =\left\{\boldsymbol{x}_{0}+\boldsymbol{u}_{0} s, \boldsymbol{u}_{0}\right\} \\
\mathcal{R}\left(\left\{\boldsymbol{x}_{0}, \boldsymbol{u}_{0}\right\}, \theta, \phi\right) & =\left\{\boldsymbol{x}_{0}, \Re\left(\theta_{0}, \phi_{0}\right) \Re(\theta, \phi) \Re^{-1}\left(\theta_{0}, \phi_{0}\right) \boldsymbol{u}_{0}\right\}
\end{aligned}
$$

donde $\boldsymbol{x}_{0}$ es la posición inicial de la partícula, $\boldsymbol{u}_{0}$ es la dirección inicial de la partícula asociada a los ángulos $\left(\theta_{0}, \phi_{0}\right)$ y $\Re(\theta, \phi)$ es una matriz de rotación; las rotaciones se realizan tomando la dirección actual de la partícula como el eje $Z$, por lo que es necesario salir del sistema de coordenadas fijo y luego volver a él.

De este modo, lo único que hace falta para tener una descripción completa del proceso de transporte es especificar los mecanismos por los que se generan los valores de $s, \theta$ y $\phi$ en cada operación. La aplicación del método de Monte Carlo al transporte de partículas se basa en generar estos parámetros a partir de las distribuciones de probabilidad asociadas a la física de las interacciones de la radiación con la materia, las cuales varían de acuerdo con el tipo de interacción, las características físicas de las partículas - esencialmente su carga y su energía - y la composición del medio en que transitan.

De manera general, el transporte por el método de Monte Carlo de una sola partícula se puede ver como una caminata aleatoria a lo largo de la cuál se modelan las colisiones utilizando las ecuaciones físicas y los datos correspondientes sobre secciones eficaces, se determina el camino libre entre colisiones utilizando una descripción computacional de la geometría, se registran los eventos de interés y se guardan las partículas secundarias para su posterior transporte. Este proceso puede resumirse como una iteración entre el rastreo de la partícula a través de la geometría y el análisis del resultado de las colisiones ocurridas. En este contexto, una historia corresponde a la simulación del transporte de una partícula y de todas las partículas secundarias producidas por las interacciones a lo largo de su trayecto. A través de la realización de un gran número de historias pueden hacerse estadísticas de los conteos efectuados, obteniéndose información relevante como puede ser la energía promedio depositada en cierta región, el número promedio de partículas que cruzan cierta superficie o el número promedio de partículas secundarias generadas de cierto tipo, etc.

El muestreo aleatorio, componente principal del método de Monte Carlo, está involucrado en casi todas las etapas del proceso de transporte de partículas, como es la elección de las características iniciales (energía, dirección y posición) de una partícula a partir de las propiedades de la fuente, la elección de la distancia a la siguiente interacción y del tipo de interacción a partir de los datos de las secciones eficaces, y la elección del resultado de una interacción (nueva energía y dirección, también para las partículas secundarias) a partir de los datos de las secciones eficaces diferenciales en ángulo y energía. Un aspecto importante del transporte de partículas así planteado es que cada sorteo se realiza de manera independiente y que las distribuciones de probabilidad dependen solamente de las características actuales y locales de la partícula y del medio, de modo que cada evento es independiente de los anteriores; en este sentido, puede decirse que se trata de un proceso markoviano. Si bien existe una formulación analítica para este mismo tipo de proceso de transporte, conocida como la ecuación de transporte de Boltzmann, se considera que la validez del método de Monte Carlo reside en que parte de primeros principios, por lo que no es necesario mostrar la equivalencia formal entre este método y la solución de tal ecuación ${ }^{[38]}$.

Otro componente esencial para la simulación del transporte de partículas es la descripción de la geometría. En muchas aplicaciones se busca modelar estructuras reales, como son detectores, cabezas de tratamiento de aceleradores clínicos, blindajes, etc. por lo que no basta considerar medios infinitos y homogéneos. La manera como se procede es dividiendo el espacio en regiones caracterizadas por una forma y una composición material específicas - que representan las estructuras de interés- y realizando el transporte dentro de cada una de ellas como si de un medio infinito y homogéneo se tratara, teniendo especial cuidado al cruzar las fronteras entre regiones. De este modo, el rastreo de la partícula a través de la geometría requiere conocer en todo momento la región en que se encuentra la partícula - para poder considerar las propiedades de interacción propias del medio - así como la distancia a la frontera más cercana - para poder determinar las medidas a tomar para cruzarla-; se necesita entonces una descripción computacional de la geometría que permita determinar estas de manera rápida y que a la vez permita construir objetos con formas elaboradas. 
Un enfoque utilizado con éxito es el de la geometría combinatoria, que parte de la descripción de superficies simples (planos, cuádricas, etc.) y las combina mediante operaciones lógicas para formar volúmenes.

Finalmente, toda simulación realista del transporte de partículas requiere de una base de datos de secciones eficaces experimentales para los procesos de interacción considerados, que comprenda los medios disponibles (usualmente descritos a partir de su composición elemental) y el rango de energía posible para las partículas simuladas. Las secciones eficaces están asociadas a la probabilidad de interacción en un medio y varían en función del tipo de interacción, el tipo y energía de la partícula y el medio. El cociente entre la sección eficaz para un tipo particular de interacción y la sección eficaz total - dada por la suma de las secciones eficaces de todas las interacciones consideradas - es igual a la probabilidad de que ocurra esa interacción particular.

\subsubsection{Transporte de fotones}

El transporte de fotones es relativamente sencillo, y consiste a grandes rasgos en la alternancia entre el transporte de la partícula al próximo sitio de interacción y la determinación del efecto de tal interacción, contemplando la creación de partículas secundarias que son transportadas aparte. En términos de una implementación concreta, utilizando un stack (pila) para registrar las partículas presentes en la simulación y sus características, y considerando una energía de corte debajo de la cuál ya no vale la pena transportar las partículas, se presenta en la Figura 1.1 el diagrama de flujo de un algoritmo simplificado. Claramente, en caso de que la partícula superior del stack no sea un fotón se utiliza el algoritmo de transporte correspondiente.

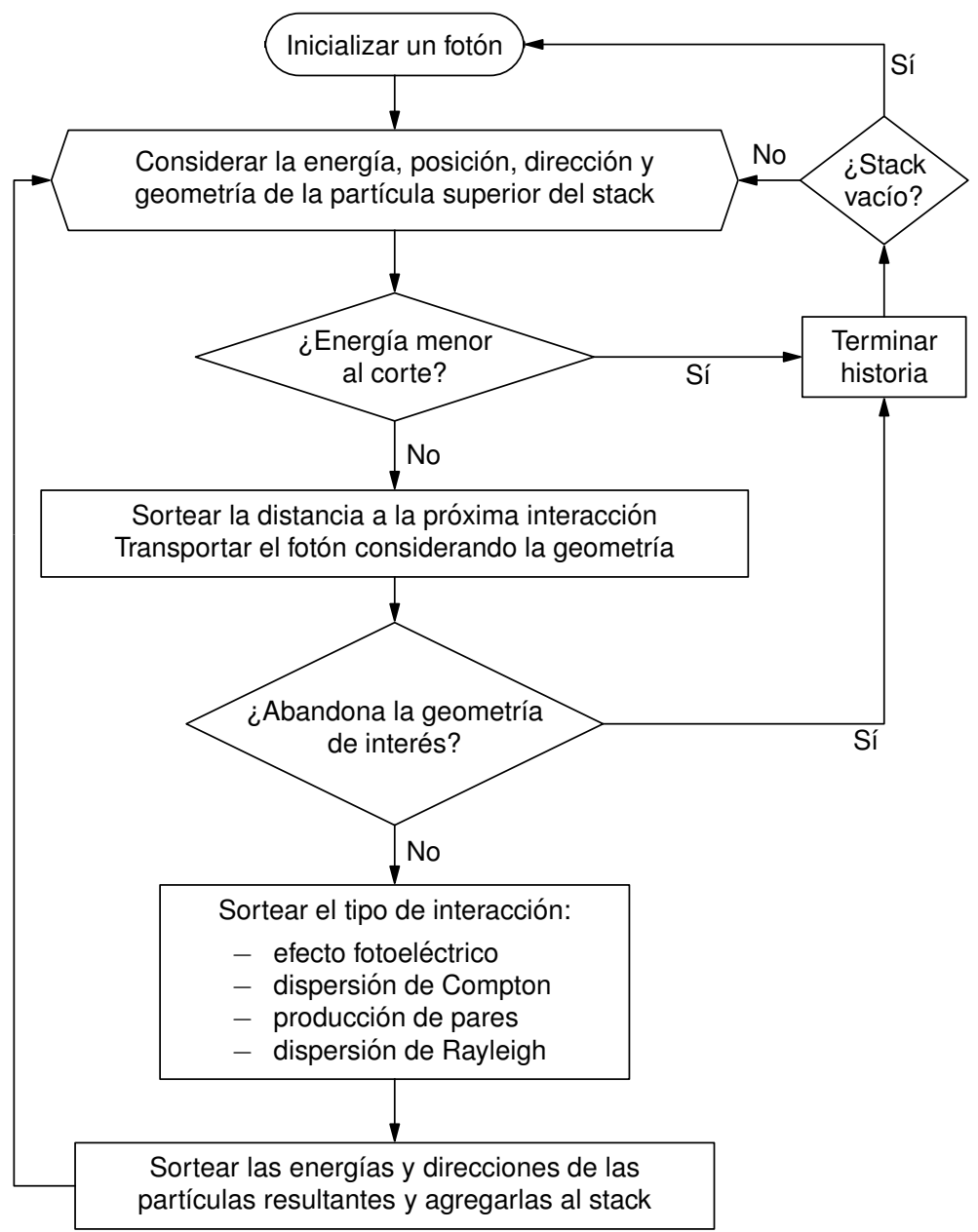

Figura 1.1. Diagrama de flujo de un algoritmo simplificado para el transporte de fotones ${ }^{[33]}$. 


\subsubsection{Transporte de electrones}

El transporte de electrones (y positrones) es considerablemente más complicado que el transporte de fotones, pues al ser partículas cargadas cuentan con una campo eléctrico, lo que ocasiona la interacción del electrón con prácticamente cada átomo que encuentra a su paso. Si bien es posible realizar la simulación de cada interacción individual - lo que se conoce como el enfoque microscópico - esto no es práctico salvo en el caso de energías muy bajas (algunas decenas de keV), por lo que para aplicaciones arriba de este rango se utiliza el enfoque de agrupar múltiples interacciones en un sólo paso de la simulación — lo que se conoce como el enfoque macroscópico o de historia condensada - de manera tal que se obtengan resultados correctos en un tiempo razonable. Los algoritmos de historia condensada se clasifican en dos categorías, los algoritmos de clase I y los de clase II, que difieren en la manera como se agrupan las pérdidas de energía y cómo se describen las interacciones individuales que ocasionan grandes transferencias de energía.

En el transporte de electrones las interacciones de estos con la materia se agrupan en dos categorías: la primera consta de las interacciones catastróficas que ocasionan grandes transferencias de energía, incluyendo las colisiones directas con los electrones atómicos, el Bremsstrahlung en el campo electromagnético del núcleo y la aniquilación de positrones; la segunda considera las interacciones suaves que ocasionan transferencias de energía muy pequeñas, incluyendo aquellas interacciones que se modelan mediante el poder de frenado, así como la dispersión elástica múltiple con los átomos. Debido al efecto pequeño de las interacciones suaves, es impráctico simularlas de manera individual, por lo que suele considerarse el efecto conjunto de múltiples interacciones a la vez con base en teorías estadísticas bien establecidas; es por esto que también se conocen como interacciones agrupadas estadísticamente. Es importante señalar que la distinción entre las interacciones catastróficas y las agrupadas estadísticamente depende de las exigencias planteadas por la física del problema y de la precisión esperada en los resultados.

El transporte de electrones puede describirse a grandes rasgos como una alternancia entre el transporte de la partícula al próximo sitio de interacción catastrófica — a lo largo de un trayecto compuesto por múltiples pasos de dispersión múltiple que conlleva una pérdida «continua» de energía- y la determinación de los efectos de tal interacción catastrófica, considerando nuevamente las partículas secundarias generadas para su posterior transporte. Cada paso de dispersión múltiple corresponde al efecto combinado de las interacciones con múltiples átomos y se caracteriza idealmente por una longitud de arco recorrida a lo largo de un trayecto un tanto errático que resulta en una cierta deflexión angular; en la práctica se considera únicamente la distancia recorrida en la dirección original de la partícula, se calcula la deflexión angular y se aplican correcciones por la longitud de arco y por el desplazamiento horizontal (la distancia recorrida perpendicular a la dirección original de la partícula). Un aspecto muy importante específico del transporte de electrones, es la existencia de una longitud de paso prescrita para estos incrementos, asociada usualmente a la pérdida fraccionaria de energía en cada paso; esto impone el reto a los algoritmos de simulación de obtener resultados que sean independientes del tamaño de paso utilizado, pues se trata de una característica artificial del algoritmo de transporte de electrones que no corresponde a ninguna característica física del proceso. Otra consecuencia de la existencia de un tamaño de paso definido es que debe tenerse especial cuidado en los algoritmos de realizar una descripción correcta del cruce de fronteras - en una geometría con regiones de distinta composición - y de la posible retrodispersión.

En la Figura 1.2 se presenta el diagrama de flujo de un algoritmo simplificado de historia condensada (clase II) para el transporte de electrones, el cuál es semejante al algoritmo de transporte de fotones antes mostrado, pero difiere en la naturaleza de las interacciones consideradas así como en la existencia del mecanismo de pérdida continua de energía y la dispersión múltiple. Nuevamente, en caso de que la partícula superior del stack no sea un electrón se utiliza el algoritmo de transporte correspondiente. 


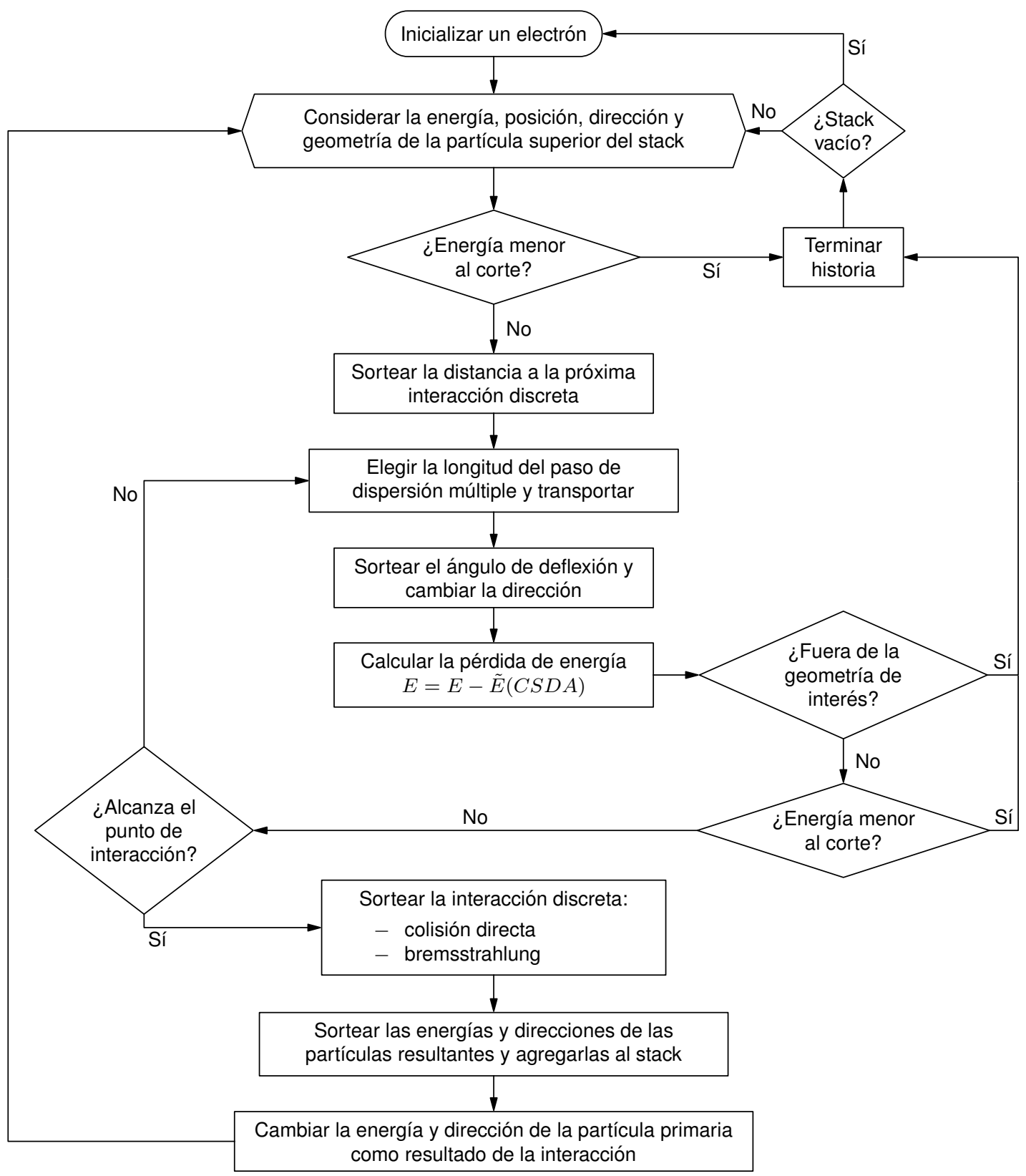

Figura 1.2. Diagrama de flujo de un algoritmo simplificado de historia condensada (clase II) para el transporte de electrones $^{[33]}$.

\subsubsection{Códigos EGSnrc y DOSXYZnrc}

El sistema de códigos EGS (Electron-Gamma-Shower) es un paquete de propósito general para la simulación del transporte acoplado de electrones y fotones por el método de Monte Carlo, en una geometría arbitraria y para partículas con energía desde unos pocos $\mathrm{keV}$ hasta varios cientos de $\mathrm{GeV}^{[39]}$. EGS representa la tecnología de punta en la simulación del transporte de radiación debido a que es muy flexible, está bien documentado y ha sido extensamente probado. Algunos consideran a este código como el estándar de referencia para la dosimetría de radiación clínica ${ }^{[21]}$. EGSnrc es una versión actual de este código, desarrollada por el Consejo Nacional de Investigación de Canadá con base en la versión EGS4 del Centro del Acelerador Lineal de Stanford y que incorpora colaboraciones de investigadores de varios lugares del mundo. 
Algunas de las capacidades del código EGSnrc son:

- Simular el transporte de electrones (+ ó -) y fotones en cualquier elemento, compuesto o mezcla, utilizando tablas de secciones eficaces elementales procesadas por el programa de preparación de datos PEGS4.

- Transportar partículas cargadas con energía cinética desde unas pocas decenas de keV hasta unos pocos cientos de $\mathrm{GeV}$ y fotones con energía entre $1 \mathrm{keV}$ y varios cientos de $\mathrm{GeV}$.

- Utilizar un algoritmo de punta para el transporte de electrones denominado PRESTA-II, capaz de producir resultados independientes del tamaño de paso para simulaciones de cámaras de ionización y retrodispersión, dos de los problemas más difíciles para los códigos Monte Carlo de historia condensada.

- Considerar una gran cantidad de procesos físicos, incluyendo: la producción de Bremsstrahlung, la aniquilación de positrones, la dispersión múltiple de las partículas cargadas por los núcleos atómicos incluyendo efectos de espín, la dispersión por los electrones atómicos, la pérdida continua de energía a lo largo del trayecto de una partícula cargada, la producción de pares, la dispersión de Compton ligada, la dispersión de Rayleigh, el efecto fotoeléctrico, la cascada de relajación atómica con la producción de rayos X fluorescentes y electrones Auger y Coster-Kronig, y la ionización por impacto de electrones.

- Permitir el registro de casi cualquier parámetro de la simulación para su posterior procesamiento, la descripción de una geometría arbitraria definida por el usuario y la implementación de diversas técnicas de reducción de varianza.

EGS está escrito en MORTRAN, un preprocesador para el lenguaje Fortran77 con amplias capacidades de uso de macros, los cuales permiten redefinir partes específicas del código de acuerdo a las necesidades del programador. Para utilizar el sistema EGS es necesario escribir un código de usuario que consiste de un programa principal MAIN y tres subrutinas: HOWFAR, que determina si la partícula cruza una frontera al moverse una longitud de paso en su dirección actual; HOWNEAR, que reporta la distancia perpendicular a la frontera más cercana y AUSGAB, que determina el registro de resultados. El programa MAIN se comunica con el código principal a través de las subrutinas HATCH, que se encarga de realizar la inicialización de los datos necesarios para la simulación y SHOWER, la cuál inicia una historia y llama a su vez las rutinas de transporte ELECTR y PHOTON las veces que sea necesario; de forma recíproca, estas rutinas de transporte llaman a las rutinas de usuario para consultar la geometría y registrar las cantidades de interés.

DOSXYZnrc es un código de usuario de EGSnrc diseñado para el cálculo de distribuciones de dosis absorbida en matrices tridimensionales de voxeles rectangulares ${ }^{[40]}$, el cuál forma parte del sistema de códigos BEAMnrc para la modelación de fuentes de radiación en radioterapia ${ }^{[41]}$. DOSXYZnrc simula el transporte de fotones y electrones en un volumen cartesiano y registra el depósito de energía en los voxeles designados. Las dimensiones de los voxeles pueden variar en las tres direcciones y cada voxel puede tener un material y una densidad diferentes. El código permite utilizar diversos tipos de fuentes, como son haces monoenergéticos paralelos o divergentes, datos de espacio fase generados mediante la simulación de la cabeza de un acelerador lineal con BEAMnrc, fuentes volumétricas isotrópicas, etc. Mediante el programa complementario ctcreate es posible utilizar información proveniente de una CT para asignar la composición de los voxeles y realizar una simulación realista del depósito de dosis al interior de un paciente. 


\section{CAPÍtulo 2}

\section{DESARRollo}

La metodología para la estimación de la distribución interna de dosis absorbida en un tumor sólido consta de las siguientes etapas:

Adquirir una serie de estudios SPECT / CT
que permitan conocer la anatomía (CT) y cuantificar la actividad del radionúclido (SPECT)
distribuida en el interior del tumor como función del tiempo

Para auxiliar en la implementación de la metodología, se desarrolló como parte de este trabajo el programa de computadora (software) xgrid3d, el cuál se describe a detalle en el capítulo 3.

\subsection{AdQUISICIÓN DE LAS IMÁGENES TOMOGRÁFICAS}

Las imágenes tomográficas fueron adquiridas con un equipo Albira ${ }^{[42]}$ (Oncovision, España) de imagen trimodal microPET/SPECT/CT para animales pequeños, en la configuración SPECT/CT. Estas imágenes se obtuvieron de un modelo tumoral de xenotransplantes de cáncer de páncreas en ratones atímicos, inyectados intratumoralmente con el radiofármaco ${ }^{177} \mathrm{Lu}$-DOTATOC, un análogo de la hormona somatostatina que tiene afinidad por los receptores de ésta presentes en la membrana celular de muchos tipos de tumores neuroendócrinos. Se utilizó Lutecio-177 $\left({ }^{177} \mathrm{Lu}\right)$ en lugar de Renio-188 - como se planeó en un inicio - debido a la falta de disponibilidad de este radionúclido; sin embargo la metodología aplica de igual manera, pues el Lutecio-177 es también un emisor beta-gamma ${ }^{[15]}$, con una emisión beta moderadamente energética (133 keV promedio, $498 \mathrm{keV}$ máxima) y emisiones principales de fotones (113 keV y $208.4 \mathrm{keV}$ ) en el rango de detección de las cámaras gamma.

Se realizaron estudios con dos tumores, obteniéndose imágenes in vivo a diferentes tiempos pos-inyección ( 0 , 1 y 3 horas) y una imagen ex vivo tras la fijación del tumor en una matriz de agarosa (cubo). La Tabla 2.1 resume los parámetros geométricos de las imágenes reconstruidas. Los detalles del crecimiento del modelo tumoral, la realización de los estudios y la fijación de los tumores se encuentran en el apéndice de este trabajo. 
Tabla 2.1. Parámetros geométricos de las imágenes reconstruidas.

\begin{tabular}{|c|c|r|}
\cline { 2 - 3 } \multicolumn{1}{c|}{} & Matriz & Tamaño de voxel \\
\hline SPECT & $100 \times 100 \times 100$ & $0.65 \mathrm{~mm}$ \\
\hline CT & $558 \times 558 \times 516$ & $0.125 \mathrm{~mm}$ \\
\hline fusión & $279 \times 279 \times 258$ & $0.25 \mathrm{~mm}$ \\
\hline
\end{tabular}

La cuantificación de las imágenes comprendió la calibración de las cámaras gamma del equipo Albira para la emisión principal (208.4 keV) del Lutecio 177, la inclusión de la corrección por dispersión en la reconstrucción y la aplicación de una curva de calibración global obtenida con distintos valores conocidos de concentración de actividad. Los detalles del proceso de cuantificación se encuentran en el apéndice de este trabajo.

El software Albira Suite 5.6 del equipo Albira realiza de manera automática la fusión de las imágenes de las dos modalidades. Las imágenes reconstruidas por este software son almacenadas como datos crudos, con un archivo de encabezado en formato Concorde/microPET y pueden leerse con el software xgrid3d. Una vez cuantificadas, el valor de cada voxel en estas imágenes representa la concentración de actividad dentro de ese volumen en $\mathrm{KBq} \cdot \mathrm{ml}^{-1}$, por lo que basta multiplicar por el volumen de un voxel $\left(V=1.5625 \times 10^{-5} \mathrm{~cm}^{3}\right.$ en las imágenes fusionadas) para obtener valores de actividad absolutos en KBq.

\subsection{SELECCIÓN DE LAS REgIONES DE INTERÉS}

Para determinar la región de interés (ROI), se aprovechó que las imágenes de SPECT y CT estaban previamente fusionadas, lo que permite realizar la selección en la imagen anatómica y posteriormente trasladarla a la imagen funcional. De esta manera, el problema consiste en poder identificar la anatomía del tumor en las imágenes de CT.

Para realizar la selección se siguió un enfoque que combina la capacidad de visualización y selección tridimensional del software ParaView 5.1.2 (www.paraview.org) con la capacidad de selección bidimensional del software xgrid3d. La Figura 2.1 ilustra este proceso.
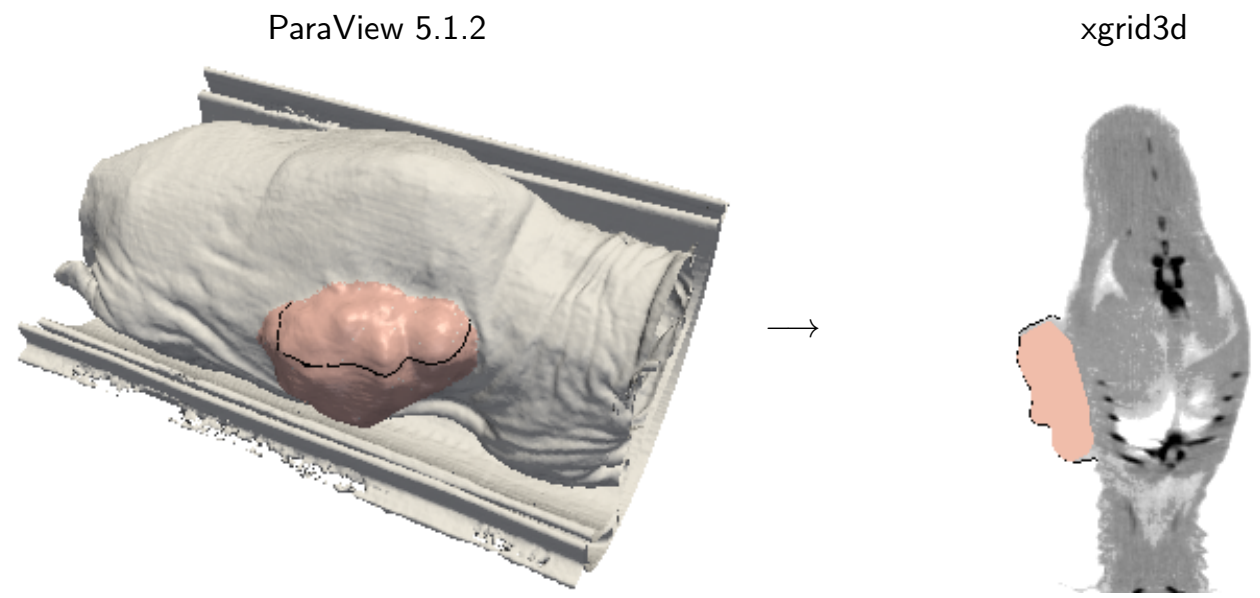

Figura 2.1. Proceso de selección siguiendo el enfoque 3D/2D.

Con ParaView 5.1.2 es posible generar superficies de nivel de datos volumétricos, en la forma de mallas no estructuradas sobre las que se pueden realizar selecciones y extraer un subconjunto de los polígonos; esto se hizo para las imágenes de CT, en las que el nivel con valor -100 permitió visualizar de manera clara la forma del tumor bajo la piel del ratón, por tratarse de tumores subcutáneos. Este software permite también calcular las curvas de intersección entre una malla no estructurada y un plano cualquiera; esto se utilizó para obtener los contornos del tumor dentro de los cortes de la imagen tomográfica, en la vista coronal. 
Con ayuda de un script de Python (python.org) se exportaron imágenes de estos contornos en la misma geometría de las imágenes tomográficas, las cuales fueron posteriormente convertidas a datos binarios y cargadas en xgrid3d como selecciones. Estos contornos se utilizaron como guía para determinar la extensión del tumor en cada corte. Como primera aproximación se utilizó una línea recta entre los extremos del contorno como margen interno del tumor, sin embargo esto se fue refinando sucesivamente utilizando las tres vistas (transversal, coronal y sagital) y buscando consistencia en la forma seleccionada. Al finalizar se aplicó un filtro gaussiano a la selección para suavizar los bordes. Con el propósito de evaluar la variabilidad del proceso, éste se realizó para cada una de las tres imágenes de cada tumor, obteniéndose tres regiones de interés para cada tumor.

En el caso de las imágenes de los tumores ex vivo no fue posible seguir este enfoque, ya que el bajo contraste entre el tumor y la agarosa (ambos de composición similar a la del agua) ocasionó que las imágenes fueran ruidosas y no se pudiera extraer una superficie de nivel que delimitara al tumor dentro del cubo. Ante este panorama, se procedió a realizar la selección directamente sobre la imagen con xgrid3d, previa aplicación de un filtro gaussiano bilateral para aumentar la definición de los bordes del tumor.

\subsection{CORRESPONDENCIA DE LA SERIE TEMPORAL}

Para lograr la correspondencia geométrica entre las distintas imágenes de SPECT dentro de una serie temporal, resultó nuevamente recomendable realizar el ajuste con las imágenes de CT, en las que puede reconocerse la anatomía, y posteriormente aplicar la transformación a las imágenes de SPECT. Esto se hizo con el objeto de obtener curvas de actividad vs. tiempo más precisas al utilizar las mismas regiones de interés para todos los tiempos.

El co-registro de las imágenes de CT se realizó con ayuda del software NiftyReg 1.3.9 (niftyreg.sf.net), que implementa el algoritmo Aladin ${ }^{[43,44]}$. Este algoritmo está basado en un enfoque de correspondencia de bloques y un esquema de mínimos cuadrados recortados: con el primero se determina un conjunto de puntos correspondientes entre la imagen flotante y la imagen de referencia, el cuál se utiliza posteriormente para evaluar la mejor transformación rígida o afín entre las imágenes con el segundo; este ciclo de dos pasos se itera hasta obtener convergencia. En esta implementación particular se obtiene la correspondencia calculando la correlación cruzada normalizada entre los bloques de ambas imágenes, el tamaño de bloque es constante (4 voxeles) y se utiliza un enfoque de grueso a fino, donde el co-registro se realiza primero para una versión de baja resolución de las imágenes y se va refinando hasta alcanzar a la resolución original ${ }^{[45]}$.

Para realizar el co-registro se eligió una transformación rígida y se utilizaron como máscara las regiones de interés obtenidas previamente, de modo que el algoritmo ajustara solamente en la región del tumor. Las transformaciones de allí derivadas se aplicaron a las imágenes de SPECT mediante interpolación trilineal. La elección de una transformación rígida se basa en que es razonable suponer que al realizar los estudios, la variación en la disposición geométrica del tumor fue en efecto una transformación rígida, por lo que no es necesario introducir una deformación artificial (transformación afín o no lineal) para lograr un mejor ajuste entre las imágenes, lo que además introduciría alteraciones indeseables en la distribución de actividad dentro del tumor.

Con el propósito de evaluar la variabilidad del proceso de co-registro, se generaron tres series de imágenes co-registradas para cada tumor, considerando cada una de las imágenes ( 0,1 y 3 horas) a su vez como referencia y ajustando las otras dos.

\subsection{CÁlCUlo de la ACtividad ACUMUladA}

Para obtener la distribución de actividad acumulada, una vez realizado el co-registro de las imágenes de la serie temporal, es necesario ajustar un modelo que describa la cinética del radionúclido en cada voxel e integrar la curva de actividad vs. tiempo resultante. 
Si bien es común utilizar modelos exponenciales que capturan la fase de eliminación del radiofármaco de la región de interés ${ }^{[17]}$, al estar trabajando en la escala de voxeles se tiene información más detallada sobre la cinética y puede ocurrir que haya voxeles donde la actividad aumente con el tiempo a pesar de que ésta disminuya de manera global en la región. Una posible explicación de este fenómeno es la redistribución de la actividad en el interior de la región, aunque también pudiera ser un defecto artificial introducido por el proceso de co-registro, en el sentido de que se hicieran corresponder voxeles que no participaran de una misma cinética.

$\mathrm{Al}$ no tener elementos para discriminar entre estas dos situaciones, ni contar con un modelo para describir la redistribución interna de actividad, lo que se hizo fue suponer que la distribución de actividad se mantuvo estática a partir de la última imagen de la serie $(3 \mathrm{~h})$ y considerar una eliminación de tipo exponencial en cada voxel, de modo que la actividad acumulada se obtiene mediante:

$$
\tilde{A}(\boldsymbol{r})=A_{0}(\boldsymbol{r}) \int_{0}^{T} \mathrm{e}^{-\lambda t} d t=\frac{A_{0}(\boldsymbol{r})}{\lambda}\left(1-\mathrm{e}^{-\lambda T}\right),
$$

donde $A_{0}$ es la actividad en el voxel con posición $\boldsymbol{r}$ dentro de la última imagen de la serie, $\lambda$ es una constante de eliminación y $T$ es el intervalo de irradiación, posterior a la toma de la última imagen de la serie.

Se siguieron dos enfoques para escoger la constante de eliminación: por un lado se consideró únicamente la constante de decaimiento del radionúclido $\lambda$ y por el otro se ajustó un modelo exponencial $A(t)=A_{0} \mathrm{e}^{-\lambda_{\text {eff }} t}$ a la actividad total en la región de interés, para obtener una constante de decaimiento efectiva $\lambda_{\text {eff }}$ que contempla también la eliminación fisiológica.

En el caso de las imágenes de los tumores ex vivo, es razonable suponer que la distribución de actividad se mantuvo estática, salvo por la posible difusión pasiva que no fue considerada. De este modo, la única contribución a la cinética es el decaimiento radiactivo, por lo que se calculó la actividad acumulada siguiendo solamente el primer enfoque.

\subsection{CÁlculo del Kernel de dosis POR VOXeL}

Para realizar la estimación de la dosis absorbida se eligió utilizar un kernel de dosis por voxel, calculado para una matriz tridimensional idéntica a la de las imágenes tomográficas y un medio con una composición análoga a la del tejido blando, considerando las emisiones principales del radionúclido.

La principal ventaja del uso de un kernel de dosis por voxel es que permite obtener una estimación de la dosis de manera muy rápida, pues se calcula una sola vez y se utiliza posteriormente realizando una convolución con la distribución de actividad acumulada. Al calcularlo en una matriz idéntica a la de las imágenes se evita la necesidad de interpolar una función radial, así como la complicación de escoger una ubicación dentro del voxel como representativa; sin embargo, esto restringe la aplicabilidad de los kernel calculados, pudiendo utilizarse solamente para imágenes con el mismo tamaño de voxel. A pesar de que un kernel de dosis es válido estrictamente bajo la suposición de un medio infinito y homogéneo, en la práctica pueden satisfacerse estas condiciones si se restringe su uso a una región finita de tejido aproximadamente homogéneo, por lo que utilizando un kernel calculado para un medio análogo al tejido blando, puede obtenerse en principio una estimación satisfactoria de la dosis al interior de un tumor sólido.

La manera como se modela un radionúclido es calculando un kernel para cada tipo de emisión (beta, electrones monoenergéticos y fotones), los cuales se suman para obtener el kernel total, que representa la emisión promedio del radionúclido. El kernel para la emisión beta se calcula muestreando el espectro de energías al generar las partículas en la simulación, mientras que el kernel para los fotones y el kernel para los electrones monoenergéticos se calculan mediante una suma pesada de los kernel calculados para cada emisión discreta en la proporción de sus intensidades. De esta manera se hace posible el cálculo por separado de la contribución a la dosis de cada tipo de emisión.

Se simuló un kernel total para Lutecio-177, el emisor beta-gamma utilizado en los estudios con los tumores. En la Tabla 2.2 se resumen las propiedades radiactivas de este radionúclido, donde las emisiones principales se tomaron como aquellas cuya energía promedio por transformación, calculada como el producto de su energía por su intensidad, diera un valor mayor a $1 \mathrm{keV}$. 
Tabla 2.2. Propiedades radiactivas del Lutecio- $177^{[15]}$.

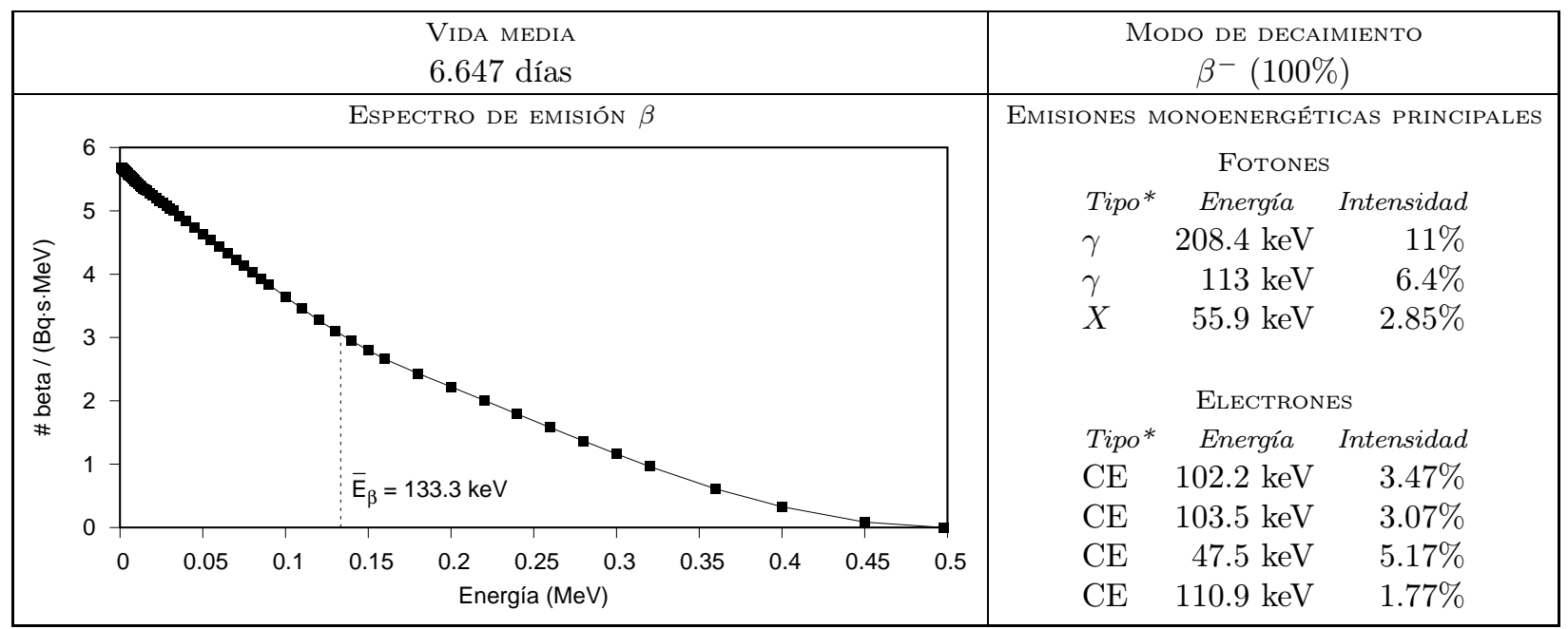

${ }^{*} \gamma$ es una emisión gamma, $X$ es un rayo X característico y CE es un electrón de conversión

\subsubsection{Parámetros de simulación}

A continuación se indican y se explican los parámetros utilizados para el cálculo de los kernel.

Parámetros de DOSXYZnrc.

Maniquí - Matriz de voxeles cúbicos idénticos abarcando una cierta distancia máxima desde el voxel central.

Medio - Tejido blando ICRU de cuatro componentes (ICRUTISSUE521ICRU) con densidad de $1 \mathrm{~g} \cdot \mathrm{cm}^{-3}$ y composición dada por:

$$
\begin{array}{|l|l|l|l|l|l|l|l|l|}
\hline \mathrm{H} & 10.1172 \% \\
\hline \mathrm{C} & 11.1 \% & 2.6 \% \\
\hline
\end{array}
$$

definido en el archivo 521icru.pegs4dat distribuido con EGSnrc.

Partícula incidente — fotón (carga 0) o electrón (carga -1), según el caso.

Tipo de fuente - Paralelepípedo uniforme con radiación isotrópica dentro del maniquí (isource=6), correspondiente al voxel central del maniquí.

Número de historias - $10^{9}$, suficientes para obtener errores menores al $2 \%$ en las distancias hasta las que se deposita el $99.9 \%$ de la energía emitida por la fuente, en el caso de los electrones.

HOWFARLESS - Activado. Esta opción aumenta la eficiencia del cálculo de dosis en un maniquí homogéneo al considerar solamente la distancia a la frontera externa, pues al tratarse de un mismo medio no hay necesidad de detenerse en las fronteras de los voxeles, lo que acelera el transporte de partículas cargadas.

Rechazo por rango - Desactivado. Esta técnica de reducción de varianza consiste en absorber localmente las partículas cargadas cuya energía es insuficiente para alcanzar la frontera de un voxel. En nuestro caso es irrelevante debido al tamaño pequeño de los voxeles utilizados.

Fraccionamiento de fotones - Desactivado. Esta técnica de reducción de varianza consiste en fraccionar los fotones n veces, a la vez que se reduce su peso estadístico por el mismo factor, consiguiendo aumentar drásticamente el número de fotones presentes en la simulación sin sesgar los resultados. Debido a la gran rapidez con que se realiza la simulación del transporte de los fotones, no es necesario utilizarla en nuestro caso. 


\section{Parámetros de EGSnrc.}

Energía de corte para el transporte de electrones (ECUT) $-0.521 \mathrm{MeV}$, que corresponde a una energía cinética mínima de $0.01 \mathrm{MeV}$.

Energía de corte para el transporte de fotones (PCUT) $-0.01 \mathrm{MeV}$.

Tamaño máximo de paso de electrón (SMAX) - 1e10 cm, valor por omisión cuando se utiliza el algoritmo de transporte de electrones PRESTA-II y el algoritmo EXACT de cruce de fronteras; su significado es esencialmente que no hay restricción.

Fracción máxima de pérdida de energía por paso de electrón (ESTEPE) -0.25 , valor por omisión que se recomienda no modificar.

Máximo del primer momento de dispersión elástica múltiple (XIMAX) - 0.5, valor por omisión asociado al algoritmo de transporte de electrones PRESTA-II.

Algoritmo de cruce de fronteras (bca_algorithm) - EXACT, es el mejor posible y su uso no disminuye la eficiencia gracias a tener HOWFARLESS activado.

Grosor superficial para el algoritmo de cruce de fronteras (skindepth_for_bca) - 3 caminos libres medios elásticos; es el valor por omisión para el algoritmo EXACT de cruce de fronteras y significa que a esa distancia perpendicular de la frontera de una región, el algoritmo de transporte cambia a usar dispersión simple.

Algoritmo de transporte de electrones (transport_algorithm) - PRESTA-II, el algoritmo por omisión y el más preciso de historia condensada para el transporte de electrones.

Efectos de espín (spin_effects) - On, valor por omisión para mayor realismo en los cálculos.

Muestreo angular de Bremsstrahlung (IBRDST) — KM, que utiliza la distribución angular completa de Koch y Motz para determinar el ángulo de los fotones producidos por Bremsstrahlung y que se recomienda para energías bajas.

Secciones eficaces de Bremsstrahlung (ibr_nist) — NRC, utiliza las secciones eficaces de NIST (Instituto Nacional de Estándares y Tecnología) corregidas.

Dispersión de Compton ligada (IBCMP) - Norej, utiliza las secciones eficaces totales para la dispersión de Compton ligada y no rechaza ninguna interacción de Compton durante la simulación; esto es importante debido a que en el rango de energía tratado esta es la principal interacción.

Secciones eficaces de dispersión de Compton (comp_xsections) - Default, valor por omisión que utiliza los datos presentes en la distribución de EGSnrc.

Corrección radiativa para la dispersión de Compton (radc_flag) — Off, valor por omisión que deshabilita las correcciones radiativas para la dispersión de Compton.

Muestreo angular de producción de pares (IPRDST) - Simple, valor por omisión que utiliza solamente el término líder en la distribución angular de Motz. En nuestro caso la producción de pares es irrelevante pues la sección eficaz es nula en el rango de energía utilizado.

Secciones eficaces de producción de pares (pair_nrc) - NRC, utiliza las secciones eficaces de NRC (Consejo Nacional de Investigación de Canadá) que son de interés a bajas energías.

Muestreo angular de fotoelectrones (IPHTER) — On, utiliza la fórmula de Sauter para la distribución angular del fotoelectrón. 
Dispersión de Rayleigh (IRAYLR) — On, se recomienda para simulaciones de energía menor a $1 \mathrm{MeV}$ y se debe utilizar junto con la dispersión de Compton ligada.

Relajaciones atómicas (IEDGFL) — On, simula la cascada de relajación atómica incluyendo la generación de rayos X de fluorescencia, electrones Auger y electrones Coster-Kronig, y se recomienda para aplicaciones de bajas energías.

Ionización por impacto electrónico (eii_flag) — Off, debido a que para el medio utilizado y en el rango de energías utilizado, no hay capas electrónicas con energía de enlace mayor al umbral para la simulación de este proceso.

Secciones eficaces de fotones (photon_xsections) - epdl, utiliza las secciones eficaces de la Biblioteca Evaluada de Datos de Fotones (EPDL) del Laboratorio Nacional Lawrence Livermore, considerada la más actualizada que existe ${ }^{[21]}$.

Generador de números aleatorios — RANLUX, en nivel de calidad 2.

\subsubsection{Simulación con el código DOSXYZnrc}

El código DOSXYZnrc produce un archivo de texto .3ddose que consta de seis líneas: la primera indica el número de voxeles en las tres direcciones $(x, y, z)$, las tres siguientes contienen las fronteras de los voxeles en cada una de las tres direcciones y las dos últimas contienen los valores de dosis y los errores relativos para cada voxel de la matriz, respectivamente. Sin embargo, es más conveniente utilizar directamente los archivos binarios . pardose generados por cada hilo de ejecución durante una corrida en paralelo y que contienen la siguiente información ${ }^{[40]}$ :

NHIST. el número de historias simuladas por el hilo de ejecución;

IMAX , JMAX , KMAX. las dimensiones de la matriz;

EDEP. $\frac{1}{\rho} \sum_{i=1}^{\text {NHIST }}$ edep $_{i}$ para cada voxel, donde $\operatorname{edep}_{i}$ es la energía (en MeV) depositada por la historia $i$ y $\rho$ es la densidad del voxel $\left(\mathrm{en} \mathrm{g} \cdot \mathrm{cm}^{-3}\right)$;

EDEP2. $\frac{1}{\rho^{2}} \sum_{i=1}^{\mathrm{NHIST}} \operatorname{edep}_{i}^{2}$ para cada voxel, con el mismo significado que arriba.

Procesando estos archivos es posible sumar las contribuciones de todos los voxeles localizados a una misma distancia del voxel central (utilizando los índices dentro de la matriz como coordenadas) y dividir entre el número de tales voxeles (el cuál se tabula previamente), obteniéndose las cantidades EDEP y EDEP2 totales, a partir de las cuales se calcula la dosis y su error relativo como sigue:

$$
\begin{aligned}
\text { dosis } & =\operatorname{EDEP} \times \frac{1.60217662 \times 10^{-10}}{\mathrm{VOL} \times \mathrm{NRUN}} \\
\text { error relativo } & =\sqrt{\frac{1}{\mathrm{NRUN}-1}\left[\frac{\mathrm{EDEP} 2}{\mathrm{NRUN}}-\left(\frac{\mathrm{EDEP}}{\mathrm{NRUN}}\right)^{2}\right]} / \frac{\mathrm{EDEP}}{\mathrm{NRUN}},
\end{aligned}
$$

donde VOL es el volumen del voxel $\left(\mathrm{cm}^{3}\right)$, NRUN es el número total de historias simuladas y el factor numérico involucra el cambio de unidades de energía y masa $(\mathrm{eV} \rightarrow \mathrm{J} \mathrm{y} \mathrm{g} \rightarrow \mathrm{kg}$ ), de modo que se obtiene la dosis en unidades de Gy/partícula. Una vez que se cuenta con esta información, se genera una matriz para el kernel en la que se asigna el mismo valor de dosis para todos los voxeles a una misma distancia del voxel central y se anulan todos los voxeles fuera de la máxima esfera inscrita en el cubo simulado, imponiendo así la isotropía requerida para un kernel de dosis. 
Una razón importante para realizar el cálculo de la dosis y su error de esta manera, respecto al uso del archivo .3ddose, es que al usar este último se obtiene la cantidad «dosis en un voxel» con su correspondiente error, pero lo que se busca calcular es más bien la cantidad «dosis a una distancia del voxel central»con su correspondiente error, y esto es lo que se logra con el procedimiento arriba descrito. Para operar de esta manera se modificó la rutina que escribe los archivos . pardose para utilizar doble precisión, pues es la precisión nativa de la simulación, y se asignó el macro \$DOSEZERO=0 para evitar que se anularan los voxeles con errores mayores al 50\%, dejando el manejo del error plenamente en nuestras manos. Otra alteración menor es el uso del valor $1.60217662 \mathrm{E}-19^{[46]}$ para la carga del electrón en lugar de 1.602E-19, lo que ocasiona ligeras diferencias numéricas entre nuestro procedimiento y el procesamiento estándar del código DOSXYZnrc.

\subsection{EstimACIÓN DE LA DOSIS ABSORBIDA}

Para estimar la dosis absorbida $D(\boldsymbol{r})$ es necesario realizar la convolución entre el kernel de dosis por voxel $k(\boldsymbol{r})$ y la distribución de actividad acumulada $\tilde{A}\left(\boldsymbol{r}^{\prime}\right)$ :

$$
D(\boldsymbol{r})=(\tilde{A} * k)(\boldsymbol{r})=\int_{\Omega^{\prime}} \tilde{A}\left(\boldsymbol{r}^{\prime}\right) k\left(\boldsymbol{r}-\boldsymbol{r}^{\prime}\right) d \Omega^{\prime}
$$

donde $\Omega^{\prime}$ es el dominio de la distribución de actividad acumulada (región fuente).

En nuestro caso, la actividad acumulada está definida sobre la matriz de las imágenes tomográficas, por lo que se trabajó en un dominio discreto y la integral anterior se convierte en una suma sobre los índices de esta matriz:

$$
D(j, i, k)=\sum_{j^{\prime}, i^{\prime}, k^{\prime}} \tilde{A}\left(j^{\prime}, i^{\prime}, k^{\prime}\right) k\left(j-j^{\prime}, i-i^{\prime}, k-k^{\prime}\right) .
$$

El cálculo de la convolución discreta en tres dimensiones puede tomar un tiempo considerable si se realiza de manera directa, por lo que es preferible utilizar el Teorema de Convolución para la transformada de Fourier, el cuál afirma que la operación de convolución corresponde a la multiplicación en el espacio de Fourier:

$$
\mathcal{F}[\tilde{A} * k]=\mathcal{F}[\tilde{A}] \times \mathcal{F}[k],
$$

de modo que basta calcular la transformada de Fourier (discreta, en nuestro caso) tanto del kernel de dosis por voxel como de la distribución de actividad acumulada, multiplicarlas entre sí y luego calcular la transformada de Fourier inversa.

Para calcular la transformada discreta de Fourier se utilizó el software FFTW 3.3.4 (fftw.org), una biblioteca libre para calcular la transformada discreta de Fourier en una o más dimensiones, con entrada de tamaño arbitrario y para datos tanto reales como complejos ${ }^{[47]}$, la cuál utiliza el algoritmo «transformada rápida de Fourier» y es conocida por su rapidez de ejecución, flexibilidad y portabilidad. Se utilizó la función para rea-

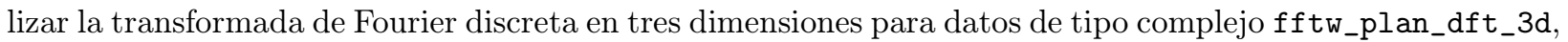
anulando la parte imaginaria de los datos de entrada y descartando la parte imaginaria de los datos de salida. Debido a que la matriz del kernel de dosis por voxel y la de la distribución de actividad acumulada tienen dimensiones distintas, es necesario adaptarlas (centrarlas y rellenarlas con ceros) a un tamaño común lo suficientemente grande para evitar el traslape entre bordes opuestos, pues con la transformada de Fourier lo que se obtiene es la convolución periódica, que considera bordes periódicos; rellenando con ceros se evita este problema y se obtiene la convolución lineal, que es la operación deseada. La Figura 2.2 ilustra esta situación.

Otras operaciones que es necesario realizar para obtener la distribución de dosis son: reacomodar la matriz resultante de la transformada de Fourier inversa, pues el algoritmo ubica al voxel central en la primer celda de memoria, y normalizar dividiendo por el número total de voxeles, pues el algoritmo no realiza esta operación. 


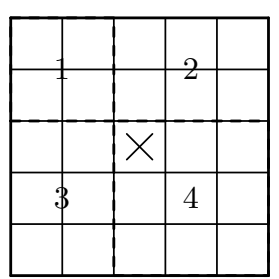

Matriz del kernel

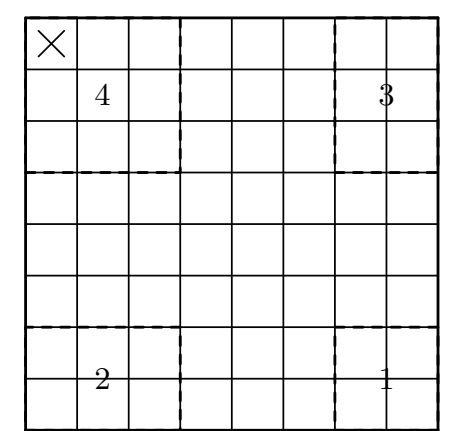

Matriz de la distribución de actividad acumulada, mostrando los bordes periódicos

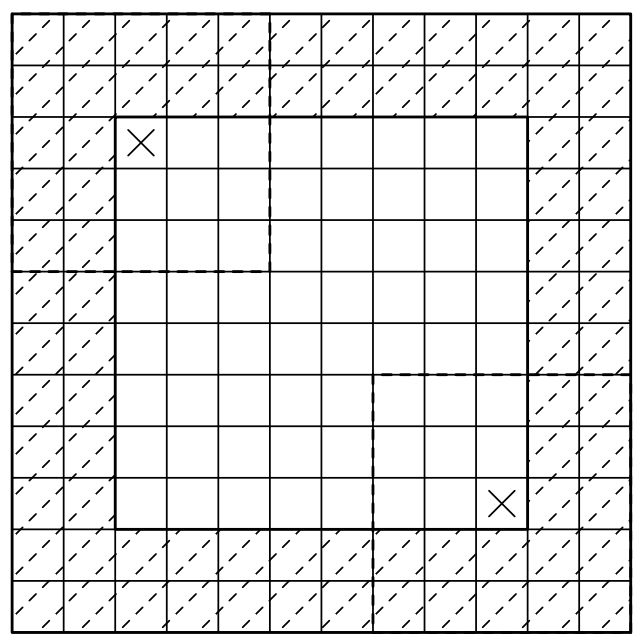

Matriz adaptada para evitar el traslape, donde la parte sombreada es nula

Figura 2.2. Adaptación de la matriz para realizar la convolución lineal mediante la transformada de Fourier.

Una vez que se ha obtenido la distribución de dosis absorbida en la región de interés, es preciso describirla de manera que se aproveche toda la información disponible, pues al contar con una distribución puede decirse mucho más que sólo la dosis promedio.

Por ejemplo, el histograma volumétrico de dosis, que puede ser diferencial o integral, indica la fracción del volumen con una dosis absorbida dentro de cierto intervalo o bien la fracción del volumen con una dosis absorbida mayor a cierto valor, respectivamente. El histograma integral, en particular, permite establecer el nivel mínimo de dosis recibido por la mayor parte del tumor, el cuál pudiera servir como un indicador del efecto biológico. Por otro lado, el trazo de contornos de isodosis permite establecer los lugares que recibieron mayor o menor dosis dentro de la región de interés. Ambos pueden calcularse mediante el software xgrid3d.

\subsection{COMPARACIÓN DE LA DOSIS ESTIMADA CON MEDICIONES}

Con el propósito de tener un punto de comparación para las estimaciones de dosis, se realizaron mediciones de la dosis depositada en el interior de los tumores con película de tinte radiocrómico (GafChromic ${ }^{\circledR}$ EBT3, no. lote A10171102). Las características principales de este tipo de película son que cuenta con una resolución espacial fina (hasta $25 \mu \mathrm{m}$ ) y un rango dinámico amplio (desde cGy hasta $>40 \mathrm{~Gy}$ ), y que muestra una dependencia débil con el tipo y energía de la radiación, por lo que puede utilizarse para la dosimetría de fotones, electrones e incluso protones en diversas aplicaciones ${ }^{[48-50]}$.

Para realizar estas mediciones, se practicaron cortes en los cubos de agarosa donde se fijaron los tumores y se insertaron cuadrados de película de tinte radiocrómico; los cuadrados de película fueron cortados de una misma hoja y marcados para preservar la orientación de la película. Los cubos de agarosa con las películas permanecieron en refrigeración durante $T=843240 \mathrm{~s} \cong 234.2 \mathrm{~h}$ en el caso del tumor 1 y $T=840720 \mathrm{~s} \cong$ $233.5 \mathrm{~h}$ en el caso del tumor 2. Estos tiempos se usaron como intervalo de irradiación en el cálculo de la actividad acumulada.

La lectura de las películas consistió en digitalizarlas y aplicar a cada pixel de la imagen una curva patrón obtenida con anterioridad, que asocia la respuesta del escáner con un valor de dosis conocido. Se utilizó la respuesta del canal verde del escáner por tener sensibilidad a dosis mayores (hasta $40 \mathrm{~Gy}^{[51]}$ ). Los detalles del procedimiento de lectura de las películas pueden encontrarse en el apéndice de este trabajo. A partir de estos mapas bidimensionales de dosis fue posible calcular contornos de isodosis para su comparación con los obtenidos a partir de las imágenes tomográficas. 



\section{CAPÍtulo 3 SOFTWARE xgrid3d}

Como paso previo para poder realizar la estimación de la dosis, es necesario determinar las regiones dentro de las imágenes tomográficas que servirán como fuente y objetivo de la radiación, por lo que es necesario contar con una manera de seleccionarlas que sea fácil y acorde a criterios cuantitativos. Con esto en mente, se desarrolló un programa de computadora (software) que además de satisfacer esta necesidad, permite llevar a cabo el flujo de trabajo completo de la metodología: desde la lectura de los datos hasta la realización de la estimación de dosis absorbida; prueba de ello son los resultados de este trabajo, obtenidos con este programa.

El software tiene por nombre xgrid3d, está escrito en lenguaje C, cuenta con más de 30 mil líneas de código y es software libre, distribuido bajo la licencia GPLv3+. Las ventajas de contar con un programa de esta naturaleza bajo una licencia libre son que puede extenderse o modificarse según el uso deseado y que puede comprobarse su funcionamiento en todo momento examinando el código fuente, dos factores muy importantes para una herramienta de investigación.

\subsection{SoftWARE UTILIZADo}

La interfaz gráfica de usuario se implementó mediante la biblioteca de componentes de interfaz gráfica de usuario XForms Toolkit (xforms-toolkit.org), y se encuentra disponible en idioma inglés o español. Las funciones para la lectura de datos crudos en forma de matrices tridimensionales y su procesamiento se implementaron en la biblioteca libgrid3d, que utiliza algunas funciones de la biblioteca GNU Scientific Library (gnu.org/software/gsl) para cómputo científico, la biblioteca FFTW (fftw.org) para el cálculo de la transformada discreta de Fourier y la biblioteca niftilib (niftilib.sf.net) para la lectura y escritura de imágenes en el formato NIfTI-1.1.

El software xgrid3d utiliza a su vez otros códigos de software libre, así como algoritmos y paletas de color de diversos orígenes, que se describen a continuación:

- DOSXYZnrc, código de usuario de EGSnrc para el cálculo de distribuciones de dosis absorbida en matrices tridimensionales de voxeles rectangulares (nrc-cnrc.github.io/EGSnrc).

- NiftyReg, código para el co-registro de imágenes tomográficas mediante el algoritmo Aladin, originalmente en $\mathrm{C}++$ pero se hizo una interfaz a C (cmictig.cs.ucl.ac.uk/wiki/index.php/NiftyReg).

- GNU libmatheval, biblioteca para el análisis y evaluación de expresiones matemáticas simbólicas (gnu.org/software/libmatheval).

- GNU parallel, script para ejecutar tareas en paralelo en una o más computadoras ${ }^{[52]}$ (gnu.org/software/parallel).

- gnuplot, software para la graficación de funciones y datos en 2D y 3D (gnuplot.info).

- gnuplot_i, interfaz de lenguaje C para el programa gnuplot (ndevilla.free.fr/gnuplot).

- CONREC, subrutina para la extracción de contornos de nivel (paulbourke.net/papers/conrec).

- sort, biblioteca de algoritmos de ordenamiento en lenguaje C (www.yendor.com/programming/sort).

- toconic, subrutina para calcular los coeficientes de una cónica general a partir de cinco puntos (mathforum.org/library/drmath/view/51735.html).

- line3d, subrutina para dibujar una línea tridimensional discreta con el algoritmo de Bresenham (ftp://ftp.isc.org/pub/usenet/comp. sources.unix/volume26/line3d).

- HeapHull2, código para calcular el armazón convexo de un conjunto de puntos en dos dimensiones ${ }^{[53]}$ (cglab.ca/ morin/publications/insitu/insitu-src.tgz). 
- bresenham, conjunto de códigos para dibujar curvas discretas utilizando el algoritmo de Bresenham (members.chello.at/easyfilter/bresenham.html).

- babl, biblioteca de lenguaje C para la transformación de formatos de pixeles, incluyendo espacios de color (gegl.org/babl).

- ColorBrewer, conjunto de paletas de colores optimizadas para mapas (colorbrewer2.org).

- Msh, espacio de color perceptualmente uniforme para paletas de color divergentes ${ }^{[54]}$ (www.kennethmoreland.com/color-maps).

- Color Universal Design, conjunto de paletas de color amigables con las personas con daltonismo (jfly.iam.u-tokyo.ac.jp/color).

La información sobre radionúclidos que utiliza el software se tomó de la publicación "Datos de Decaimiento Nuclear para Cálculos Dosimétricos" (ICRP 107) ${ }^{[15]}$.

\subsection{Detalles De implementación}

El software está diseñado con énfasis en el análisis cuantitativo, más que en la visualización de las imágenes. Por este motivo, se considera fundamental el no alterar los datos y mostrar una representación fiel de los mismos, así que las unidades naturales son los voxeles y los datos se preservan en su tipo de dato original, siendo convertidos al vuelo en flotantes de doble precisión cuando se opera con ellos.

Una característica del software es que prioriza la eficiencia y la funcionalidad, por lo que todas las operaciones sobre los datos están paralelizadas con OpenMP (openmp.org) y la interfaz gráfica de usuario es austera. En cuanto al uso de memoria, se busca mantenerlo al mínimo, lo cuál es ventajoso considerando el tamaño que pueden llegar a tener las imágenes tomográficas, pero sin que esto afecte la eficiencia (por ejemplo, se carga la imagen completa en memoria para facilitar su manipulación).

La biblioteca XForms Toolkit (utilizada para construir la interfaz gráfica de usuario) trabaja con el Sistema de Ventanas X (x.org), muy común en los sistemas UNIX, pero disponible también para Windows y Mac, por lo que el software es multiplataforma. Otra ventaja de esto es que las operaciones de dibujo y composición de imágenes se realizan directamente sobre las ventanas, lo que aumenta la eficiencia del software y evita la necesidad de una biblioteca de gráficos adicional.

El formato de imagen nativo del software es NIfTI-1.1 (nifti.nimh.nih.gov/nifti-1), basado en ANALYZE 7.5 y desarrollado originalmente para imágenes de fMRI, aunque sirve para cualquier tipo de imagen tomográfica. Este formato es de especificación abierta y cuenta con una implementación de referencia en lenguaje C del dominio público. Además, soporta cualquier tipo de dato y la compresión de los datos, lo que representa una ventaja para el almacenamiento de las imágenes.

Como se mencionó más arriba, una de las ventajas de tener una herramienta de investigación bajo una licencia de software libre es que puede extenderse en función de las necesidades del usuario. En este sentido, el software exhibe en todo momento los datos y la interfaz gráfica de usuario en su totalidad a través de una estructura global, por lo que es relativamente sencillo agregar nueva funcionalidad que se relacione con la ya existente, así como nuevos diálogos utilizando el programa de diseño distribuido con el XForms Toolkit.

Por último, el software soporta la internacionalización mediante GNU gettext (gnu . org/software/gettext), por lo que puede traducirse a una gran variedad de idiomas. Con este fin, se distribuye junto con el software el tipo de letra GNU Unifont (unifoundry.com/unifont.html) que soporta el juego de caracteres Unicode, el cuál comprende todos los idiomas utilizados hoy día. La interfaz gráfica de usuario ha sido diseñada para acomodar los mensajes en inglés y español, pero puede adaptarse de ser necesario.

\subsection{EstruCTURA Y FUNCIÓN DE LA INTERFAZ GRÁficA DE USUARIO}

A continuación se describe la función de cada una de las partes de la interfaz gráfica de usuario, cuya estructura general se presenta en la Figura 3.1. 


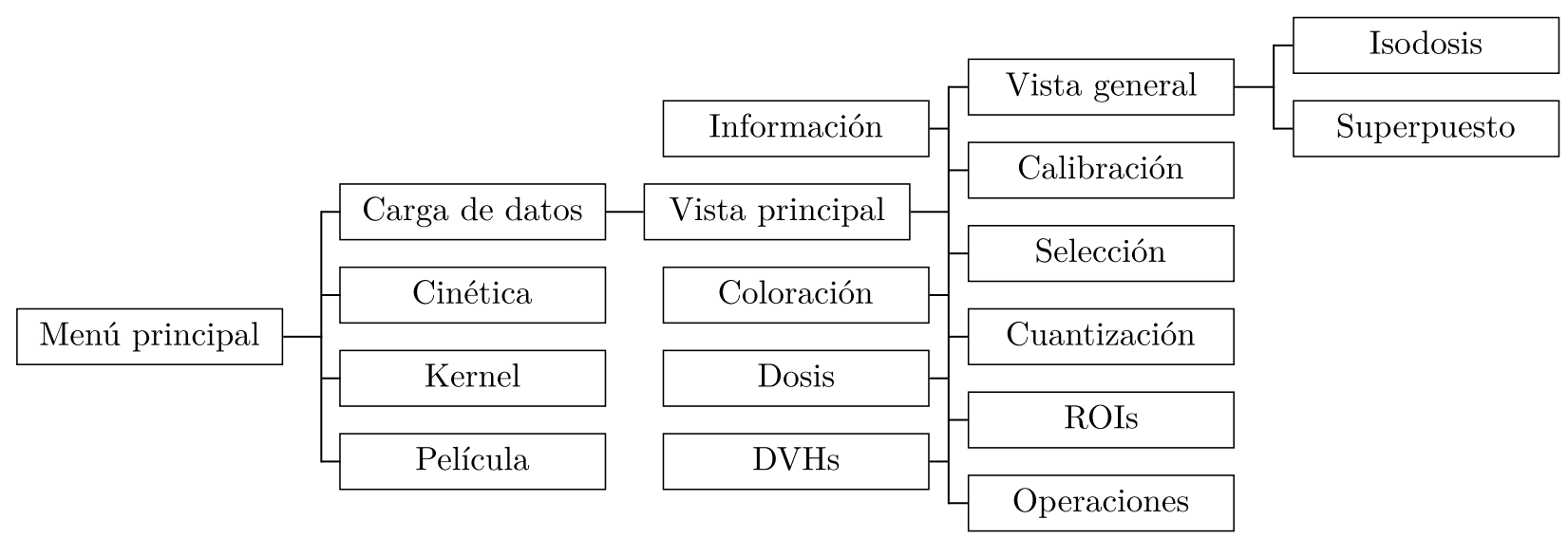

Figura 3.1. Estructura general de la interfaz gráfica de usuario del software xgrid3d.

\section{Menú principal.}

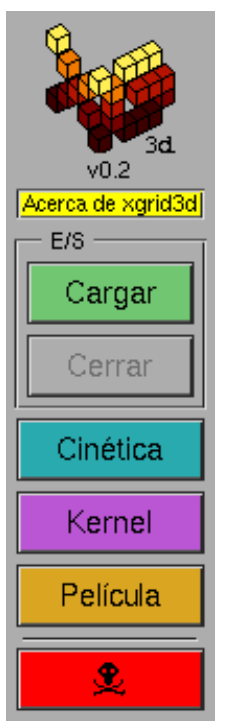

El menú principal cuenta con botones para Cargar datos mediante el diálogo de carga de datos y para Cerrar el archivo en uso. El botón Cinética abre el diálogo de manejo de la cinética, el cuál utiliza información de más de un archivo de datos, por lo que puede utilizarse independientemente del archivo de datos en uso. El botón Kernel abre el diálogo para calcular kernel de dosis por voxel y no requiere cargar ningún archivo de datos. El botón Película abre el diálogo para realizar la dosimetría de película de tinte radiocrómico, el cuál actúa sobre el archivo de datos en uso. Finalmente, el icono de la calavera cierra el programa. El botón Acerca de xgrid3d muestra una ventana con los créditos del software.

\section{Carga de datos.}

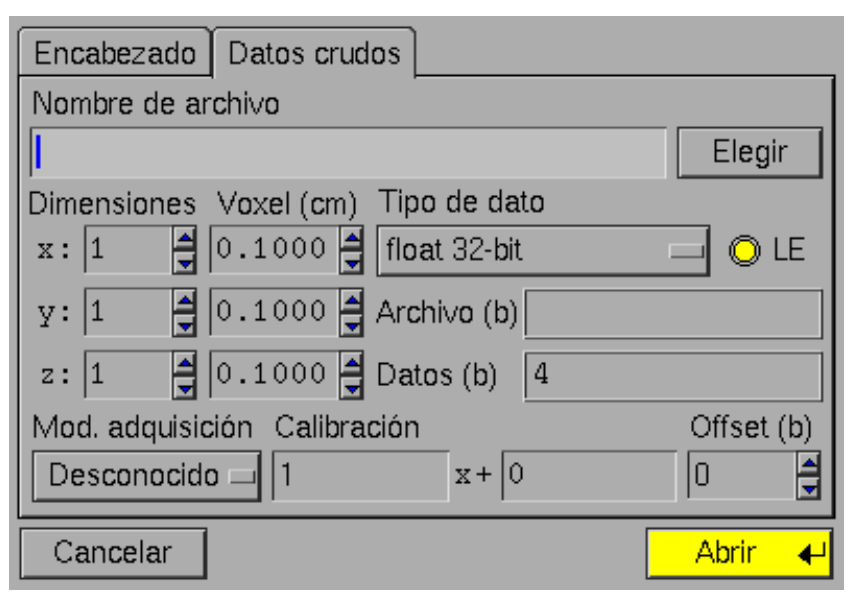

El diálogo de carga de datos tiene dos modos: Encabezado, que permite cargar datos a partir de un archivo de encabezado en el formato microPET utilizado por el equipo Albira o en formato NIfTI-1 y Datos crudos, que permite cargar datos desde cualquier archivo a partir de la especificación de las dimensiones y el tipo de dato. Los tipos de dato soportados son: enteros de $8,16,32$ y 64 bits con o sin signo y flotantes de 32 o 64 bits.

Como información adicional puede especificarse el tamaño de voxel, la modalidad de adquisición y la recta de calibración de los datos. 


\section{Vista principal.}

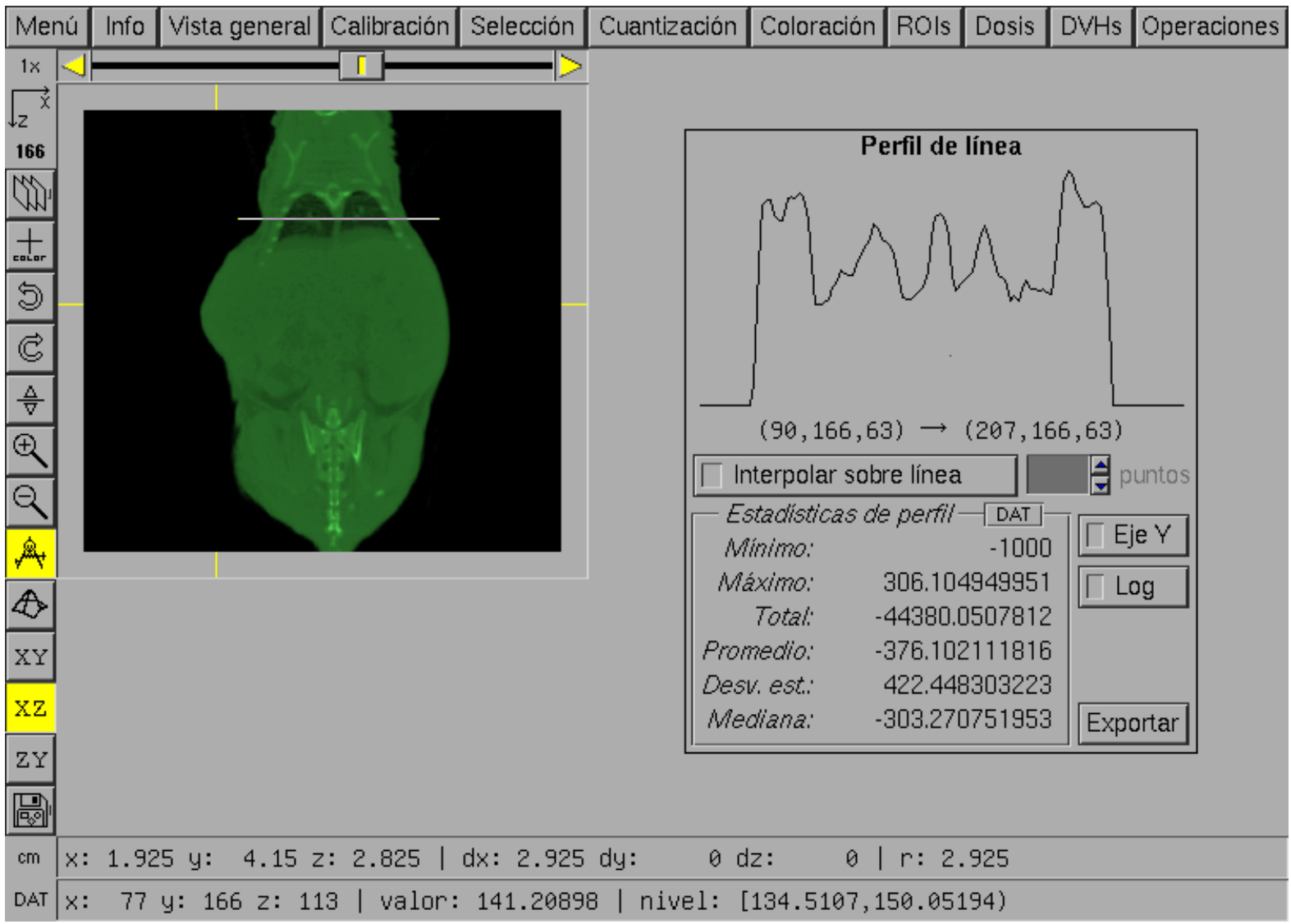

La vista principal tiene cuatro partes. Al centro se muestra la imagen en color falso correspondiente a un corte tomográfico en la posición definida por la barra de desplazamiento de arriba y en el plano definido por los botones XY, XZ y ZY; nótese que para que estos planos correspondan respectivamente al transversal, coronal y sagital, es necesario que los datos en el archivo estén guardados como cortes transversales sucesivos. El área donde se muestra la imagen es un lienzo en que se pueden dibujar las selecciones de las regiones de interés directamente sobre la imagen; los cursores que rodean al lienzo indican la posición dentro del corte. En el caso de que la imagen sea más grande que la pantalla, se muestran barras de desplazamiento para navegar por la imagen.

En la barra de botones de la izquierda puede controlarse el nivel de aumento (indicado por la leyenda «1x»), la orientación de la imagen (indicada por el dibujo de los ejes) y la posición del corte mostrado (indicado por el número). Para mejorar la visibilidad del cursor es posible cambiar su color. Otras funciones disponibles desde esta barra son la medición de distancias y el trazo de perfiles de línea entre los centros de dos voxeles de la matriz tridimensional y la representación como superficie tridimensional coloreada del corte actual. Por último, es posible guardar en disco la imagen mostrada, con la opción de incluir la paleta de colores como parte de la imagen.

En la parte de abajo se tienen dos barras, que muestran la posición actual del cursor sobre la matriz tridimensional en unidades de voxeles o distancias, así como el valor del voxel bajo el cursor y el rango de valores (nivel) correspondiente a su color; si está activado el modo de medición, se muestra además la distancia entre las puntas del compás. A la izquierda hay dos botones que permiten cambiar las unidades de distancia entre $\mathrm{cm}$ y $\mathrm{mm}$, y las de los datos entre nativas (DAT) y calibradas (CAL).

Finalmente, la barra de botones de la parte de arriba permite desplegar las demás funciones del programa. 


\section{Información.}

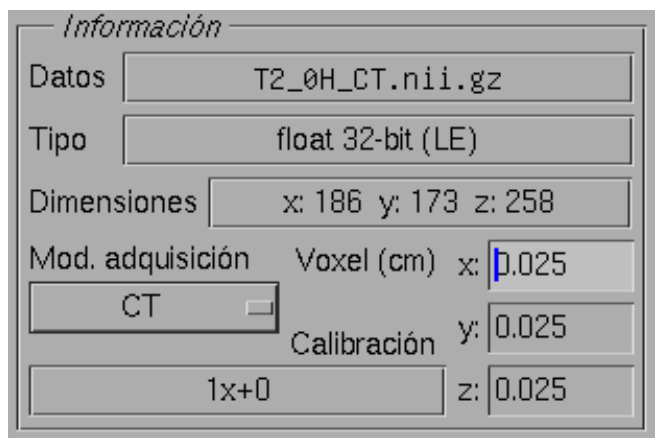

El diálogo de información muestra la información (nombre, tipo de dato, dimensiones, etc.) del archivo de datos y permite cambiar las dimensiones del voxel, lo que afecta el cálculo de volúmenes y distancias sobre la imagen.

\section{Vista general.}

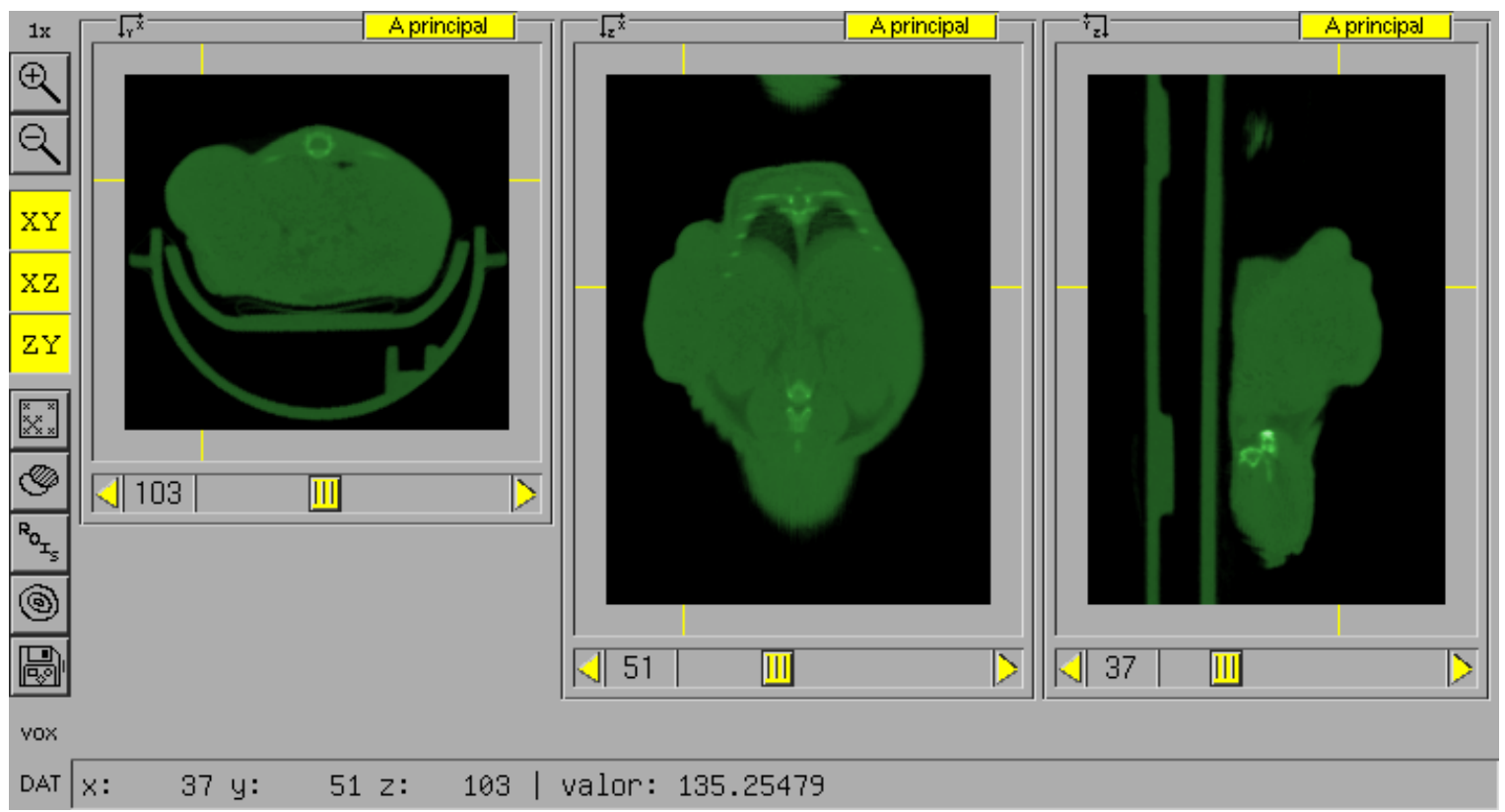

La vista general sirve para navegar con facilidad por la imagen tridimensional. En ella se muestran los tres planos a la vez, cada uno con un indicador de orientación (controlada desde la vista principal), una barra de desplazamiento y un conjunto de cursores para indicar la posición dentro del corte; el nivel de aumento es el mismo para las tres vistas. Con los botones XY, XZ y ZY se puede mostrar u ocultar cada una de las vistas.

En términos de navegación, es posible cambiar la posición del corte en cada vista de manera independiente, así como centrar la atención en un voxel específico mediante un cursor interactivo que se despliega al hacer clic sobre cualquiera de las vistas, teniendo el efecto de cambiar los cortes mostrados de modo que se visualicen las tres vistas del voxel seleccionado, indicado por los cursores y con la información de la barra de abajo. Además, es posible llevar a la vista principal cualquiera de las aquí mostradas.

Desde la barra de la izquierda es posible activar el resaltado de las regiones de interés y de la selección actual, lo que permite ubicarlas de manera más completa dentro de la geometría de la imagen, así como el trazado de contornos de isodosis y la superposición de una segunda imagen. Por último, pueden guardarse las imágenes mostradas en cada una de las vistas, con la opción de incluir una leyenda con las regiones de interés y los contornos de isodosis y también las paletas de color de la imagen principal y la superpuesta, tanto en formato mapa de bits como vectorial (postscript). 


\section{Superpuesto.}

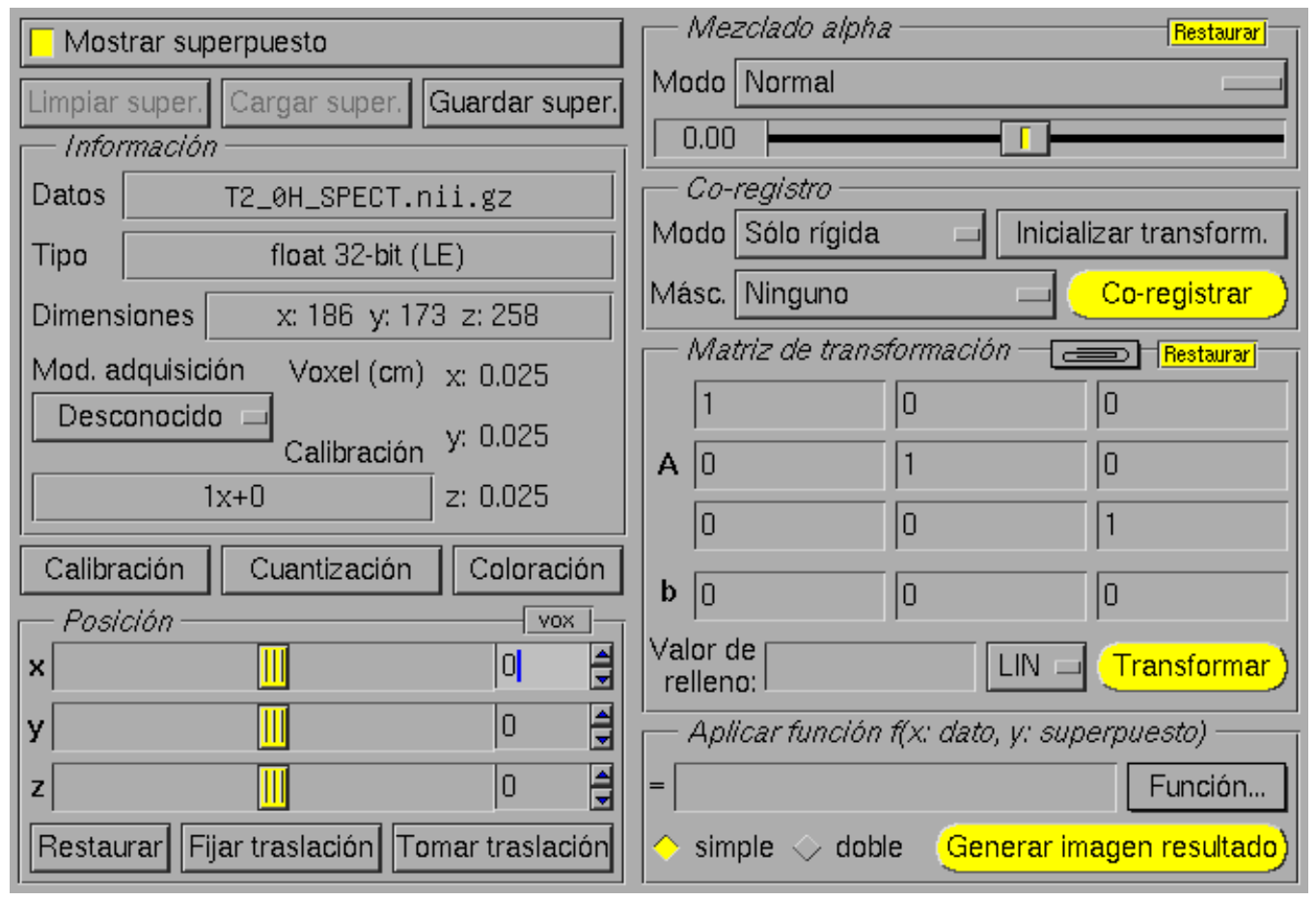

El diálogo de superpuesto permite cargar un segundo archivo de datos y mostrarlo mediante imágenes superpuestas a las tres vistas de la vista general. Al igual que con el archivo de datos original, es posible cambiar la calibración, la cuantización y la coloración para acomodarse a las necesidades de visualización buscadas. Con este mismo propósito, es posible variar la posición de la imagen superpuesta y escoger el modo de mezclado alpha de las imágenes, así como la transparencia.

La segunda función principal es que permite realizar el co-registro entre la imagen superpuesta y la imagen original, mediante una transformación rígida, afín o una después de la otra, utilizando una región de interés como máscara y con la opción de utilizar la posición actual de la imagen superpuesta como condición inicial. Al ejecutar el co-registro se obtiene una matriz de transformación, la cuál se representa mediante una transformación lineal $A$ y un vector de traslación $b$. Esta matriz puede copiarse y pegarse y también puede introducirse a mano.

Una vez que se tiene la matriz de transformación entre dos geometrías, sea como resultado de un co-registro o introducida a mano, es posible aplicarla a cualquier número de imágenes, cargando cada una a la vez como superpuesto y guardándola posteriormente. Las opciones para la transformación son el tipo de interpolación (primeros vecinos, lineal o cúbica) y el valor de relleno (valor asignado al espacio fuera de la imagen transformada).

Por último, es posible generar una imagen como resultado de aplicar punto a punto una función matemática arbitraria de la imagen original y la imagen superpuesta, siempre y cuando ambas tengan las mismas dimensiones. 


\section{Contornos de isodosis.}

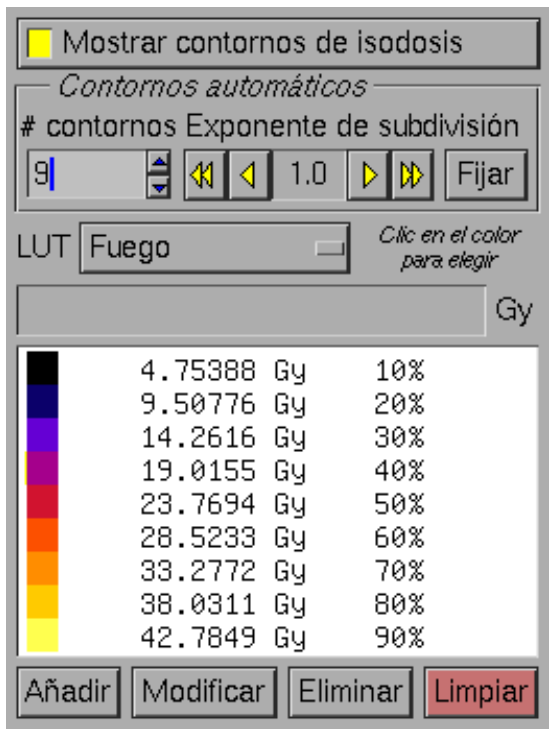

El diálogo de contornos de isodosis permite especificar los valores de los contornos de isodosis trazados sobre las imágenes de la vista general. Para poder trazar contornos de isodosis es necesario calcular o cargar primero una distribución de dosis en la misma geometría de la imagen.

Se tiene la opción de calcular de manera automática los contornos de isodosis subdividiendo (con un exponente) el rango de valores de la distribución de dosis en cierto número de intervalos, así como especificarlos de manera individual por valor o como porcentaje de la dosis máxima.

Además, es posible cambiar la paleta de colores de los contornos o elegir los colores de manera individual para mejorar su visualización.

\section{Cuantización.}

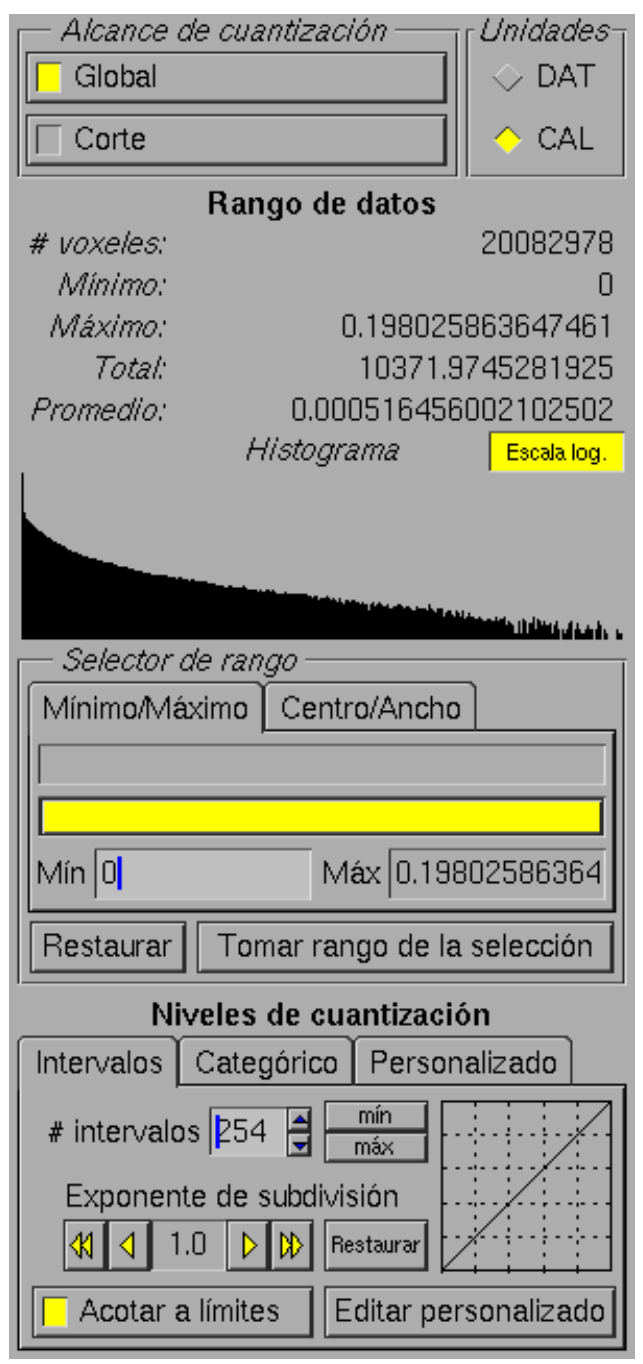

El diálogo de cuantización permite establecer niveles de cuantización, es decir, intervalos de valores que discretizan el rango de los datos y permiten visualizarlos mediante las imágenes a color falso que se muestran en la vista principal.

El rango en que se definen los niveles puede establecerse de dos maneras: eligiendo un valor mínimo y un máximo o eligiendo un valor central y un ancho. Para asistir en esta tarea, se muestra el histograma de los datos (escala lineal o logarítmica) y algunas estadísticas (valor mínimo, máximo, total y promedio). El histograma puede leerse haciendo clic y desplazándose sobre el mismo.

La selección del rango puede realizarse en unidades nativas (DAT) o calibradas (CAL) y en el contexto de la imagen completa (Global) o el corte actual (Corte). También es posible tomar el rango a partir de la selección.

Dentro de las maneras de elegir los niveles de cuantización está la división del rango seleccionado en intervalos uniformes elevados a una potencia, el agrupamiento en categorías según el orden de magnitud y la entrada personalizada de los límites de los intervalos.

El uso de un exponente distinto a 1 hace que la paleta de colores lineal ya no sea una buena representación de la progresión de valores de los datos, sin embargo, usar un exponente mayor/menor que 1 aumenta el número de niveles asignados a los valores pequeños/grandes, lo que mejora su visualización.

$\mathrm{Al}$ establecer los intervalos con base en criterios cuantitativos se vuelve posible trabajar con imágenes donde los colores son significativos y pueden auxiliar en la selección de las regiones de interés. 


\section{Calibración.}

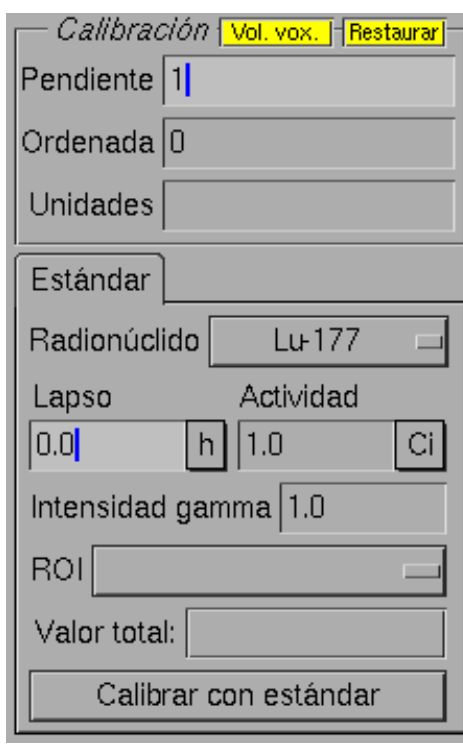

El diálogo de calibración permite asignar la pendiente y la ordenada de la recta de calibración aplicada a los datos cuando se reportan unidades calibradas (CAL), con una etiqueta opcional de la unidad a que corresponde la calibración. Esta operación no afecta los valores de los datos en memoria ni en el archivo guardado.

Para facilitar la conversión de valores de concentración de actividad a actividad absoluta, puede asignarse el volumen del voxel como la pendiente con el clic de un botón.

Si se conoce la actividad de un estándar en la imagen, es posible también establecer la calibración a partir de él.

\section{Coloración.}

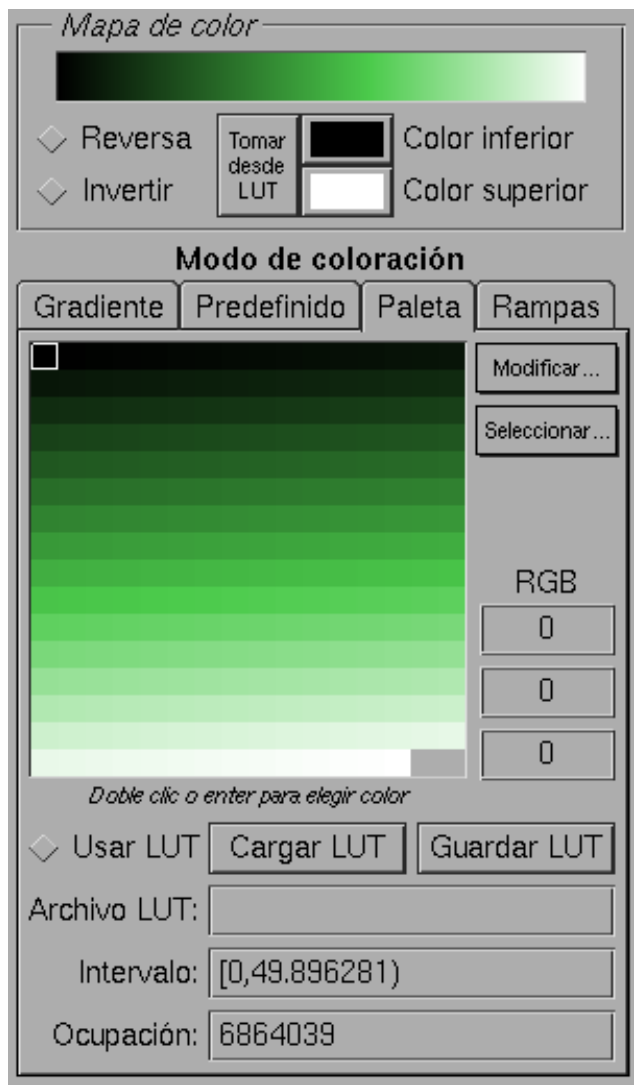

El diálogo de coloración permite definir y manipular la paleta de color con que se visualizan los datos. El software soporta hasta 256 colores en la paleta, que corresponden al mismo número de niveles de cuantización. De ellos, 254 se asignan a los intervalos dentro del rango seleccionado en la cuantización y los dos restantes a los valores fuera del intervalo, por arriba (color superior) y por abajo (color inferior).

La elección de distintos esquemas de colores es importante porque puede mejorar el contraste y por lo tanto la discriminación espacial entre regiones de la imagen que corresponden a intervalos de valores distintos, lo que puede servir como auxiliar en la selección de la regiones de interés.

Entre los modos de coloración disponibles está: un gradiente con tonalidad variable basado en alguna propiedad cromática o esquema de color, un esquema de colores predefinido, una paleta de colores personalizada o cargada de un archivo (LUT) y un gradiente definido a partir de rampas de color en los tres canales RGB.

El modo Paleta (mostrado) indica además los límites del intervalo y la ocupación del nivel que corresponde al color seleccionado. 


\section{Selección.}

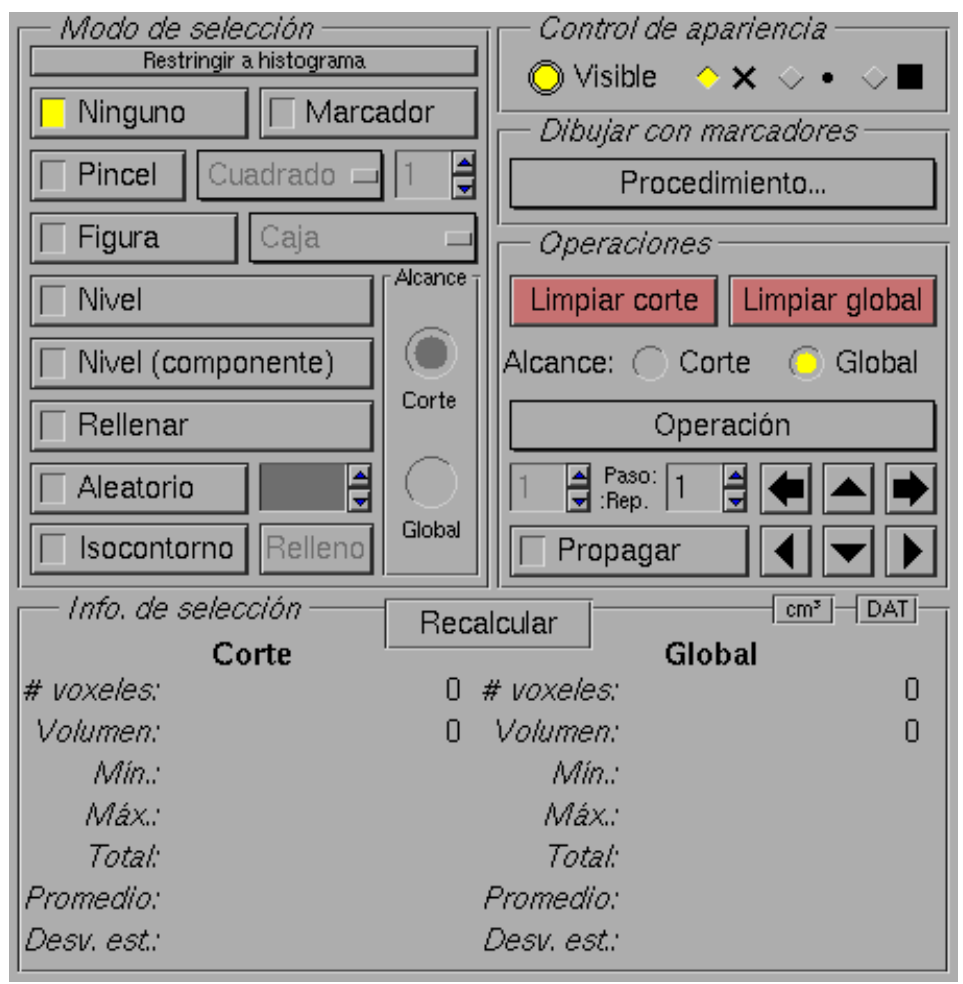

El diálogo de selección permite controlar la apariencia de la selección, reportar la información sobre la selección actual y elegir el modo de selección, así como realizar operaciones y procedimientos de dibujo sobre la misma.

El control de apariencia permite ocultar o mostrar la selección y establecer la marca utilizada para dibujarla sobre la imagen de la vista principal.

La información sobre la selección contempla el número de voxeles, el volumen y los valores mínimo, máximo, total y promedio, así como la desviación estándar. Esta información se actualiza con cada voxel que se añade o sustrae de la selección (salvo la desviación estándar) y puede ser recalculada utilizando el algoritmo de Kahan para la suma ${ }^{[55]}$ para reducir los errores por redondeo.

Los modos de selección disponibles son:

Ninguno - no realiza una selección

Marcador - establece marcadores que son utilizados por los procedimientos de dibujo

Pincel - permite dibujar la selección sobre la imagen utilizando pinceles de distintas formas (cuadrado, círculo, diamante y líneas en distintas orientaciones) y de tamaño arbitrario

Figura - permite dibujar la selección sobre la imagen a partir de dos puntos que definen una figura (caja, esfera, elipsoide, cilindro, línea o plano)

Nivel - permite seleccionar todos los voxeles cuyos valores caen en uno de los intervalos (niveles) definidos en la cuantización y que corresponde a un color en la imagen

Componente de nivel - igual que en el caso anterior pero limitado a una componente conexa

Rellenar — rellena un espacio acotado por la propia selección

Aleatorio - selecciona voxeles de manera aleatoria (útil para hacer muestras sobre la imagen)

Isocontorno - selecciona todos los voxeles que pertenecen al isocontorno del voxel seleccionado; se tiene la opción de seleccionar también todos los voxeles con valores mayores (rellenar el contorno)

Estos últimos cinco modos operan en el contexto del corte actual (Corte) o de toda la imagen (Global). Algunos modos pueden operar afectando solamente los voxeles con valores dentro de los límites del histograma establecido en la cuantización. Todos los modos permiten realizar una selección o una deselección según si se hace clic con el botón derecho o izquierdo del ratón, respectivamente.

Las operaciones disponibles incluyen limpiar la selección, invertirla, agrandarla, achicarla, tomar el borde, rellenar los huecos, suavizarla, calcular el armazón convexo o restringirla al histograma establecido en la cuantización. Entre los procedimientos de dibujo se cuenta con polígonos abiertos o cerrados, círculos completos o arcos de círculo, elipses completas o arcos de elipse, puntos y líneas horizontales o verticales. 


\section{Regiones de interés (ROIs).}

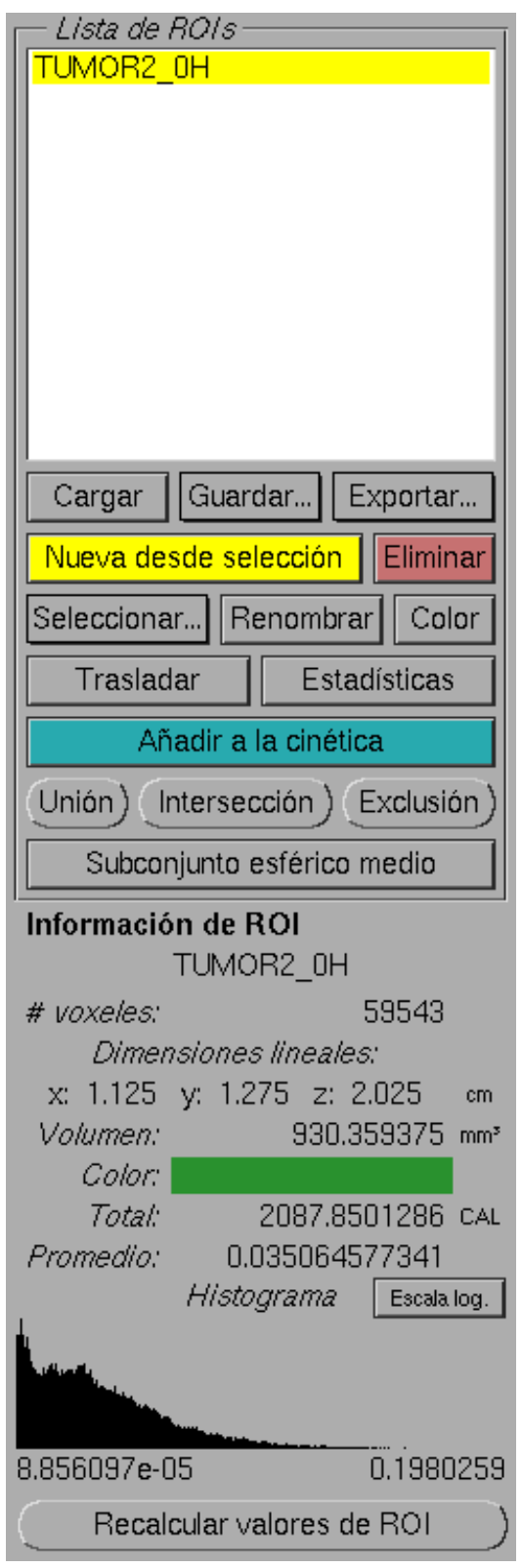

El diálogo de regiones de interés permite crear y manipular regiones de interés dentro de la imagen. Las regiones pueden ser creadas a partir de la selección actual o cargadas desde archivos previamente guardados, y pueden guardarse como listas de voxeles y exportarse como máscaras (1-bit) o submatrices de la imagen original. Entre las manipulaciones disponibles están las operaciones booleanas de unión (OR), intersección (AND) y exclusión (XOR) de cualquier número de regiones y la traslación:

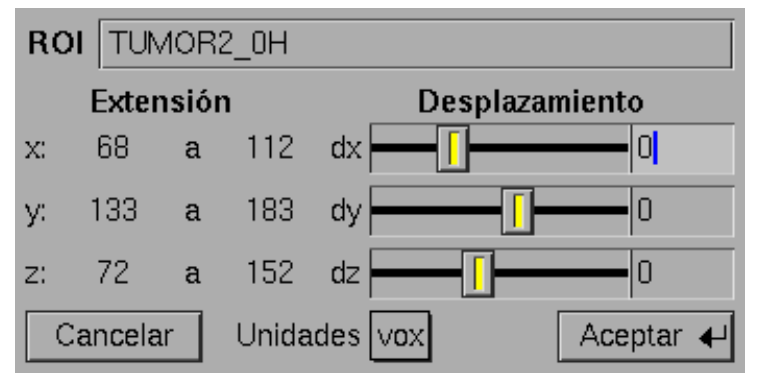

La información que se despliega para cada región de interés incluye el número de voxeles, las dimensiones lineales, el volumen, los valores total, promedio, mínimo y máximo, y el histograma (escala lineal o logarítmica); además se muestra el nombre que la identifica y el color que se usa para su visualización en la vista general. El histograma puede leerse haciendo clic y desplazándose sobre el mismo.

Además de renombrar y cambiar el color de una región, puede agregarse o quitarse de la selección, o bien seleccionarse solamente. También pueden desplegarse estadísticas completas de una o más regiones y guardarlas a un archivo:

\begin{tabular}{|c|c|c|}
\hline $\begin{array}{l}\text { Nombre de ROI } \\
\text { \# voxeles } \\
\text { Volumen } \\
\text { Extensión } x \\
\text { Extensión y } \\
\text { Extensión } z \\
\text { Total } \\
\text { Minimo } \\
\text { Máximo } \\
\text { Promedio } \\
\text { Desv. est. } \\
\text { Mediana }\end{array}$ & $\begin{array}{l}\text { TUMOR2_ӨH } \\
59543 \\
0.930359375 \\
1.125 \quad \mathrm{~cm} \\
1.275 \quad \mathrm{~cm} \\
2.025 \quad \mathrm{~cm} \\
133622408.233 \\
5.6679019928 \\
12673.6552734 \\
2244.13294985 \\
1842.00777386 \\
1831.82385254\end{array}$ & $\begin{array}{l}\text { u. arbitrarias } \\
\text { u. arbitrarias } \\
\text { u. arbitrarias } \\
\text { u. arbitrarias } \\
\text { u. arbitrarias } \\
\text { u. arbitrarias }\end{array}$ \\
\hline Actualizar & & Guardar a archivo \\
\hline
\end{tabular}

Por último, puede agregarse la región seleccionada al cálculo de la cinética o calcularse su subconjunto esférico medio, definido como la intersección de la región con la esfera cuyo centro es el valor promedio de las coordenadas de los voxeles de la región y cuyo radio es el promedio de la distancia entre todos los pares de voxeles de la región; esta construcción es un tipo de equivalente esférico de una región arbitraria. 


\section{Dosis.}

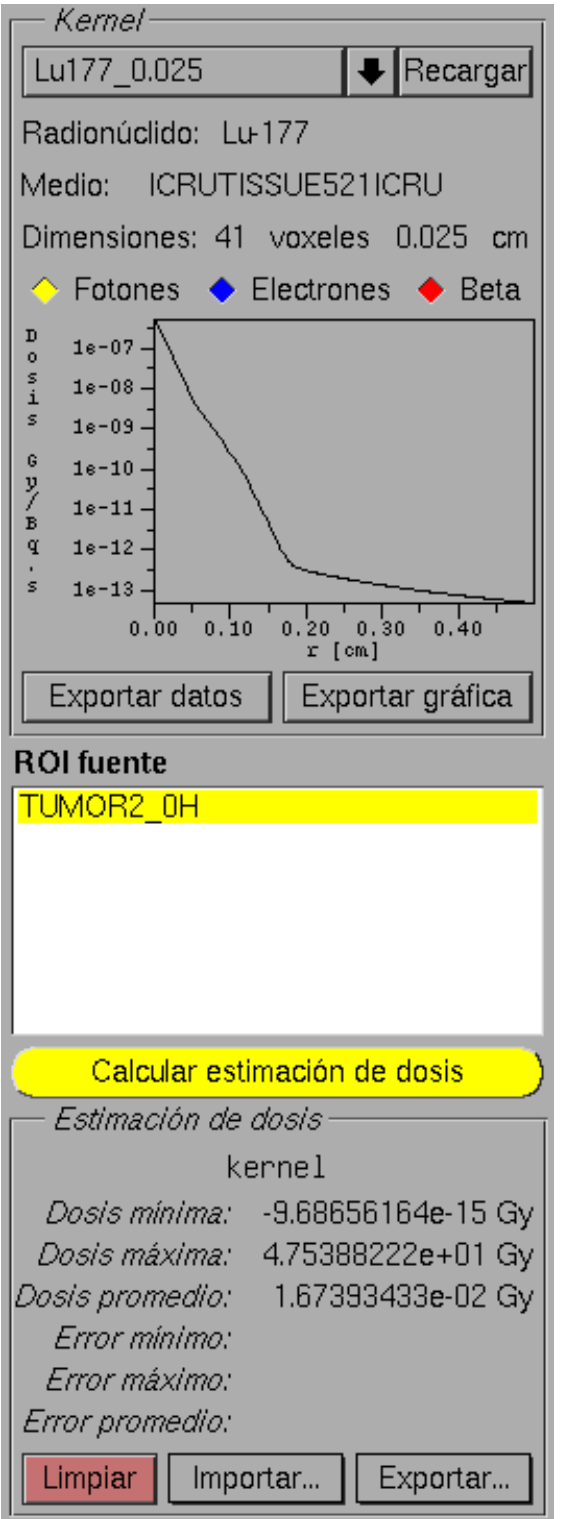

El diálogo de dosis permite elegir el kernel de dosis por voxel y la región fuente que serán utilizados para realizar la estimación de dosis por convolución, la cuál se calcula con sólo picar un botón.

La gama de radionúclidos utilizables para la estimación de dosis depende de la disponibilidad de un kernel de dosis por voxel precalculado para el radionúclido de interés, en una matriz con voxeles de las mismas dimensiones y en un medio compatible con las regiones que se estén analizando, lo que supone el trabajo adicional de calcular estos kernel de antemano. Al cargar un kernel se muestra la información del radionúclido, el medio y la matriz, además de una gráfica de la dosis promedio por partícula como función de la distancia. Si se calculan los kernel por separado, puede activarse o desactivarse la contribución a la dosis de los distintos tipos de emisiones (fotones, electrones y beta).

Una vez que se realiza la estimación de dosis (y del error en la dosis, de ser posible), se muestran los valores mínimo, máximo y promedio y se puede exportar como una matriz tridimensional del mismo tamaño que los datos para su posterior uso y análisis. También se puede cargar una estimación de dosis o del error a partir de un archivo con las mismas dimensiones que los datos y limpiar los datos actualmente en memoria. 


\section{Histogramas volumétricos de dosis (DVHs).}

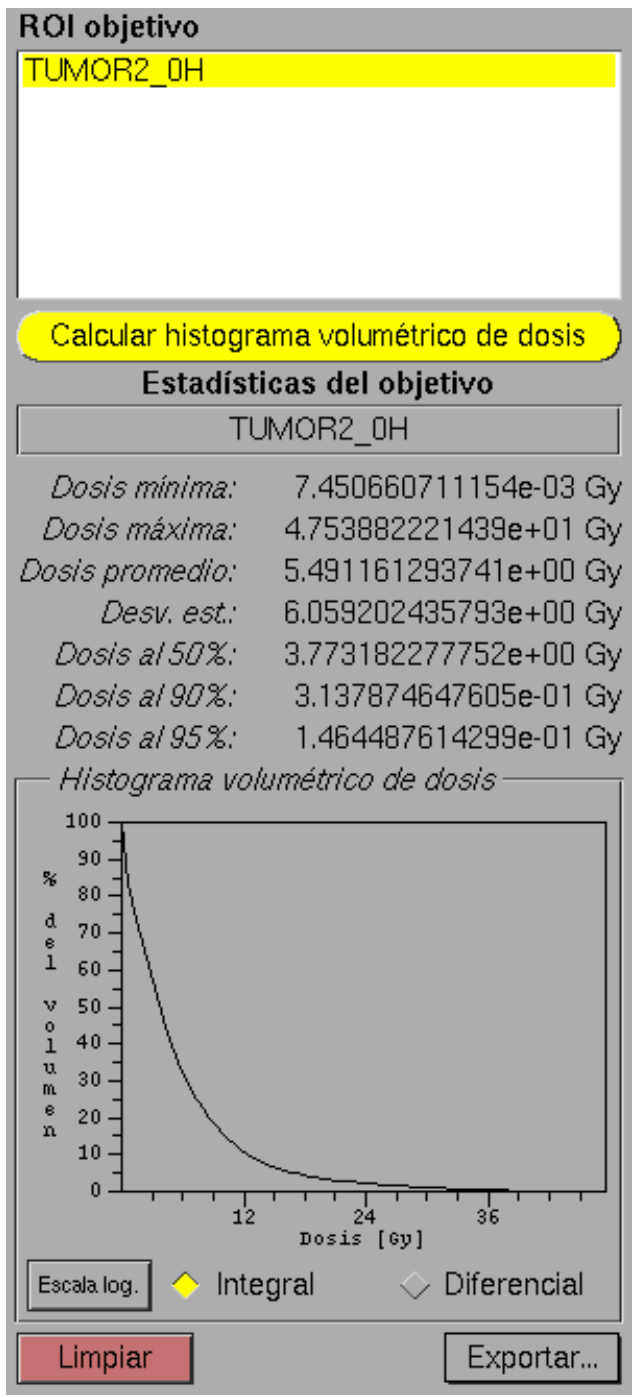

El diálogo de histogramas volumétricos de dosis permite elegir cualquier región de interés y calcular el histograma volumétrico de dosis, tanto integral como diferencial, que corresponde a la estimación de dosis cargada. El histograma puede leerse haciendo clic y desplazándose sobre el mismo.

La información que se muestra para la región objetivo incluye los valores de dosis mínima, máxima y promedio y la desviación estándar, así como la dosis mínima recibida por el 50\%, 90\% y $95 \%$ del volumen total.

Una vez calculado el histograma es posible exportarlo como datos o como imagen, o bien se pueden exportar los valores de dosis en cada voxel de la región objetivo para su análisis posterior. 


\section{Operaciones.}

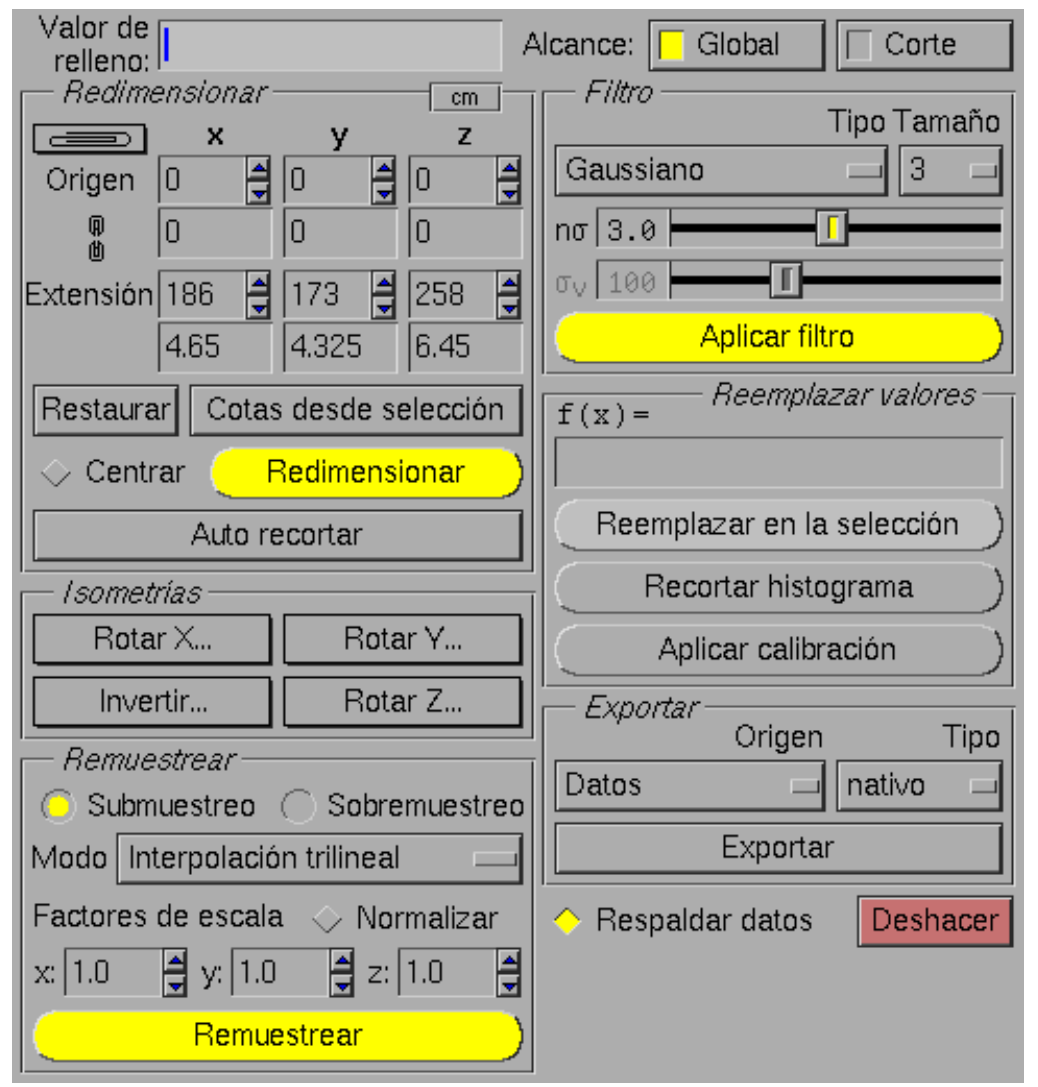

El diálogo de operaciones permite realizar diversas operaciones que alteran los valores de los datos, a diferencia de todos los demás diálogos, en que solamente se modifica la representación de los mismos. Entre las opciones disponibles está el redimensionar la matriz tridimensional, realizar isometrías (inversiones y rotaciones por múltiplos de $90^{\circ}$ ) y remuestrear los datos a una matriz con voxeles de distinto tamaño.

También es posible aplicar un filtro gaussiano unilateral o bilateral a los datos para eliminar ruido, reemplazar valores mediante una función arbitraria, restringir los valores al rango seleccionado en la cuantización o aplicar la calibración modificando los valores de los datos. Por último, es posible exportar los datos, la selección, la imagen cuantizada o la estimación de dosis como diversos tipos de dato.

Cada vez que se realiza una operación, se guarda un respaldo de los datos anteriores, por lo que puede deshacerse la última operación realizada. Si no se cuenta con suficiente memoria puede deshabilitarse esta opción. 


\section{Cinética.}

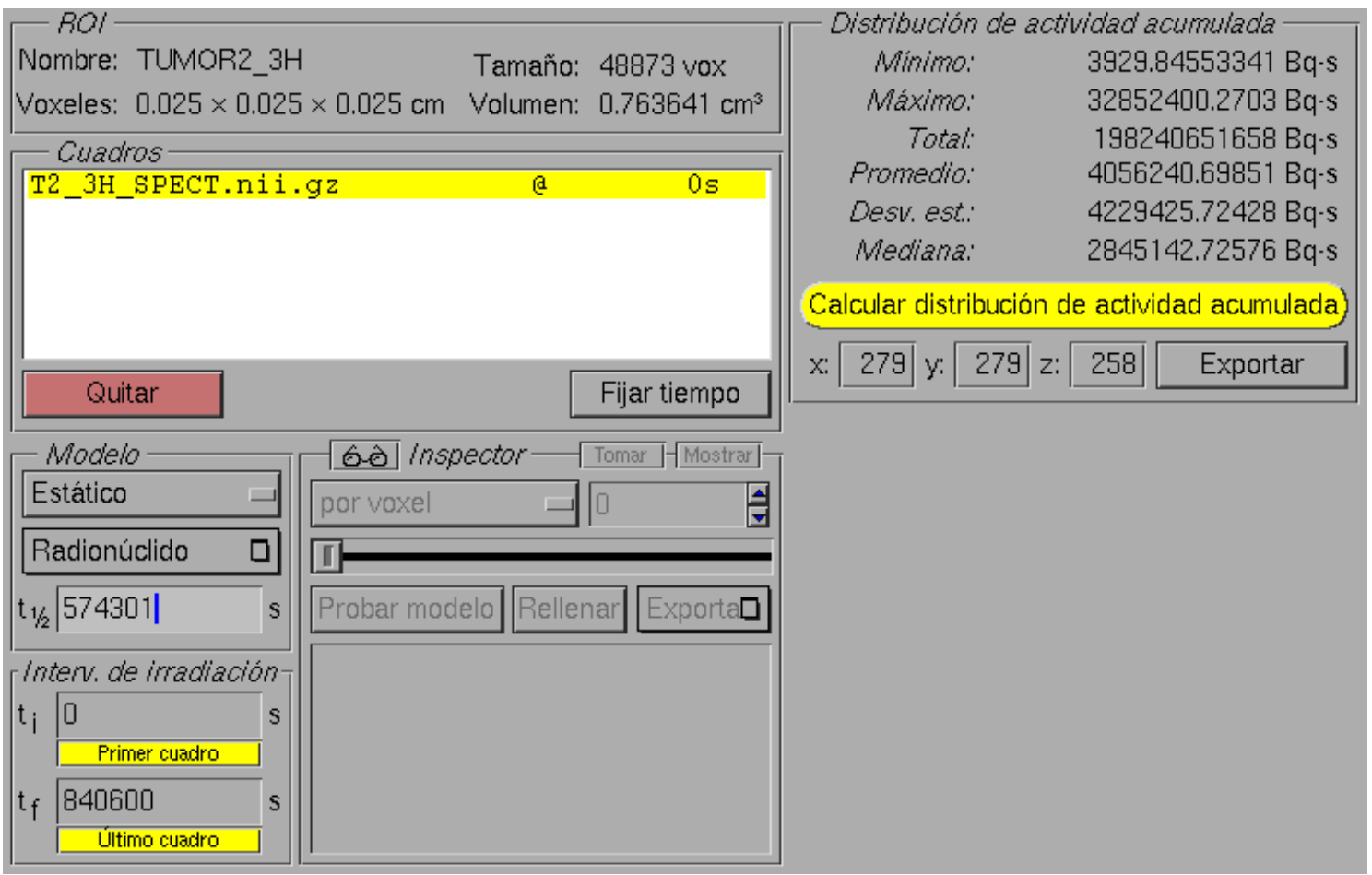

El diálogo de cinética permite ajustar un modelo de la cinética a cada voxel de una serie de imágenes para obtener una distribución de actividad acumulada. Entre los modelos posibles está un modelo estático que utiliza solo un cuadro (punto en el tiempo), un modelo efectivo que calcula una vida media efectiva a partir del comportamiento promedio en una región y un modelo biexponencial que contempla dos fases de eliminación exponencial con vidas medias efectivas distintas. Por el momento no se cuenta con una manera de ajustar modelos que varíen de voxel a voxel de maneras más elaboradas. Para calcular la actividad acumulada es necesario establecer el intervalo de irradiación.

Para poder determinar si un modelo es consistente con los datos, se cuenta con un inspector donde es posible visualizar la curva de actividad vs. tiempo para cada voxel de la región y probar el ajuste del modelo seleccionado. El voxel puede elegirse a partir de un marcador en la vista principal o bien puede mostrarse el voxel seleccionado mediante un marcador en la vista principal, con el objeto de obtener información sobre la ubicación espacial de la cinética (en qué región se tiene qué comportamiento). 


\section{Cálculo de kernel (Kernel).}

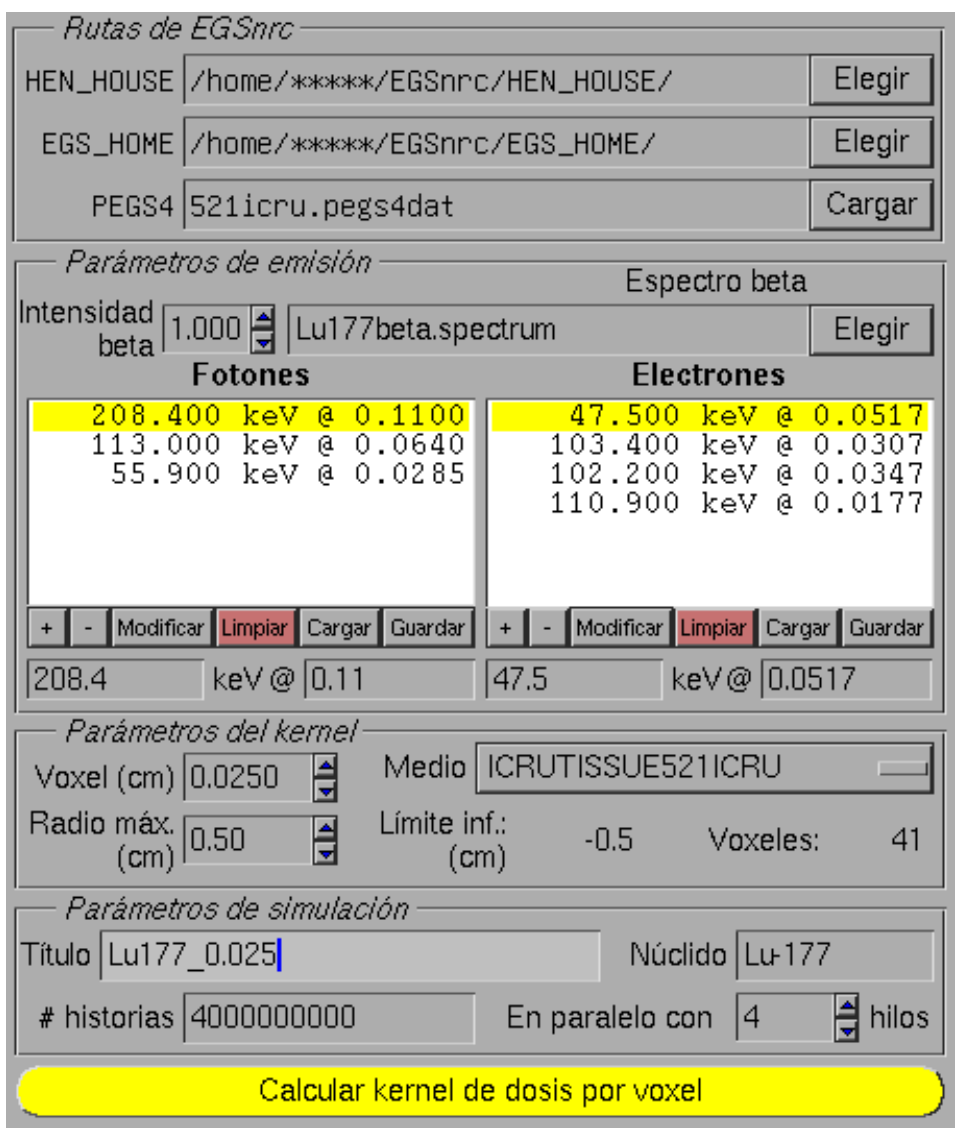

El diálogo de cálculo de kernel permite calcular un kernel de dosis por voxel para un radionúclido arbitrario en una matriz cartesiana arbitraria utilizando DOSXYZnrc.

Para modelar el radionúclido es posible establecer la energía y la intensidad de las emisiones de fotones y electrones monoenergéticos, así como cargar un espectro de emisión beta y fijar su intensidad. En cuanto a los parámetros del kernel se puede asignar el medio, la geometría y el número de historias.

Al momento de hacer el cálculo, se ejecuta DOSXYZnrc (en paralelo, si así se pide) las veces que sea necesario para obtener el kernel de cada emisión y posteriormente se suman, pesados por las intensidades, para obtener los kernel por tipo de emisión y el kernel total. Todo esto se realiza de manera automática y el kernel resultante se pone inmediatamente a disposición del software para su uso en la estimación de dosis.

Por el momento no es posible cambiar los parámetros de simulación de EGSnrc, siendo utilizados por omisión los mismos que en este trabajo. 
Dosimetría de película (Película).

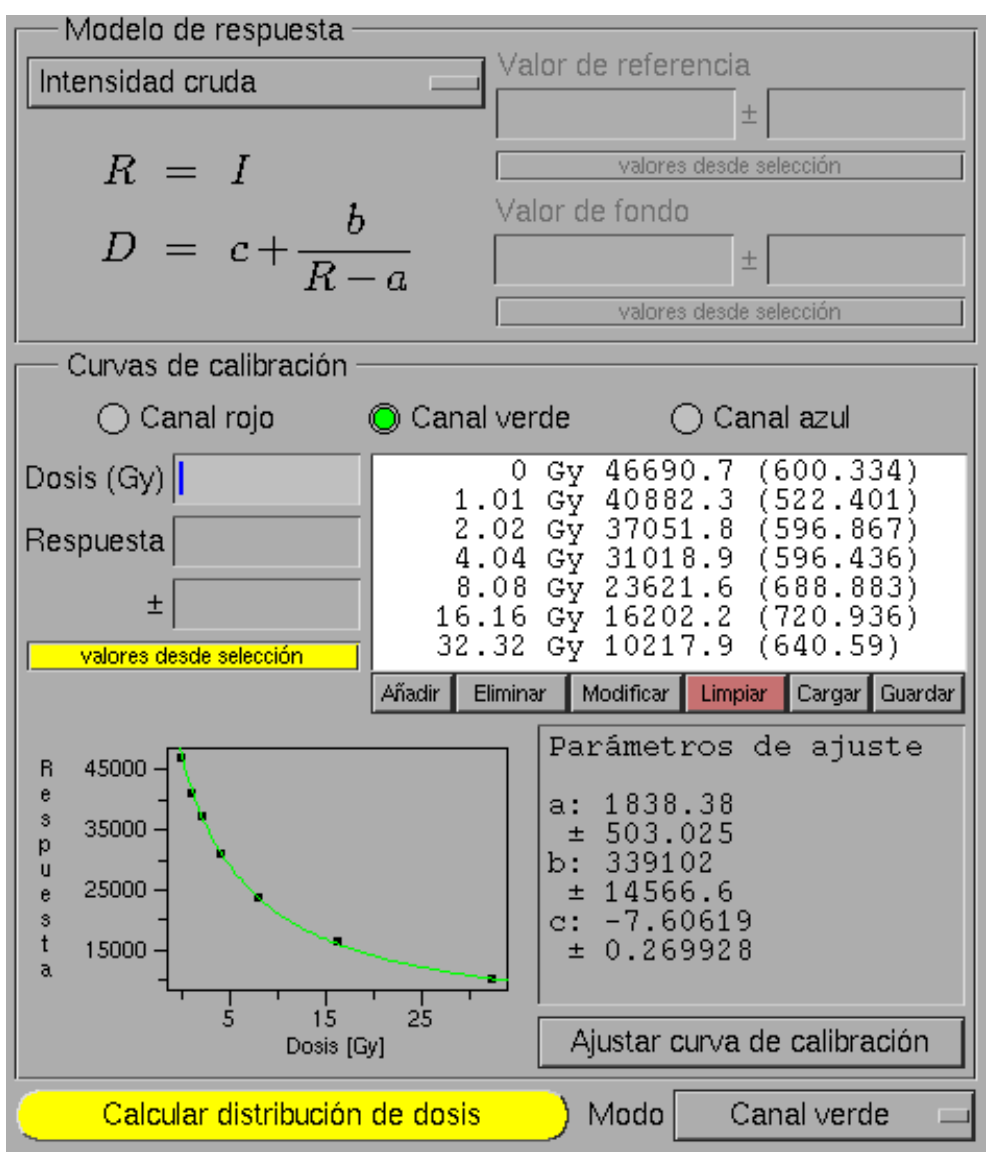

El diálogo de dosimetría de película permite establecer una curva patrón para película de tinte radiocrómico a partir de imágenes digitalizadas en RGB de películas con dosis uniforme conocida, así como aplicar posteriormente esta curva patrón a imágenes digitalizadas en RGB de películas de tinte radiocrómico arbitrarias para obtener mapas de dosis.

Además de elegirse el canal utilizado para calcular la dosis, es posible cambiar el modelo de la respuesta calculada a partir de las imágenes, estando entre las opciones la intensidad cruda (valor de pixel) y la densidad óptica con y sin fondo, a partir de los valores de referencia y de fondo introducidos. 


\section{Capítulo 4 RESULTADOS}

\subsection{IMÁGENES TOMOGRÁFICAS CUANTIFICADAS}

En la Tabla 4.1 se reportan las actividades totales presentes en cada una de las imágenes.

Tabla 4.1. Actividad inyectada y actividad total en las imágenes.

\begin{tabular}{|c|r|r|}
\cline { 2 - 3 } \multicolumn{1}{c|}{} & \multicolumn{1}{c|}{ TUMOR 1 } & TUMOR 2 \\
\hline Actividad inyectada & $(608 \mu \mathrm{Ci}) 22.5 \mathrm{MBq}$ & $(507 \mu \mathrm{Ci}) 18.8 \mathrm{MBq}$ \\
\hline Estudio & \multicolumn{2}{|c|}{ Actividad total en la imagen } \\
\hline $0 \mathrm{~h}$ & $13.3 \mathrm{MBq}$ & $10.4 \mathrm{MBq}$ \\
\hline $1 \mathrm{~h}$ & $10.6 \mathrm{MBq}$ & $4.4 \mathrm{MBq}$ \\
\hline $3 \mathrm{~h}$ & $3.8 \mathrm{MBq}$ & $2.3 \mathrm{MBq}$ \\
\hline cubo & $1.1 \mathrm{MBq}$ & $0.81 \mathrm{MBq}$ \\
\hline
\end{tabular}

En las Figuras 4.1 y 4.2 se muestran cortes representativos de las imágenes tomográficas de cada tumor, donde puede observarse el máximo de actividad correspondiente al punto de inyección.

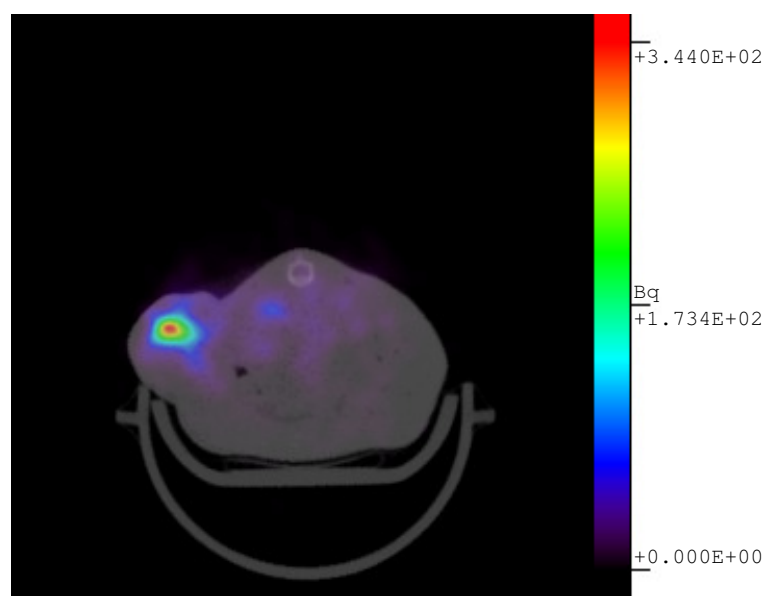

$0 \mathrm{~h}$

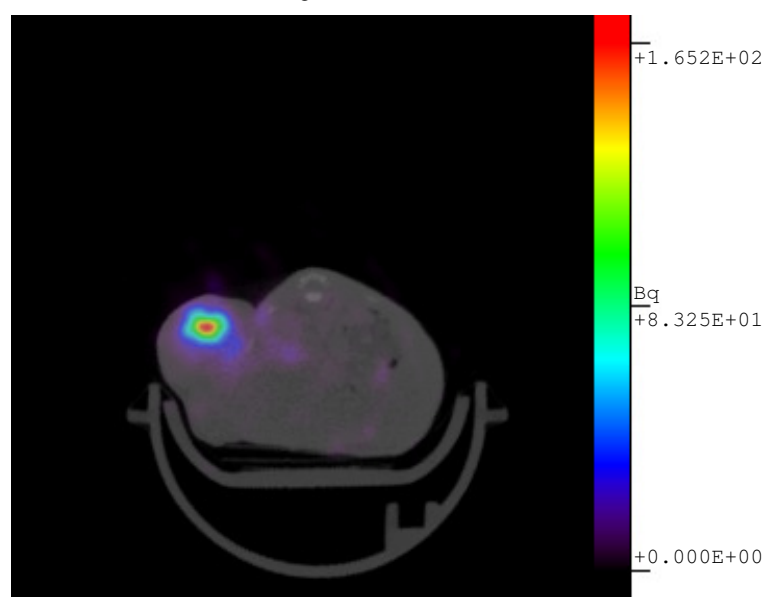

$3 \mathrm{~h}$

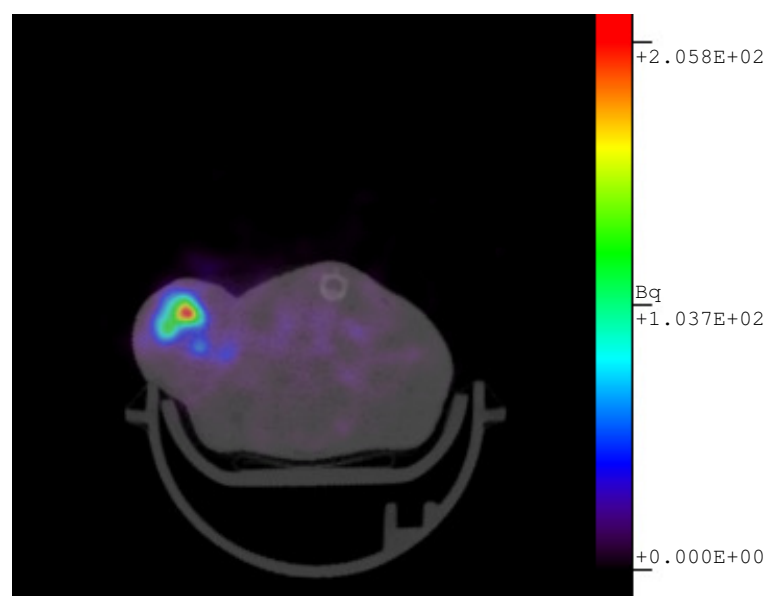

$1 \mathrm{~h}$

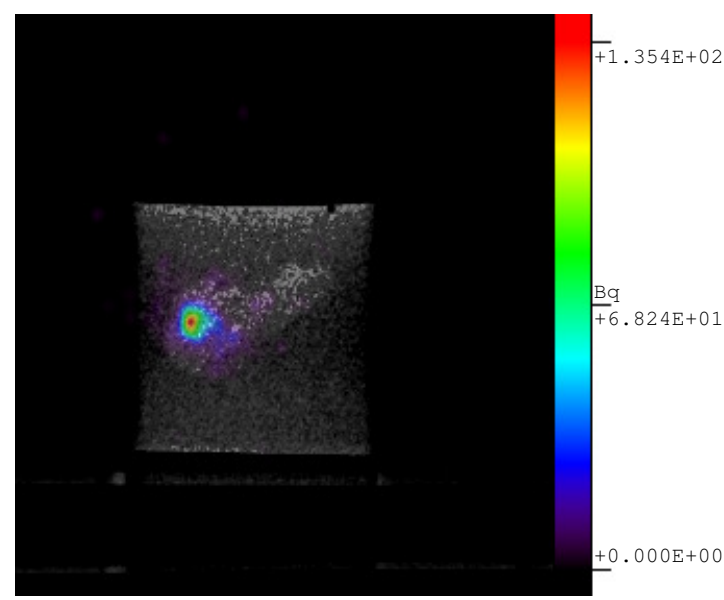

cubo

Figura 4.1. Cortes representativos de las imágenes tomográficas del tumor 1. 


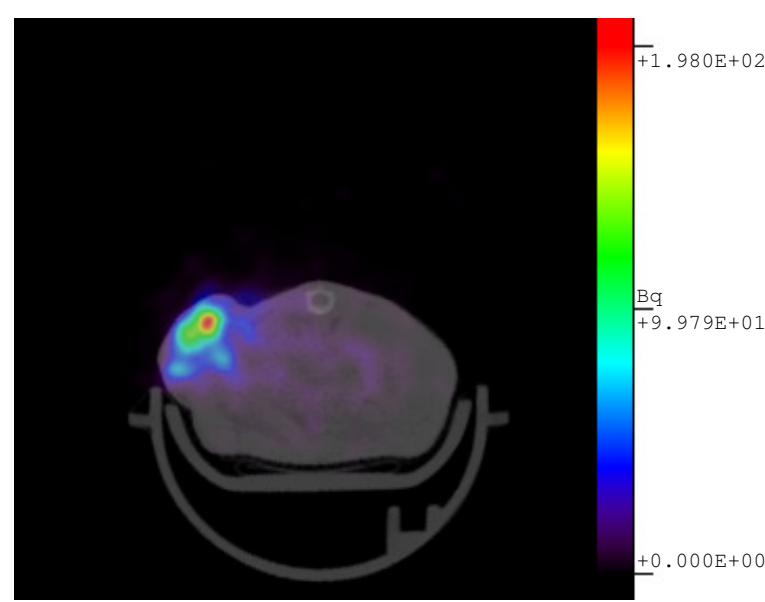

$0 \mathrm{~h}$

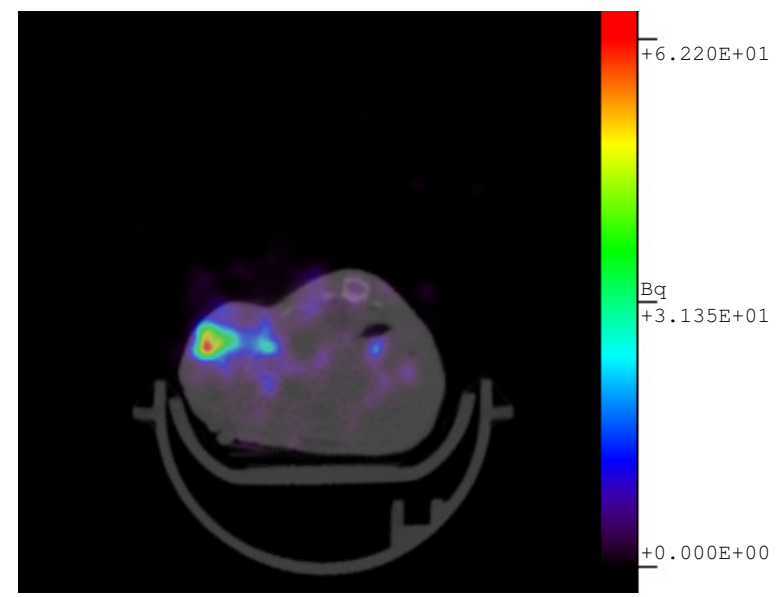

$3 \mathrm{~h}$

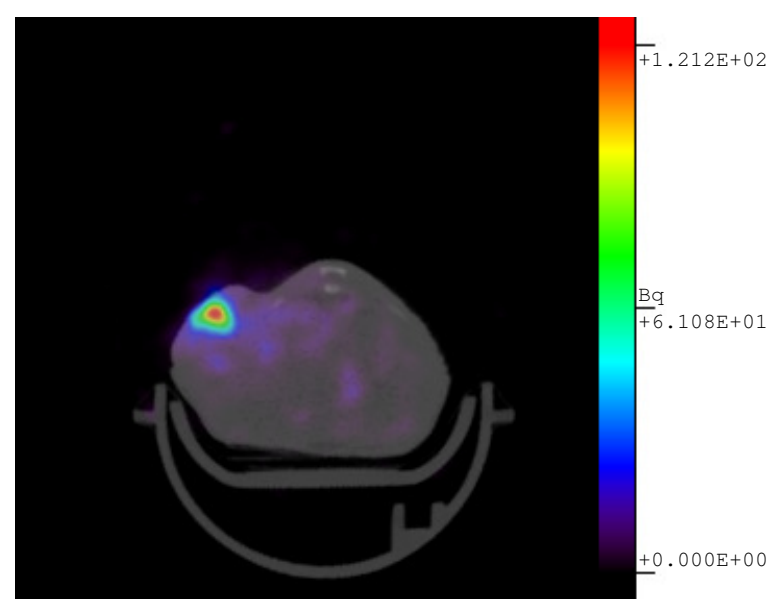

$1 \mathrm{~h}$

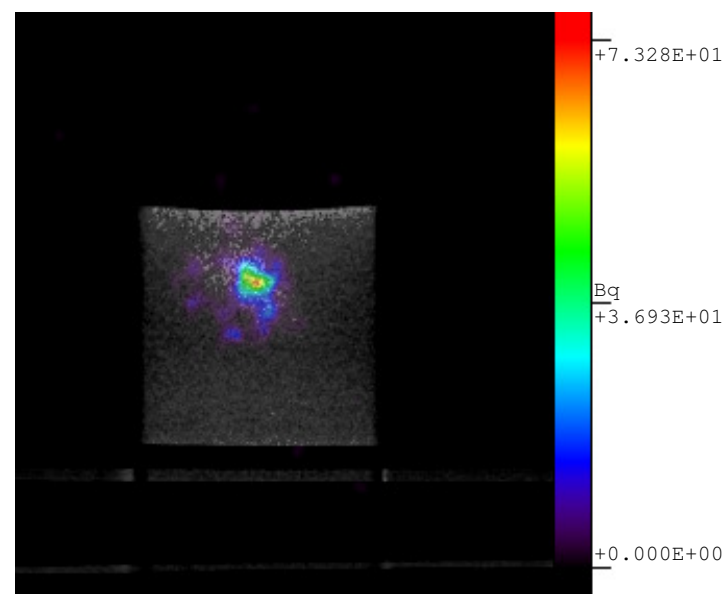

cubo

Figura 4.2. Cortes representativos de las imágenes tomográficas del tumor 2.

\subsection{KERNEL DE DOSIS POR VOXEL}

Los kernel de Lutecio-177 fueron calculados para voxeles cúbicos de $0.065 \mathrm{~cm}$ (matriz de SPECT) y $0.025 \mathrm{~cm}$ (matriz de fusión) con $4 \times 10^{9}$ historias, aunque sólo se reporta este último por ser el que se usó para la estimación de dosis. La distancia máxima desde el voxel central se escogió como $0.5 \mathrm{~cm}$, buscando que el kernel abarcara el rango de las emisiones de electrones y una parte de la «cola» de las emisiones de fotones.

La Figura 4.3 muestra en la misma escala los distintos kernel calculados para Lutecio-177: emisión beta, electrones monoenergéticos, fotones y total. En todos los casos el kernel representa la dosis promedio por transformación nuclear como función de la distancia al voxel central, para una fuente isotrópica que abarca el volumen del voxel central y en tejido blando. El kernel total se obtuvo a partir de la suma de los otros tres kernel. 

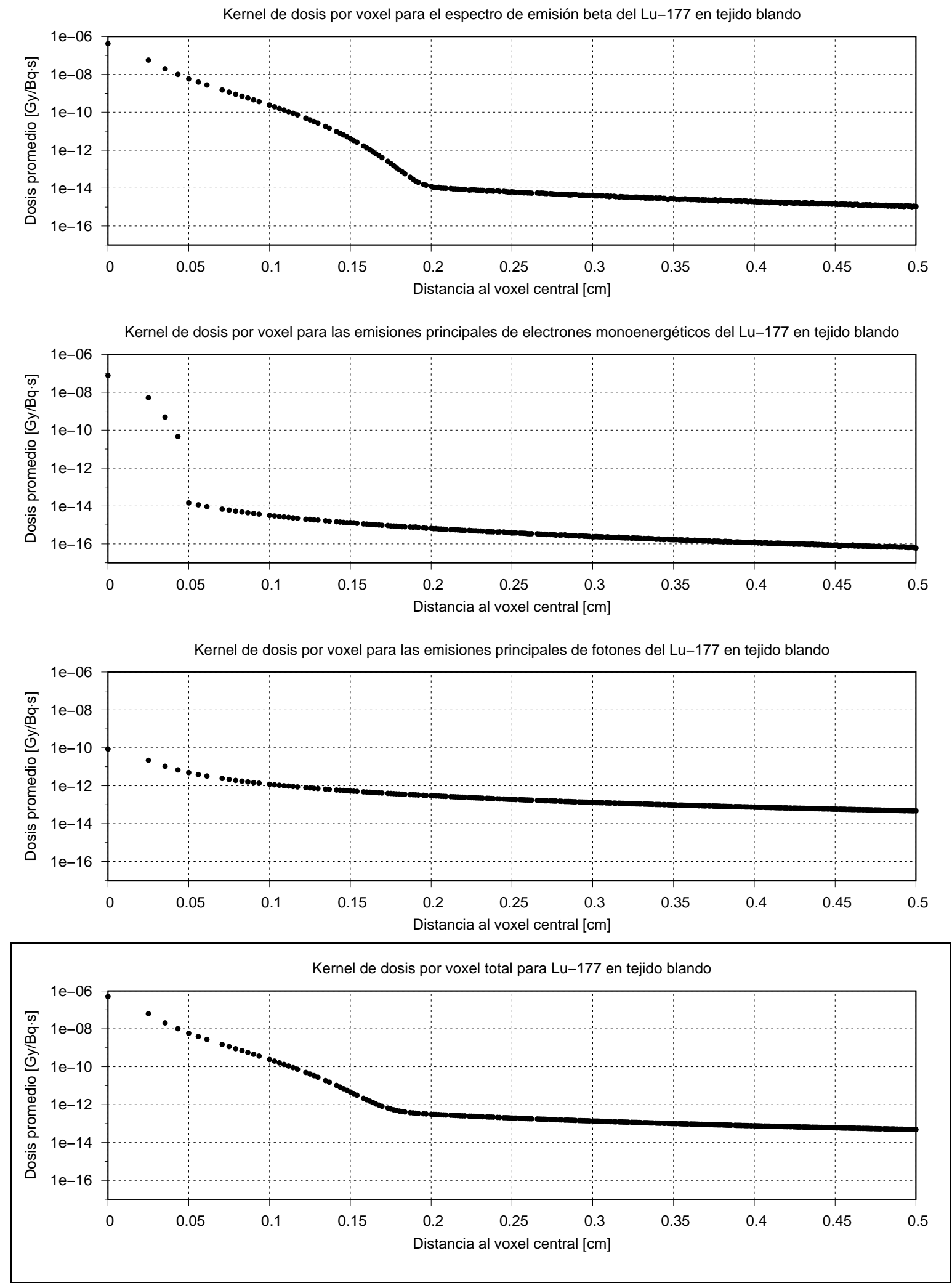

Figura 4.3. Kernel de dosis por voxel para Lu-177 en tejido blando. 
La Tabla 4.2 resume las principales características del kernel total: la dosis en el voxel central y sus primeros vecinos, y la distancia de cruce que separa el rango donde domina la contribución de los electrones del rango donde domina la contribución de los fotones. El error estadístico es $<0.1 \%$ en las dosis promedio para los voxeles listados.

Tabla 4.2. Características principales del kernel de dosis por voxel total para Lu-177 en tejido blando.

$\begin{array}{ccc}\text { Voxel } & \text { Dosis promedio } & \text { Distancia de cruce } \\ (0,0,0) & 5.025 \times 10^{-7} \mathrm{~Gy} / \mathrm{Bq} \cdot \mathrm{s} & 0.19 \mathrm{~cm} \\ (0,0,1) & 6.268 \times 10^{-8} \mathrm{~Gy} / \mathrm{Bq} \cdot \mathrm{s} & \\ (0,1,1) & 2.051 \times 10^{-8} \mathrm{~Gy} / \mathrm{Bq} \cdot \mathrm{s} & \\ (1,1,1) & 1.012 \times 10^{-8} \mathrm{~Gy} / \mathrm{Bq} \cdot \mathrm{s} & \end{array}$

\subsection{SELECCIÓN DE REGIONES DE INTERÉS}

En la Tabla 4.3 se reporta el volumen de los tumores según se determinó realizando la selección sobre las imágenes de CT, así como la actividad total ubicada en tales regiones. El volumen medido corresponde a la medición directa con un vernier sobre dos ejes principales del tumor y la aplicación de la fórmula del elipsoide $V=\frac{\pi}{6} L \cdot W^{2}$, donde $L$ es el largo y $W$ el ancho.

Tabla 4.3. Volumen y actividad presente en las regiones de interés.

\begin{tabular}{|c|r|r|r|r|}
\cline { 2 - 5 } \multicolumn{1}{c|}{} & \multicolumn{2}{c|}{ TUMOR 1 } & \multicolumn{2}{c|}{ TUMOR 2 } \\
\hline Volumen medido & \multicolumn{2}{c|}{$1034 \mathrm{~mm}^{3}$} & \multicolumn{2}{c|}{$2281 \mathrm{~mm}^{3}$} \\
\hline Estudio & Volumen & Actividad & Volumen & Actividad \\
\hline $0 \mathrm{~h}$ & $974 \mathrm{~mm}^{3}$ & $2.1 \mathrm{MBq}$ & $930 \mathrm{~mm}^{3}$ & $2.1 \mathrm{MBq}$ \\
\hline $1 \mathrm{~h}$ & $1120 \mathrm{~mm}^{3}$ & $1.4 \mathrm{MBq}$ & $861 \mathrm{~mm}^{3}$ & $0.82 \mathrm{MBq}$ \\
\hline $3 \mathrm{~h}$ & $995 \mathrm{~mm}^{3}$ & $0.81 \mathrm{MBq}$ & $764 \mathrm{~mm}^{3}$ & $0.38 \mathrm{MBq}$ \\
\hline cubo & $1236 \mathrm{~mm}^{3}$ & $0.52 \mathrm{MBq}$ & $692 \mathrm{~mm}^{3}$ & $0.29 \mathrm{MBq}$ \\
\hline
\end{tabular}

La discrepancia entre los volúmenes obtenidos a partir de las imágenes para un mismo tumor se debe a que los márgenes internos del tumor no se distinguen en las imágenes de CT, pues se trata de una interfaz entre tejido blando, por lo que hay amplia variabilidad en su determinación; además, al ser distinta la geometría en cada imagen, hay un grado de variabilidad intrínseco. Por otra parte, la discrepancia entre estos valores y los volúmenes medidos se debe a que la forma de los tumores es irregular, por lo que la fórmula del elipsoide es tan sólo una aproximación y a que en las imágenes se buscó seleccionar el tumor pero no la piel que lo cubre, mientras que la medición directa considera necesariamente esta contribución al volumen. En el caso de las imágenes de los cubos es especialmente difícil distinguir los bordes del tumor, debido al bajo contraste con el medio circundante.

\subsection{Co-REgISTRO DE IMÁGENES DE LA SERIE TEMPORAL}

En la Figura 4.4 se ilustran las tres series de imágenes co-registradas en la región del tumor 1, que surgen de tomar cada imagen de CT a su vez como referencia y ajustar las otras dos mediante una transformación rígida. La imagen de referencia se muestra en tonos amarillos y la imagen superpuesta en tonos morados, dando lugar a tonos anaranjados en las zonas de traslape. Puede observarse que la correspondencia geométrica sólo se da en la región del tumor (en color gris). Se obtuvieron resultados análogos para el tumor 2. 

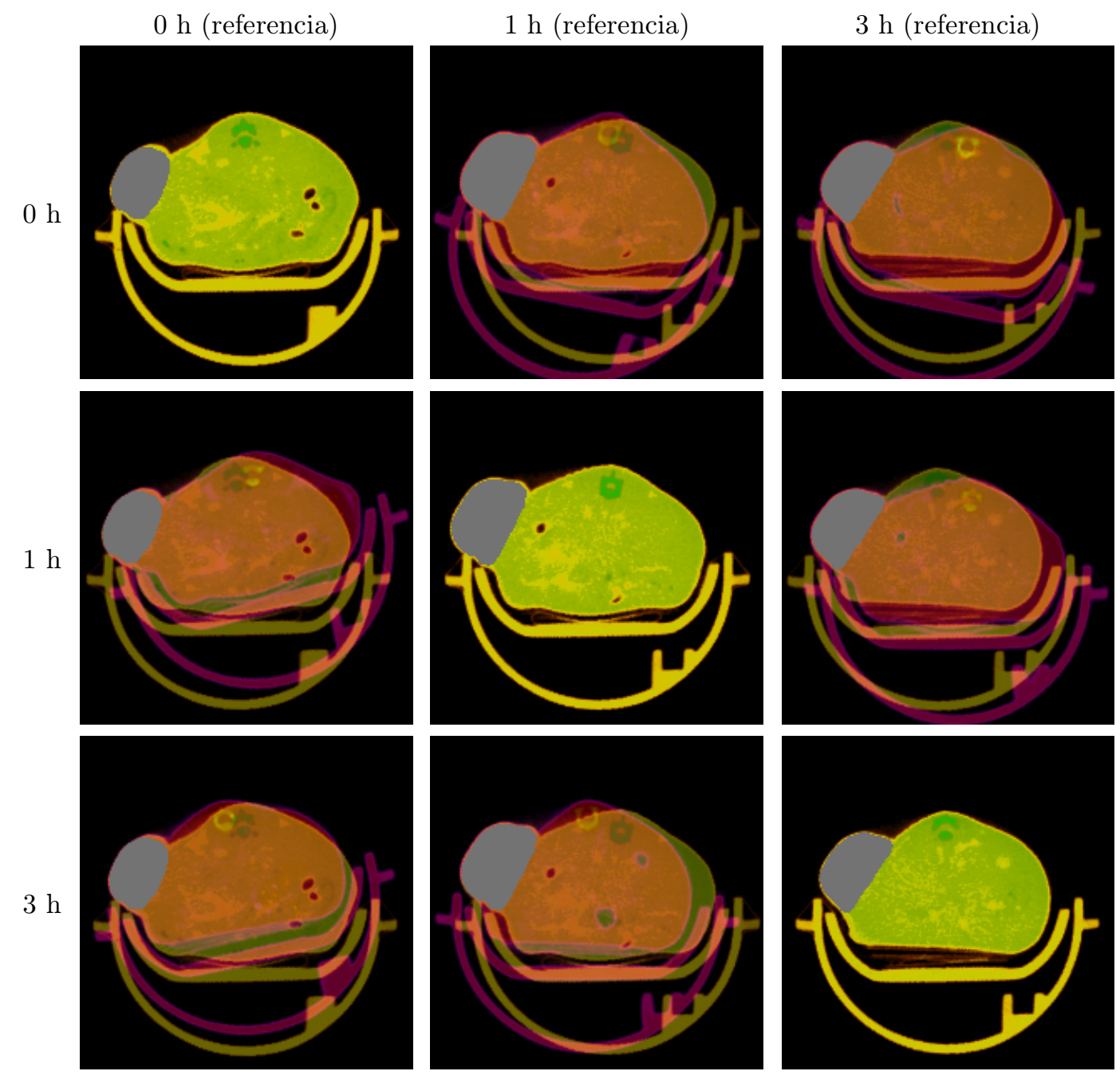

Figura 4.4. Series de imágenes co-registradas en la región del tumor 1, tomando cada una a su vez como referencia.

La transformación obtenida del co-registro de las imágenes de CT se aplicó a las imágenes de SPECT para obtener las distribuciones de actividad en una misma geometría.

\subsection{CÁlCUlo de ACtividad ACUMUladA}

Las Figuras 4.5 y 4.6 muestran los valores de actividad total en la región del tumor vs. tiempo desde la inyección, así como el ajuste exponencial a estos datos y los valores de actividad acumulada total en esta misma región siguiendo los dos enfoques: considerando solamente la vida media física del radionúclido y considerando la vida media efectiva obtenida del ajuste, e integrando a partir de la actividad presente en la imagen a $3 \mathrm{~h}$.

Los resultados y los ajustes se calcularon para cada una de las tres series de imágenes ilustradas en la Figura 4.4, obtenidas del co-registro en la región del tumor tomando cada imagen a su vez como referencia. 


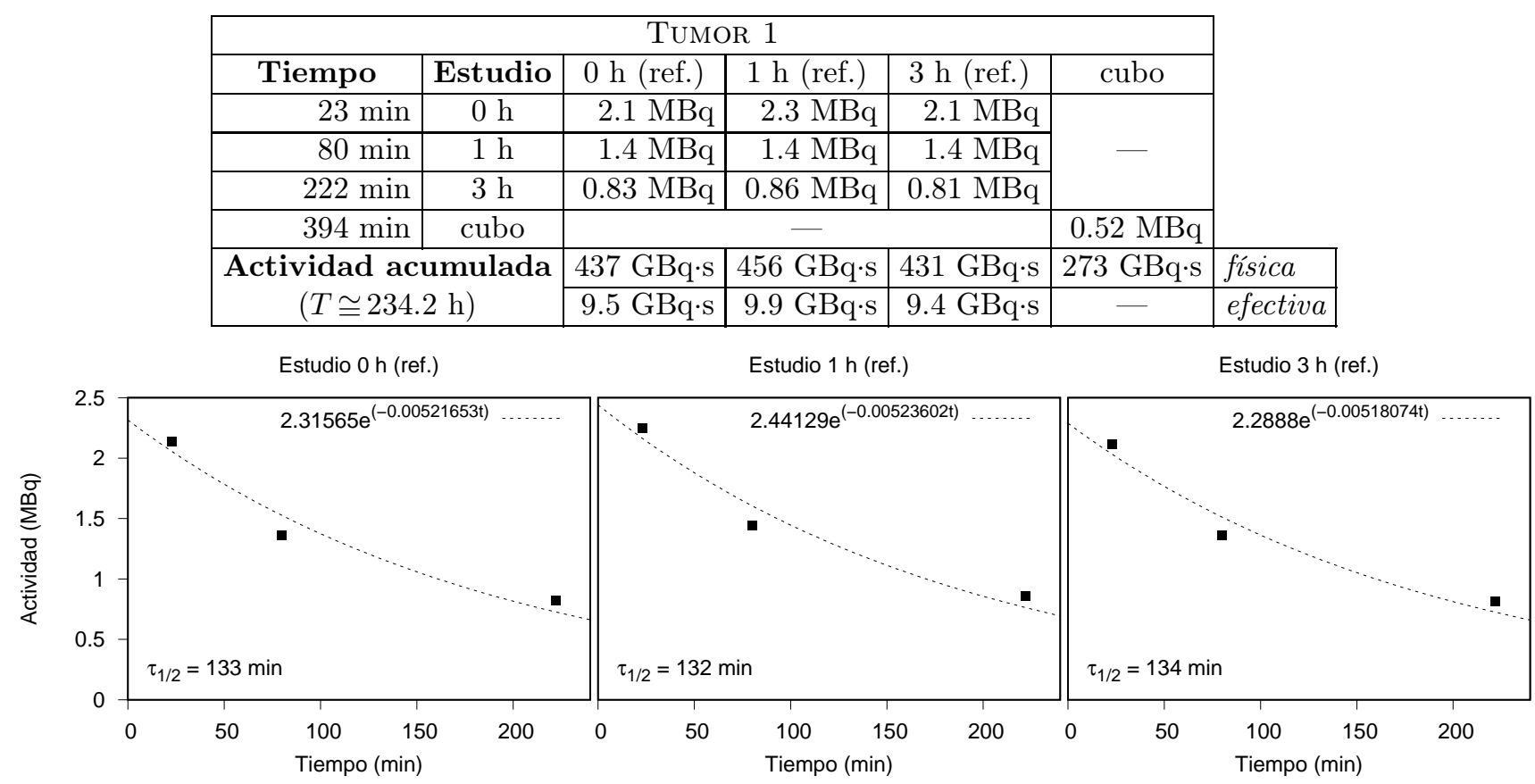

Figura 4.5. Valores de actividad total en la región del tumor vs. tiempo desde la inyección, ajuste exponencial y actividad acumulada para el tumor 1 .

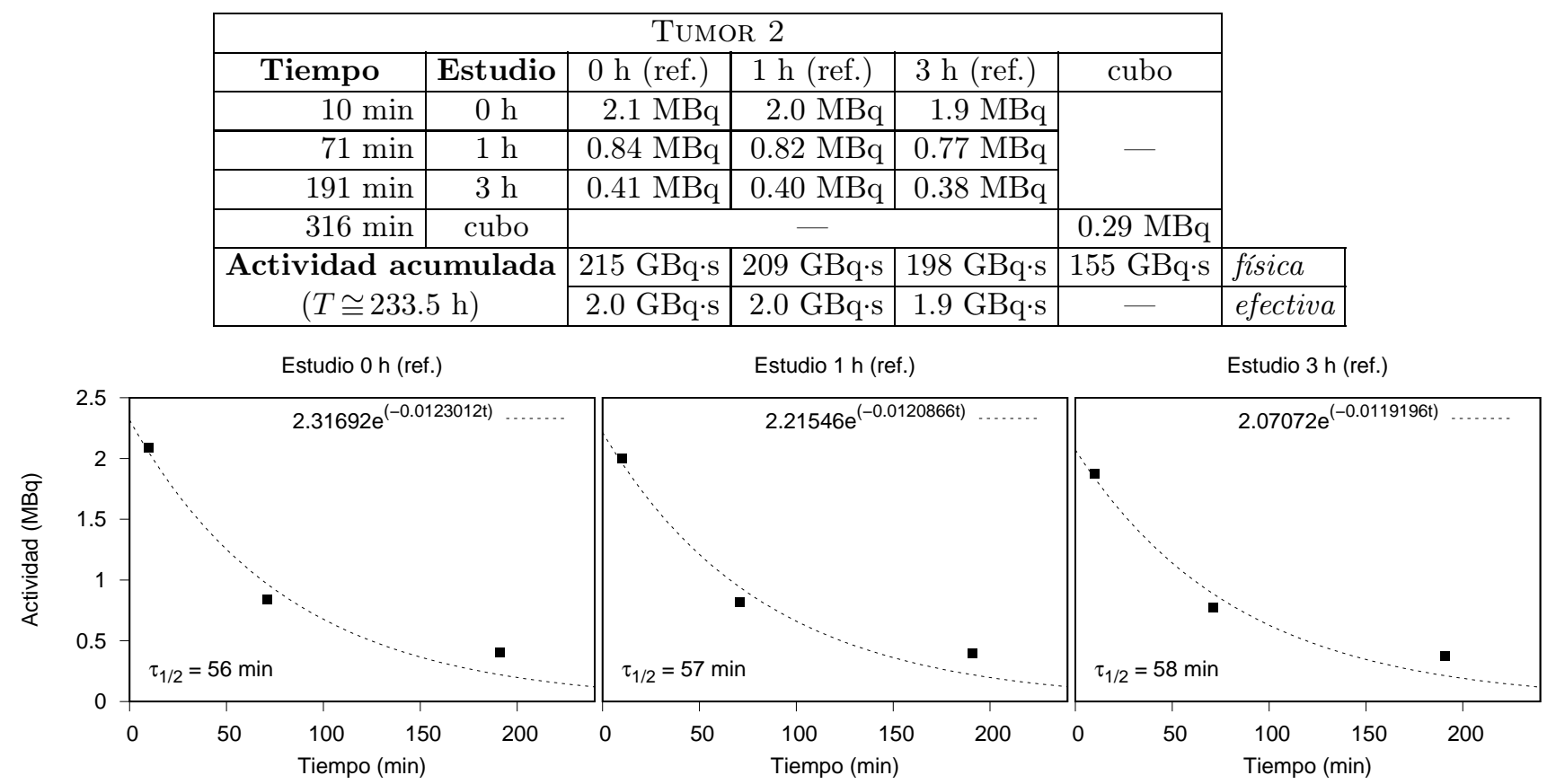

Figura 4.6. Valores de actividad total en la región del tumor vs. tiempo desde la inyección, ajuste exponencial y actividad acumulada para el tumor 2 . 


\subsection{Estimación DE DOSIS}

Las Figuras 4.7-4.9 reportan la estimación de dosis en la región del tumor. Se muestran el histograma volumétrico de dosis y los valores de dosis promedio, mínima, máxima, recibida por el $50 \%$ del volumen (mediana), recibida por el $90 \%$ del volumen y recibida por el $95 \%$ del volumen; se indica si el valor corresponde al cálculo de actividad acumulada con la vida media física o la vida media efectiva. También se muestra un corte con curvas de isodosis al interior del tumor. No se presentan incertidumbres para las dosis pues no fue posible calcularlas, ya que no se contó con incertidumbres para las actividades en primer lugar.

Se muestran nuevamente los resultados para cada serie de imágenes co-registradas tomando cada imagen a su vez como referencia.

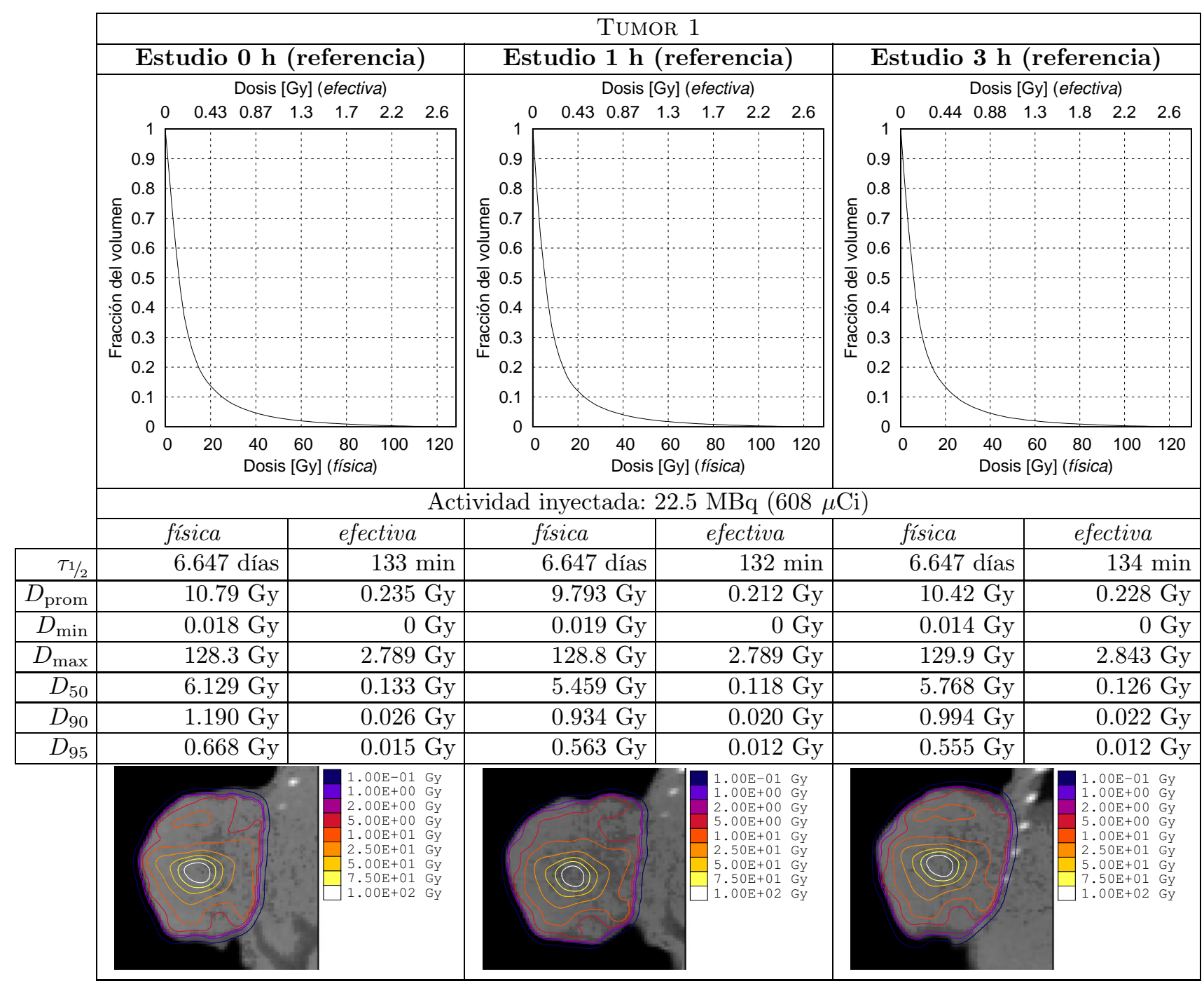

Figura 4.7. Estimaciones de dosis para el tumor 1. 


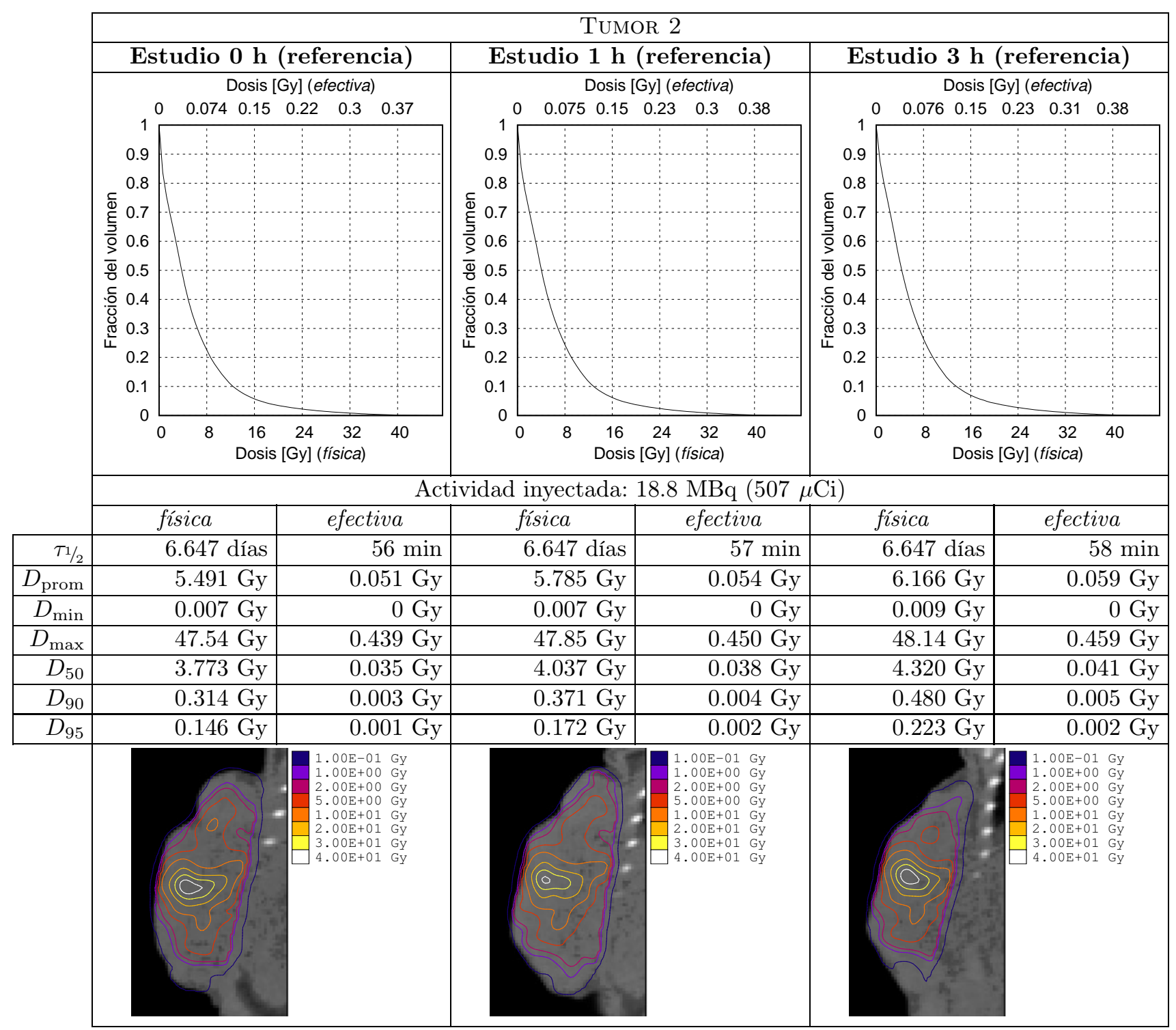

Figura 4.8. Estimaciones de dosis para el tumor 2 . 


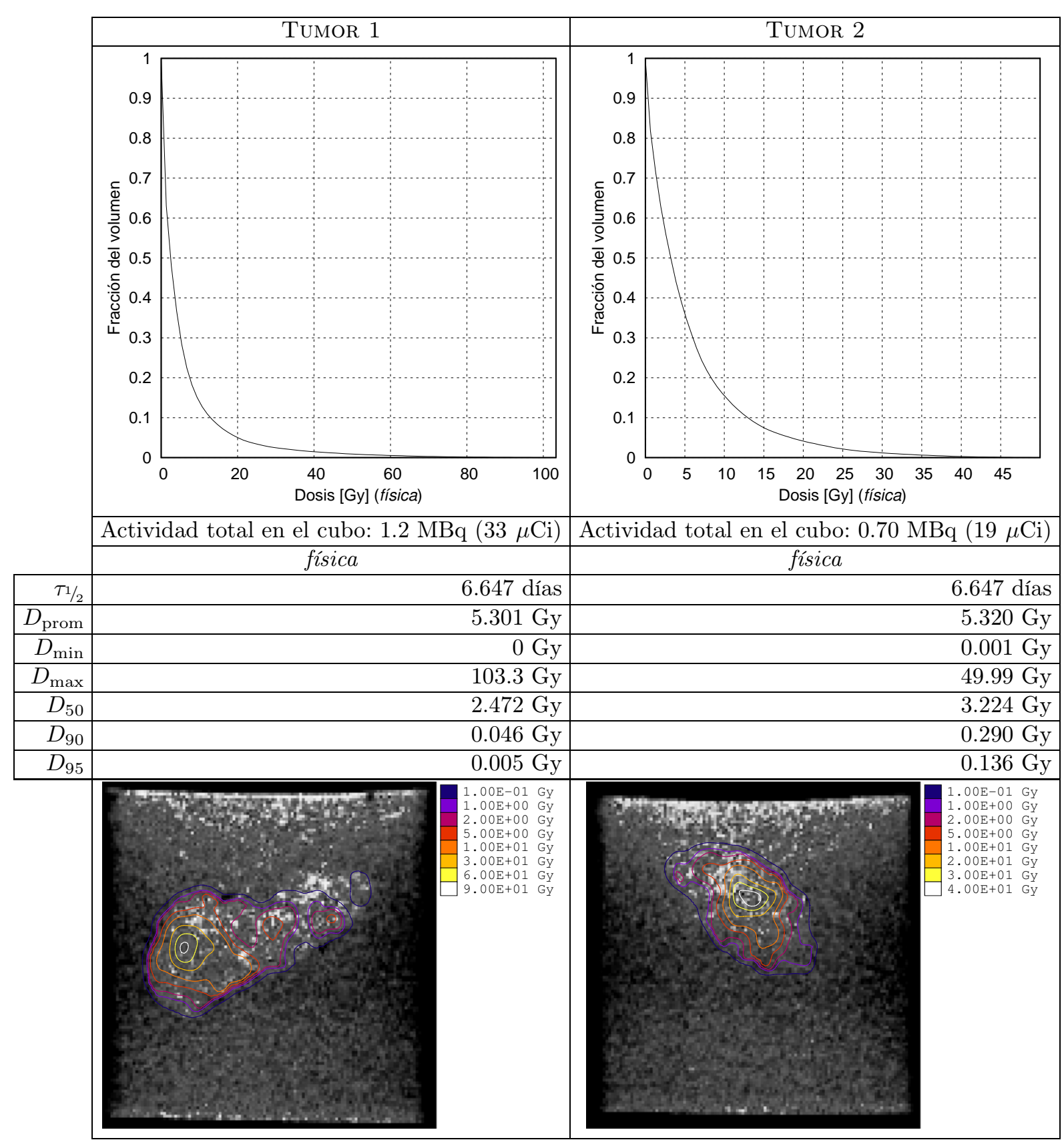

Figura 4.9. Estimaciones de dosis para los tumores fijados en los cubos de agarosa.

\subsection{Mediciones CON PELÍCUlAS DE TINTE RADIOCRÓMICO}

Las Figuras 4.10 y 4.11 muestran la comparación entre los mapas de dosis estimados a partir de las imágenes y los mapas de dosis medidos con las películas de tinte radiocrómico (PTR), para los tumores fijados en los cubos de agarosa. La estimación a partir de las imágenes se realizó tomando los cortes de la distribución de dosis estimada que corresponden a los lugares donde se insertó película de tinte radiocrómico en los cubos. Las zonas más oscuras en las imágenes de las películas de tinte radiocrómico corresponden a dosis mayores. Los valores de isodosis son los mismos en ambos casos, de acuerdo con la leyenda mostrada. 


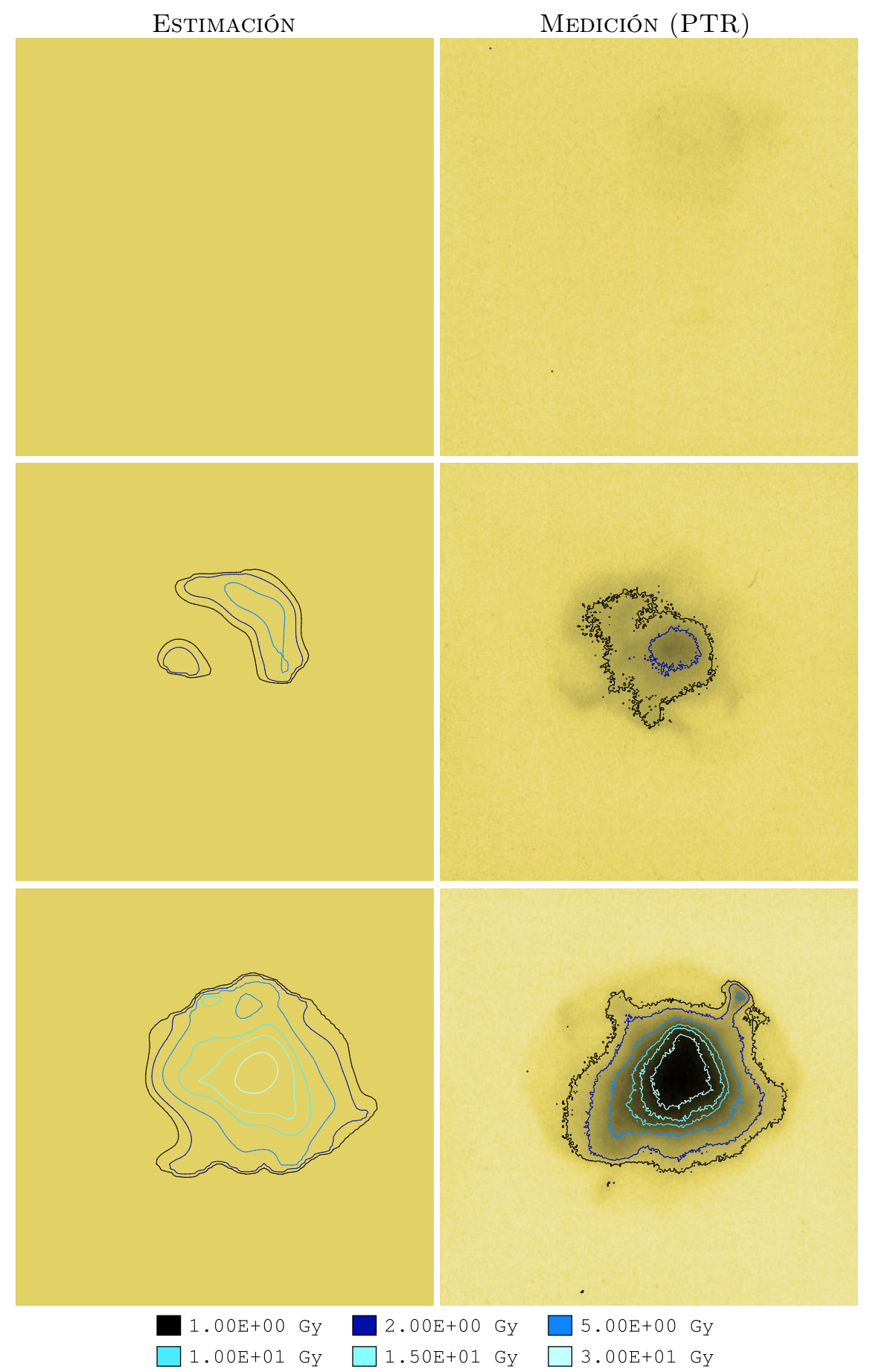

Figura 4.10. Mapas de dosis estimados y medidos para los cortes del tumor 1 . 


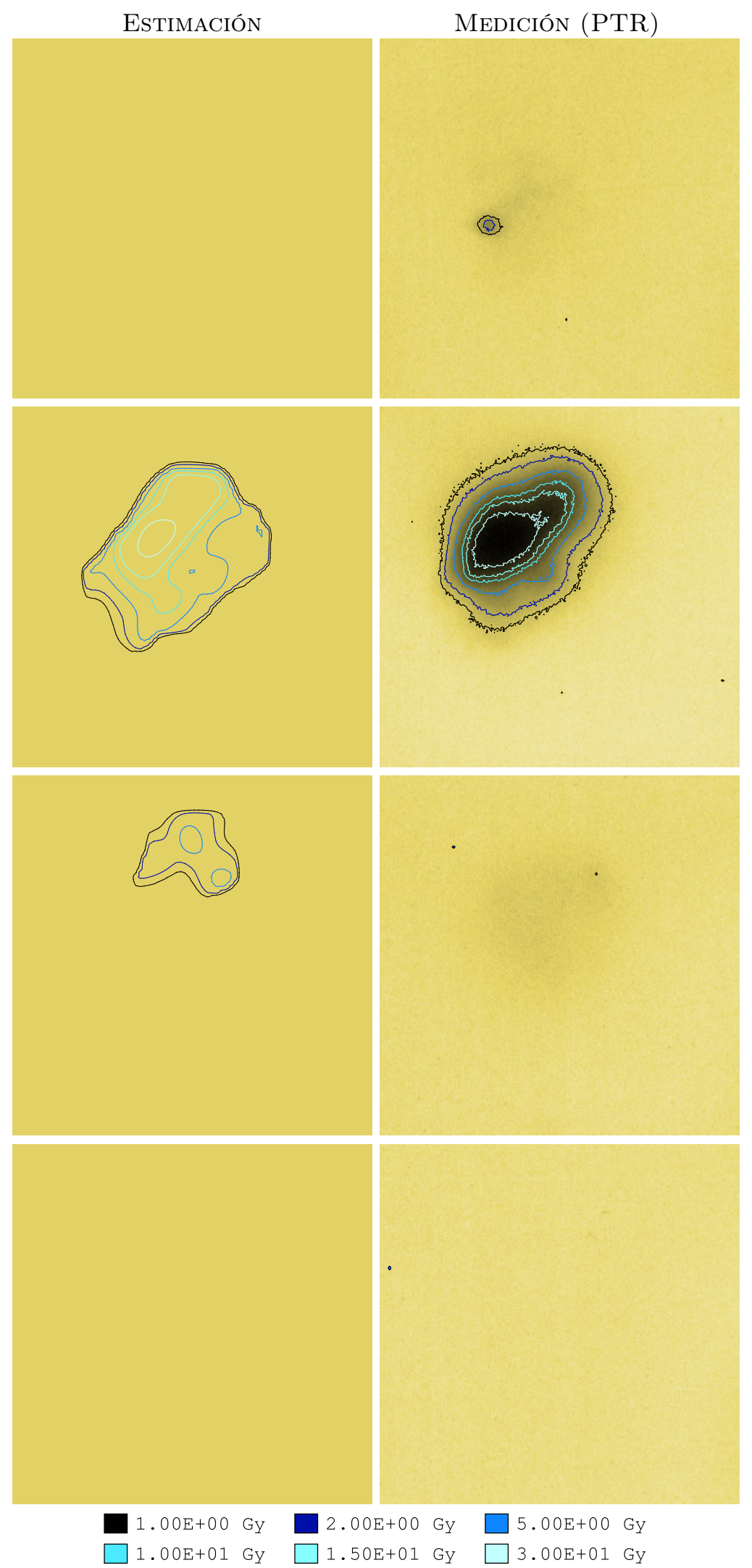

Figura 4.11. Mapas de dosis estimados y medidos para los cortes del tumor 2 . 



\section{Capítulo 5}

\section{DISCUSIÓN}

\subsection{IMÁGENES TOMOGRÁFICAS CUANTIFICADAS}

Para poder realizar una estimación certera de la dosis es necesario determinar con precisión la actividad a partir de las imágenes, siendo el objetivo último de la cuantificación el obtener un valor de actividad que sea correcto en el sentido absoluto ${ }^{[21]}$, es decir, libre de factores de proporcionalidad que dependan del estudio en cuestión. Para evaluar el comportamiento temporal es necesario el co-registro de las imágenes en la serie, lo cuál puede lograrse utilizando una CT como patrón de referencia. Si bien este segundo requisito se satisface de manera relativamente sencilla con un equipo de imagen multimodal para animales pequeños, lograr la cuantificación absoluta de la actividad es todo un reto ${ }^{[56]}$.

En el caso de la SPECT, los factores que afectan la cuantificación son múltiples y pueden dividirse en cuatro grupos de acuerdo a su origen ${ }^{[57,58,59]}$ : factores biológicos, físicos, técnicos y procedimentales. Entre los factores biológicos se encuentran la actividad administrada, la biocinética del radiofármaco y el tiempo de adquisición. Entre los factores físicos cuentan la atenuación, la dispersión y el decaimiento del radionúclido. Los factores técnicos incluyen la respuesta del sistema detector-colimador, la eficiencia de detección, el tiempo muerto, la resolución en energía, la uniformidad y linealidad de respuesta del detector y la alineación del sistema. Por último, los factores procedimentales comprenden el número de ángulos de proyección, el tiempo por proyección, la órbita del detector, el tamaño de pixel y el algoritmo de reconstrucción utilizado.

En este trabajo se trató de aproximarse lo más posible a la cuantificación absoluta en el contexto del equipo utilizado, incorporando las correcciones de calibración de los detectores (uniformidad y canales vs. energía) para la emisión del Lutecio-177 (208.4 keV), corrección por dispersión, decaimiento y el sistema colimadordetector en la reconstrucción y aplicación de un factor de calibración absoluta $(Q)$ pos-reconstrucción. Sin embargo, esto no asegura la confiabilidad de los resultados y serían necesarias más pruebas para determinar la exactitud de la cuantificación y el grado de dependencia con los factores involucrados. Sería deseable también poder estimar el error en la cuantificación de la actividad y propagarlo para ver su efecto en la estimación de la dosis.

\subsection{KERNEL DE DOSIS POR VOXEL}

Para dar validez al kernel de dosis por voxel así como al método de simulación, se realizó una comparación con algunos kernel reportados en la literatura. Dos artículos que reportan valores de un kernel para Lutecio-177 en tejido blando son Kagadis et al. (2012) ${ }^{[60]}$ y Lanconelli et al. $(2012)^{[61]}$.

Kagadis et al. calculan un kernel puntual total para Lutecio-177 en tejido blando, utilizando una geometría de esferas concéntricas voxelizadas, con el software GATE v6.1 (opengatecollaboration.org) basado en el código Geant4 4.9.4.p02 (geant4.web.cern.ch) de simulación del transporte de radiación por el método de Monte Carlo. Este kernel se genera considerando $4 \times 10^{7}$ partículas, que se emiten de manera isotrópica desde el centro de la esfera, e incluye emisiones beta, Auger y gamma, así como las partículas secundarias.

Lanconelli et al. utilizan DOSXYZnrc para calcular un kernel de dosis por voxel para Lutecio-177 en tejido blando, simulando fuentes isotrópicas monocromáticas al centro de un arreglo de voxeles cúbicos. Ellos simulan $2.5 \times 10^{7}$ partículas para cada energía de fotones y electrones y posteriormente suman las contribuciones de acuerdo al espectro del radionúclido para obtener el kernel total. El tamaño de voxel más pequeño que utilizan es de $2.21 \mathrm{~mm}$. 
La Figura 5.1 muestra la comparación entre estos dos kernel y los calculados en este trabajo, en unidades de dosis promedio por partícula como función de la distancia desde el voxel central. En primer lugar, se puede observar que la forma de los kernel cambia en función del tamaño de voxel, debido no sólo a que la dosis se calcula por unidad de volumen (si la densidad es constante) sino que las propiedades de depósito de energía de la radiación varían en función de la distancia. Debido a esto es difícil comparar directamente kernel calculados para tamaños de voxel distintos, por lo que se utiliza un enfoque cualitativo.

En el caso de Kagadis et al., al tratarse de un kernel puntual, se observa la divergencia conforme la distancia tiende a cero, la cuál impide asignar un valor de dosis al voxel central. Sin embargo, se observa que conforme disminuye el tamaño de voxel, los kernel calculados en este trabajo se le aproximan cada vez más. Para distancias alejadas del cero se observa una discrepancia muy pequeña (recuérdese que la dosis está en escala logarítmica). Por su parte, Lanconelli et al. utilizan un tamaño de voxel mucho mayor, por lo que fue necesario calcular un kernel acorde para realizar la comparación. En este caso se observa que ambos kernel son prácticamente idénticos, lo cuál no es de extrañar dado que en ambos casos se utilizó el mismo código para la simulación.

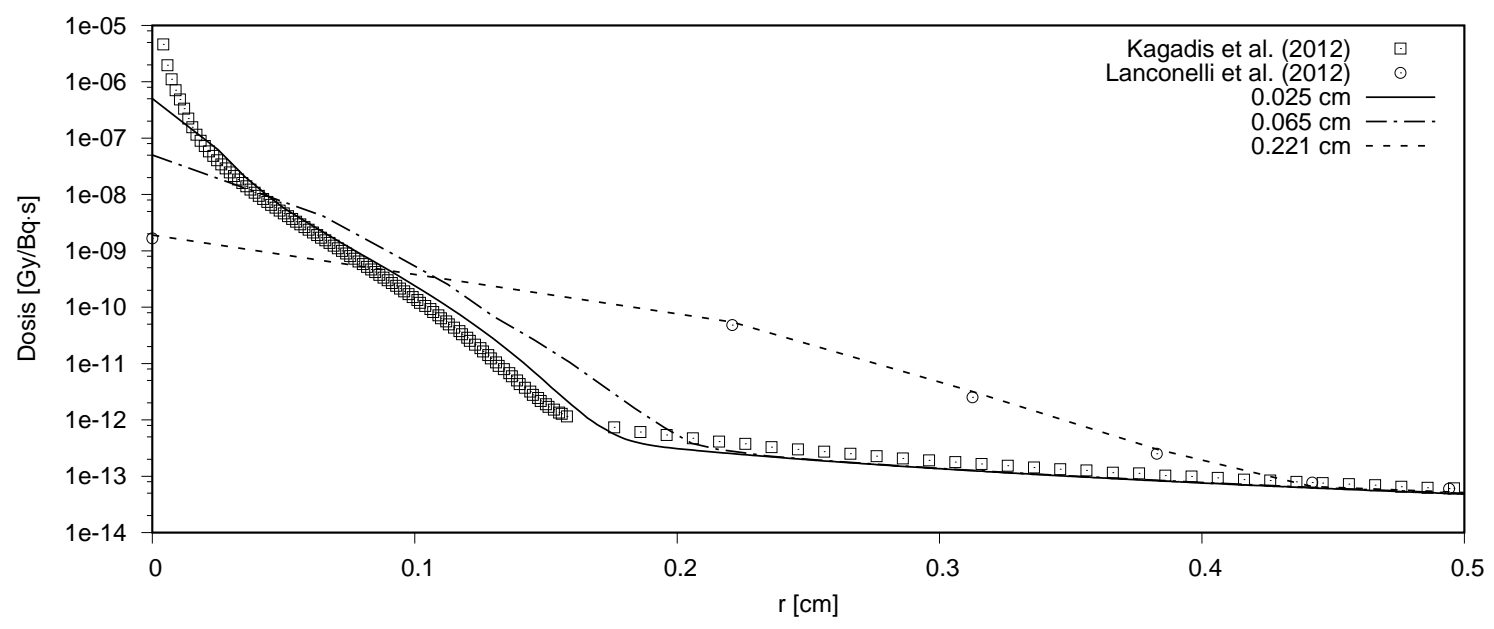

Figura 5.1. Comparación entre kernel de dosis por voxel para Lu-177: calculados vs. reportados en la literatura.

\subsection{SELECCIÓN DE REGIONES DE INTERÉS}

A partir del procedimiento seguido, se encontraron dos factores que dificultan la identificación anatómica de las regiones de interés: la falta de contraste y el ruido en las imágenes de CT. La determinación del borde interno del tumor no pudo realizarse de manera consistente en las distintas imágenes de la serie temporal, lo que dio como resultado amplias variaciones en el cálculo del volumen.

Una manera de mejorar esta situación sería utilizar rayos X de menor energía (para tener un mayor contraste en tejido blando) o bien introducir algún tipo de medio de contraste en el tumor. En el caso de los tumores fijados en los cubos de agarosa, una manera de aumentar el contraste podría ser añadiendo medio de contraste a la mezcla de agarosa y agua con que se preparan los cubos.

Sin embargo, la metodología de este trabajo no prescribe un procedimiento en particular. La identificación de regiones en imágenes anatómicas es un proceso cotidiano en el radiodiagnóstico, por lo que esta parte podría ser realizada por un experto, mejorando así la definición de la región. Además, el software xgrid3d utiliza un formato sencillo para la definición de las regiones de interés (lista de voxeles o matriz de bits), por lo que puede utilizarse otro software para definir la región y posteriormente importarse al flujo de trabajo. 


\subsection{Co-REgISTRO DE IMÁGENES DE LA SERIE TEMPORAL}

$\mathrm{Al}$ realizar el co-registro de las imágenes de CT se obtuvieron resultados consistentes sin importar cuál de las tres imágenes de la serie se usara como referencia. Si bien esto evidencia un buen procedimiento, no es posible asegurar que los voxeles en la serie de imágenes co-registradas correspondan realmente al mismo volumen físico en la geometría de adquisición de las imágenes. Esto supone una fuente de error irremediable que es necesario acotar, y que hace falta investigar para poder determinar su efecto en la calidad de los resultados finales.

Esta limitación es intrínseca al proceso de adquisición de estudios seriales (a pesar de utilizarse un mismo equipo y de contar con ambas modalidades de imagen en el mismo gantry) y al proceso de reconstrucción de las imágenes tomográficas (especialmente con voxeles tan pequeños), pues es muy difícil mantener al sujeto de estudio exactamente en la misma posición a lo largo de las adquisiciones con un margen de error menor a un milímetro, así como evitar que la imagen presente efectos de derrame (spill) entre los voxeles.

Una manera de mejorar esta situación sería utilizando voxeles de mayor tamaño, pues de este modo se facilita el traslape al nivel de voxel. Si bien las imágenes de SPECT tenían una resolución nativa mayor, debido al funcionamiento del proceso de fusión con las imágenes de CT, se terminó trabajando con voxeles más pequeños. Se hizo el intento de realizar la fusión en la matriz de SPECT, pero el resultado no fue satisfactorio; además, de este modo se dificulta la selección de las regiones de interés pues se pierde resolución anatómica. Debe recordarse, sin embargo, que la información más importante para realizar la metodología es el mapa de actividad, por lo que sería deseable trabajar con la resolución nativa de las imágenes de SPECT, evitando así la interpolación que es otra fuente de error difícil de cuantificar. En este sentido, sería conveniente realizar la fusión de las imágenes de manera externa al software del equipo utilizado, para tener mayor control y poder adaptar este proceso a los requisitos de la metodología.

\subsection{CÁlculo de aCtividad ACUmulada}

A pesar de que se obtuvieron distribuciones de actividad acumulada al nivel de voxel, ninguno de los dos enfoques utilizados es enteramente satisfactorio: el primero porque descarta el papel de la fisiología en la cinética del radiofármaco y el segundo porque utiliza un modelo global que descarta la cinética en cada voxel.

Una manera de mejorar esta situación sería realizar los estudios en intervalos de tiempo mayores tras la inyección, de modo que sólo se observase la fase de eliminación y fuera posible ajustar un modelo exponencial en cada voxel, o bien utilizar un modelo para la redistribución de la actividad al interior del tumor, que permitiera asociar una curva de actividad vs. tiempo en cada voxel de manera consistente; sin embargo, no se cuenta con un modelo de este tipo.

Otro factor que afecta la determinación de la curva de actividad vs. tiempo en cada voxel es el co-registro de las imágenes de la serie temporal, debido a las alteraciones geométricas en la forma del tumor a lo largo de la serie. Esta parece ser otra dificultad intrínseca de la metodología, pero se requiere de más pruebas para poder decir hasta qué punto afecta la calidad los resultados.

Por otro lado, si lo que se busca son solamente cálculos de tasa de dosis, estas dificultades desaparecen al utilizar cada imagen de la serie temporal de manera individual.

\subsection{EstimACIÓN DE DOSIS}

Para evaluar la confiabilidad de las dosis estimadas con la metodología de este trabajo, se realizó una comparación de la dosis promedio respecto a la calculada con el software OLINDA $1.1^{[62]}$, muy utilizado en la comunidad de medicina nuclear para la dosimetría al nivel de órganos y aprobado para uso clínico por la Food and Drug Administration (FDA). Los resultados presentados en la Tabla 5.1 utilizan los valores de actividad acumulada calculados con los dos enfoques (vida media física y vida media efectiva) como datos de entrada, por lo que son un reflejo solamente del método de estimación de dosis — la convolución con el kernel de dosis por voxel- y de la geometría de las regiones de interés. Se muestran resultados para las tres series temporales obtenidas del co-registro tomando cada una de las imágenes a su vez como referencia. 
Tabla 5.1. Comparación de la dosis promedio en los tumores: metodología de este trabajo vs. OLINDA 1.1.

\begin{tabular}{|r|r|r|r|r|r|}
\hline & Vida media & \multicolumn{2}{|c|}{ física } & \multicolumn{2}{c|}{ efectiva } \\
\hline Estudio & Volumen & Kernel & OLINDA & Kernel & OLINDA \\
\hline \multicolumn{7}{|c|}{ TuMOR 1} \\
\hline $0 \mathrm{~h}$ (ref.) & $0.974 \mathrm{~cm}^{3}$ & $10.79 \mathrm{~Gy}$ & $10.15 \mathrm{~Gy}$ & $0.235 \mathrm{~Gy}$ & $0.221 \mathrm{~Gy}$ \\
\hline $1 \mathrm{~h}$ (ref.) & $1.120 \mathrm{~cm}^{3}$ & $9.793 \mathrm{~Gy}$ & $10.59 \mathrm{~Gy}$ & $0.212 \mathrm{~Gy}$ & $0.230 \mathrm{~Gy}$ \\
\hline $3 \mathrm{~h}$ (ref.) & $0.995 \mathrm{~cm}^{3}$ & $10.42 \mathrm{~Gy}$ & $10.02 \mathrm{~Gy}$ & $0.228 \mathrm{~Gy}$ & $0.220 \mathrm{~Gy}$ \\
\hline cubo & $1.236 \mathrm{~cm}^{3}$ & $5.301 \mathrm{~Gy}$ & $6.347 \mathrm{~Gy}$ & - \\
\hline \multicolumn{6}{|c|}{ TuMOR 2} \\
\hline $0 \mathrm{~h}$ (ref.) & $0.930 \mathrm{~cm}^{3}$ & $5.491 \mathrm{~Gy}$ & $4.994 \mathrm{~Gy}$ & $0.051 \mathrm{~Gy}$ & $0.046 \mathrm{~Gy}$ \\
\hline $1 \mathrm{~h}$ (ref.) & $0.861 \mathrm{~cm}^{3}$ & $5.785 \mathrm{~Gy}$ & $4.871 \mathrm{~Gy}$ & $0.054 \mathrm{~Gy}$ & $0.046 \mathrm{~Gy}$ \\
\hline $3 \mathrm{~h}$ (ref.) & $0.764 \mathrm{~cm}^{3}$ & $6.166 \mathrm{~Gy}$ & $4.613 \mathrm{~Gy}$ & $0.059 \mathrm{~Gy}$ & $0.044 \mathrm{~Gy}$ \\
\hline cubo & $0.692 \mathrm{~cm}^{3}$ & $5.320 \mathrm{~Gy}$ & $3.604 \mathrm{~Gy}$ & - \\
\hline \multicolumn{7}{|c|}{}
\end{tabular}

Se observa que en general los valores son muy cercanos, indicando un buen acuerdo entre la estimación con el kernel calculado en este trabajo y el cálculo de OLINDA 1.1. Las discrepancias se deben a que OLINDA 1.1 calcula la dosis para esferas de densidad unitaria con un volumen de $1 \mathrm{~cm}^{3}$ (valor más cercano disponible en ese software), mientras que los tumores no son esféricos y sus volúmenes oscilan alrededor de este valor. Sin embargo, las variaciones son consistentes, siendo la dosis mayor para el kernel cuando el volumen del tumor es menor a $1 \mathrm{~cm}^{3}$ y mayor para OLINDA 1.1 cuando el volumen del tumor es mayor a $1 \mathrm{~cm}^{3}$.

Se observa también que, a pesar de que la actividad inyectada en ambos tumores fue similar $(608 \mu \mathrm{Ci}$ en el tumor 1 vs. $507 \mu \mathrm{Ci}$ en el tumor 2), en el caso del tumor 2 la eliminación fue aproximadamente el doble de rápida (vida media efectiva de $\cong 57$ min para el tumor 2 vs. $\cong 133$ min para el tumor 1 ), por lo que la actividad en la última imagen de la serie $(3 \mathrm{~h})$ fue aproximadamente la mitad ( $\cong 0.40 \mathrm{MBq}$ para el tumor 2 vs. $\cong 0.83 \mathrm{MBq}$ para el tumor 1 ); considerando que el tiempo de irradiación para la actividad acumulada fue aproximadamente el mismo en ambos casos, esto da lugar a una dosis para el tumor 2 de aproximadamente la mitad en el caso de la vida media física y la cuarta parte en el caso de la vida media efectiva, respecto al tumor 1. Por otro lado, la vida media física (6.647 días) es mucho mayor que la vida media efectiva en ambos casos, por lo que las dosis correspondientes son también mucho mayores.

\subsection{MEdiCIONES CON PELÍCULAS DE TINTE RADIOCRÓMICO}

Al comparar los mapas de dosis estimados y los obtenidos mediante las películas de tinte radiocrómico, se observan algunas discrepancias: presencia de contornos de isodosis en un caso pero no en el otro y variación en la forma de los contornos de isodosis. Sin embargo, la presencia en ambos casos de contornos de isodosis con los mismos valores en los cortes con mayor dosis, es indicativo de un acuerdo cuantitativo entre las dosis estimada y medida. Si bien no puede decirse nada a partir de este hecho sobre la confiabilidad de la estimación de dosis, no por eso deja de ser notable, ya que la estimación y la medición se realizaron por caminos completamente distintos.

Una manera de dar más fuerza a una comparación de este tipo sería asegurando que la geometría de los cubos de agarosa se mantuviera invariable a lo largo de todo el procedimiento, así como reduciendo el tiempo de exposición para evitar la saturación de la película y la degradación de los cubos durante el proceso de refrigeración, de modo que pudiera observarse un acuerdo en la forma de los contornos de isodosis entre la estimación y la medición.

De cualquier manera, se puede observar que la película de tinte radiocrómico tiene un gran potencial como herramienta para validar las estimaciones de dosis realizadas con la metodología. 


\section{Capítulo 6}

\section{CONCLUSIÓN Y PERSPECTIVAS}

Con base en los resultados, puede concluirse que se desarrolló con éxito y se implementó una metodología para estimar la distribución interna de dosis absorbida en un tumor sólido a partir de imágenes tomográficas.

Se observó que existen una multitud de factores que limitan y dificultan la dosimetría al nivel de voxel, por lo que hace falta seguir investigando para mejorar y refinar la metodología. Entre las principales dificultades están la cuantificación absoluta de las imágenes de SPECT, el co-registro geométrico de las imágenes a lo largo de la serie temporal y la falta de un modelo para la cinética que considere la redistribución de la actividad al interior de la región de interés.

Un aspecto fundamental para el desarrollo ulterior de la metodología y para establecer la confiabilidad de los resultados es la cuantificación del error introducido por cada una de las etapas en el resultado final. Considerando que se busca establecer una metodología de investigación preclínica, es imprescindible atender este problema, pues es necesario conocer el rango de operación y la exactitud de las estimaciones. El software desarrollado en este trabajo representa un esfuerzo en esta dirección, pues facilita la aplicación de la metodología y la pone al alcance de los usuarios, lo que contribuye a acelerar el proceso de validación y desarrollo de la misma.

La perspectiva a futuro es implementar la dosimetría Monte Carlo personalizada. Esta puede definirse como una metodología de evaluación dosimétrica que se basa en el uso de información específica del paciente y que utiliza la simulación del transporte de radiación por el método de Monte Carlo para estimar la distribución espacial y temporal de dosis absorbida en el paciente, con el propósito de optimizar los tratamientos de radioterapia interna ${ }^{[17]}$. La premisa de esta metodología es contar con información sobre la biodistribución y la biocinética del radiofármaco dentro del cuerpo del paciente y estimar la distribución de dosis absorbida, con el fin de realizar una evaluación sólida sobre los riesgos y beneficios del tratamiento, considerando la dosis absorbida por los tejidos enfermos y los tejidos sanos bajo las condiciones fisiológicas del paciente, y optimizar el tratamiento en términos de maximizar su eficacia manteniendo la toxicidad a los órganos limitantes dentro de los márgenes de seguridad.

La necesidad de la dosimetría Monte Carlo personalizada surge de que los procedimientos utilizados convencionalmente en la planificación del tratamiento por radioterapia interna - como la administración de actividades constantes o proporcionales al peso del paciente y el uso de maniquíes geométricos estandarizados al realizar cálculos de dosis para pacientes individuales - son inaceptables si lo que se busca es proveer de información significativa para la planificación de la terapia ${ }^{[21]}$, pues no toman en cuenta las diferencias en la geometría de los órganos y en la biocinética específicas al paciente, ni permiten calcular las distribuciones de dosis al interior de los órganos, todo lo cuál contribuye a una pobre planificación del tratamiento y una eficacia terapéutica reducida.

El software desarrollado en este trabajo puede servir también como plataforma para la implementación de este tipo de metodología más avanzado, ya que puede extenderse para atender las exigencias de la misma. 



\section{APÉNDICE}

\section{DESARROLLO EXPERIMENTAL}

\section{Crecimiento del modelo tumoral}

Para realizar la prueba de concepto de la metodología fue necesario crecer un modelo tumoral, lo cuál se llevó a cabo en Laboratorio de Física Médica e Imagen Molecular de la Unidad de Investigación Biomédica en Cáncer (INCan/UNAM) en colaboración con la Dra. Irene Vergara Bahena.

El proceso fue como sigue. Se hizo el cultivo de la línea celular MIA PaCa-2 de cáncer de páncreas humano, en medio de cultivo DMEM (Dulbecco's Modified Eagle Medium) + 10\% SFB (suero fetal bovino) y 1\% de antibiótico (PES, penicilina-estreptomicina). Las células se propagaron en cajas de $75 \mathrm{~cm}^{2}$ y se mantuvieron en incubadora a $37^{\circ} \mathrm{C}$ y $5 \% \mathrm{CO}_{2}(95 \%$ aire). Posteriormente se despegaron las células, se cuantificaron y fueron inoculadas en seis ratones atímicos machos $(\mathrm{nu} / \mathrm{nu})$, administrándose a cada uno $3 \times 10^{6}$ células en el lado derecho del lomo por vía subcutánea.

Tras nueve semanas, debido a retrasos por fallas técnicas y falta de disponibilidad del radiofármaco, los tumores habían alcanzado ya un tamaño considerable y se seleccionaron dos ratones con los tumores de mayor tamaño para realizar los estudios. Previo a la adquisición de las imágenes se midieron los tumores con un vernier en la dirección de mayor longitud $L$ y en una dirección perpendicular $W$, se pesaron los ratones, y se calcularon los volúmenes de los tumores mediante la fórmula para un elipsoide $V=\frac{\pi}{6} L \cdot W^{2}$.

Tabla 1. Peso de los ratones y dimensiones de los tumores.

\begin{tabular}{|c|c|c|c|c|}
\hline Ratón \# & Peso & $L$ & $W$ & $V$ \\
\hline 1 & $35 \mathrm{~g}$ & $14.93 \mathrm{~mm}$ & $11.50 \mathrm{~mm}$ & $1034 \mathrm{~mm}^{3}$ \\
\hline 2 & $35 \mathrm{~g}$ & $20.16 \mathrm{~mm}$ & $14.70 \mathrm{~mm}$ & $2281 \mathrm{~mm}^{3}$ \\
\hline
\end{tabular}

\section{ReAlizAción De los estudios De SPECT/CT}

Los estudios de SPECT/CT se realizaron con el equipo Albira del Laboratorio de Física Médica e Imagen Molecular de la Unidad de Investigación Biomédica en Cáncer (INCan/UNAM), en colaboración con el Dr. Luis Alberto Medina. El radiofármaco utilizado en los estudios fue ${ }^{177} \mathrm{Lu}$-DOTATOC, el cuál se utiliza en la clínica con fines terapéuticos, por lo que fue posible conseguir cantidades pequeñas $(<5 \mathrm{mCi}$, residuales) a través del Departamento de Medicina Nuclear del INCan.

Previo a la inyección, los ratones fueron anestesiados con isoflurano al $3 \%$ en oxígeno, condición que persistió durante la adquisición de las imágenes, con duración total de aproximadamente media hora por estudio. Las actividades de Lutecio-177 se determinaron con un activímetro Capintec ${ }^{\circledR}$ CRC-55tPET utilizando el número de calibración $430 * 10$. 
Al ratón 1 se le inyectó una actividad de $608 \mu \mathrm{Ci}$ y al ratón 2 se le inyectó una actividad de $507 \mu \mathrm{Ci}$, ambos de forma intratumoral; se realizaron estudios a los pocos minutos tras la inyección $(0 \mathrm{~h})$, pasada aproximadamente una hora $(1 \mathrm{~h})$ y pasadas aproximadamente tres horas $(3 \mathrm{~h})$. La Tabla 2 muestra los parámetros de adquisición de los estudios.

Tabla 2. Parámetros de adquisición de los estudios SPECT/CT de los tumores.

\begin{tabular}{|c|c|}
\hline \multicolumn{2}{|c|}{ SPECT } \\
\hline Campo de visión & $60 \mathrm{~mm}$ \\
\hline \# de proyecciones & 60 \\
\hline Tiempo por proyección & $20 \mathrm{~s}$ \\
\hline Colimador & pinhole \\
\hline Ventana principal & $208 \mathrm{keV} \pm 20 \%$ \\
\hline Ventana de dispersión ${ }^{*}$ & $145.5-166.5 \mathrm{keV}$ \\
\hline \multicolumn{2}{|c|}{ *implementada en pos-procesamiento $^{2}$}
\end{tabular}

\begin{tabular}{|c|c|}
\hline \multicolumn{2}{|c|}{ CT } \\
\hline \# de proyecciones & 600 \\
\hline Corriente & $900 \mu \mathrm{A}$ \\
\hline Voltaje & $35 \mathrm{kV}$ \\
\hline
\end{tabular}

\section{FIJACIÓN DE LOS TUMORES ex vivo EN UNA MATRIZ DE AGAROSA}

Al terminar el último estudio con cada ratón, se procedió a sacrificar al animal, extirpar el tumor y fijarlo en una matriz de agarosa al $2.5 \%$, formando un cubo semi-rígido de $3 \mathrm{~cm}$ por lado. Hecho esto, se procedió a medir su actividad con el activímetro y realizar un estudio de SPECT/CT con los mismos parámetros que en la Tabla 2, salvo 15 s por proyección.

Posteriormente se realizaron cortes transversales en cada cubo con una cuchilla afilada, cuidando de mantener la integridad y la geometría del tumor dentro del cubo. En el primer cubo se realizaron tres cortes y en el segundo cuatro, en dirección aproximadamente paralela a los cortes de las imágenes tomográficas de los estudios de SPECT/CT. En cada uno de estos cortes se introdujo un cuadrado de película de tinte radiocrómico, debidamente marcado con un número y una guía para la orientación.

\section{Cuantificación absoluta de la aCtividad}

Para lograr la cuantificación de las imágenes se contó con el apoyo de los ingenieros Emilio Giménez y Abel Orero de Oncovision (empresa que comercializa el equipo Albira), quienes realizaron la reconstrucción de las imágenes considerando la corrección por dispersión y la cuantificación para Lutecio-177, una vez que se les proporcionó la información necesaria para calcular el factor de cuantificación para este radionúclido. La corrección por atenuación fue estimada innecesaria dadas las dimensiones reducidas de los ratones.

La realización de los estudios para calcular el factor de cuantificación $(Q)$ consistió en llenar un bote de plástico con agua y Lutecio-177 a distintas concentraciones uniformes de actividad y tomar una imagen de SPECT en cada caso, utilizando la misma geometría de adquisición y algoritmo de reconstrucción que para los tumores; esto con el objeto de asociar la concentración de actividad conocida con precisión al valor de voxel promedio en la imagen reconstruida correspondiente. Dada la baja intensidad de la emisión de $208.4 \mathrm{keV}$ (11\%) del Lutecio-177, fue necesario utilizar un tiempo por proyección largo (por lo menos 2 minutos) para obtener una buena estadística de conteo. Adicionalmente se tomó una imagen sin colimadores con $\sim 20 \mu \mathrm{Ci}$ de Lutecio-177, necesaria para recalibrar las cámaras en uniformidad y correspondencia entre canales del detector y energía. La Figura 1 muestra la recta de calibración entre la concentración de cuentas en las imágenes y la concentración de actividad real obtenida para Lutecio-177. 


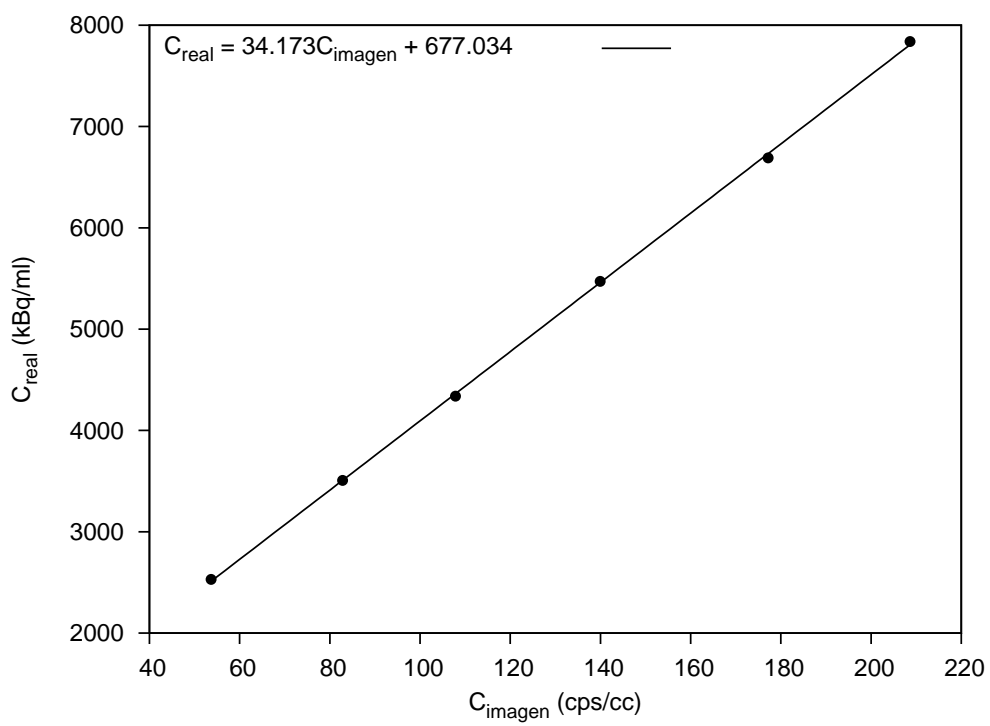

Figura 1. Recta de calibración entre la concentración de cuentas en las imágenes y la concentración de actividad real para Lutecio-177.

A pesar de realizarse este proceso de cuantificación, se encontró una actividad total en el primer estudio $(0 \mathrm{~h})$ menor que la actividad inyectada, estando involucrados los siguientes factores a tomar en cuenta ${ }^{1}$ :

1. La corrección por dispersión no se aplica al calcular el factor $Q$ pero sí al reconstruir los estudios, por lo que se descarta una parte de las cuentas y se obtienen valores menores de actividad.

2. Al no realizarse la corrección por atenuación se afecta la cuantificación, pues parte de los fotones emitidos no llegan a los detectores, resultando en un número menor de cuentas, que de no corregirse se traduce en una actividad menor.

3. Parte de la actividad inyectada puede hallarse fuera del campo de visión de la imagen.

\section{LeCtura de LAS PELÍCUlas DE TINTE RADIOCRÓMICO}

La lectura de las películas de tinte radiocrómico se llevó a cabo con un escáner de cama plana Microtek ScanMaker 8700 en modo de transmisión. Previo a la lectura se hicieron pruebas para hallar una zona lo más libre posible de líneas muertas en el detector del escáner y se limpió el vidrio de la cama del escáner con alcohol. Una vez que se retiraron las películas de cada cubo de agarosa, se lavaron con agua y espuma de jabón para retirar los residuos de material radiactivo. Al momento de la lectura se colocaron las películas irradiadas sobre el vidrio del escáner junto con un cuadrado de película sin irradiar, cuidando de preservar la misma orientación en todas y con el lado corto de la hoja original de película paralelo a la dirección del barrido de la lámpara ${ }^{[63]}$. La digitalización se realizó con ayuda del software Microtek ScanWizard Pro V7.10, utilizando los parámetros mostrados en la Tabla 3.

Tabla 3. Parámetros de digitalización de las películas de tinte radiocrómico.

\begin{tabular}{|c|c|}
\hline Modo de color & RGB 48-bit \\
\hline Resolución & 300 ppi \\
\hline Procesamiento (filtros, etc.) & ninguno \\
\hline Modo de película & positivo \\
\hline Formato de imagen & TIFF \\
\hline
\end{tabular}

1. Comunicación personal con Abel Orero. 
Para obtener la curva patrón se irradiaron cuadrados de película GafChromic ${ }^{\circledR}$ EBT3 (no. lote A10171102) de $3 \mathrm{~cm}$ por lado con dosis nominales de 1, 2, 4, 8, 16 y $32 \mathrm{~Gy}$, utilizando un acelerador lineal Varian ${ }^{\circledR}$ UNIQUE de $6 \mathrm{MV}$ en un campo de $10 \times 10 \mathrm{~cm}$ (tasa de dosis de 1.01 cGy/UM en $D_{\max }$ ). Para la irradiación se preparó un maniquí consistente de un espesor de $6.8 \mathrm{~cm}$ de lucita más un espesor de $5 \mathrm{~cm}$ de agua sólida $\left(\mathrm{PTW}^{\circledR}\right.$ RW3), por debajo de una hoja de papel con las películas acomodadas en un cuadrado de $10 \mathrm{~cm}$ por lado y un espesor de $1.5 \mathrm{~cm}\left(=D_{\max }\right.$ para $\left.6 \mathrm{MV}\right)$ de agua sólida por encima. La cama se acomodó de modo que la distancia fuente-superficie (SSD) fuera de $100 \mathrm{~cm}$ hasta la placa superior del maniquí. La irradiación fue acumulativa, retirando cada vez la película correspondiente al valor alcanzado de dosis acumulada. Esta parte se realizó en colaboración con el M. en C. Miguel Rodríguez Ponce, titular del Departamento de Biofísica de la Subdirección de Radioterapia del INCan.

A partir de las imágenes digitalizadas de las películas de calibración (con los parámetros de la Tabla 3), se graficó el valor de dosis actual contra la respuesta promedio en la parte central del cuadrado de película correspondiente y se ajustó una función racional del tipo:

$$
R(D)=a+\frac{b}{D-c}
$$

donde $R$ es la respuesta, $D$ es la dosis y $a, b, c$ son los parámetros de ajuste. Este tipo de funciones son recomendables pues son fáciles de invertir, muestran un comportamiento asintótico acorde a la saturación de la película y requieren pocos puntos de calibración ${ }^{[64]}$.

Una vez que se contó con la curva patrón, la dosis en las películas se obtuvo mediante la función inversa:

$$
D(R)=c+\frac{b}{R-a}
$$

con una incertidumbre (considerando todas las variables independientes) dada por:

$$
\sigma_{D}=\sqrt{\sigma_{c}^{2}+\left(\frac{b}{R-a}\right)^{2}\left(\frac{\sigma_{b}^{2}}{b^{2}}+\frac{\sigma_{R}^{2}+\sigma_{a}^{2}}{(R-a)^{2}}\right)} .
$$

La Figura 2 muestra la curva patrón obtenida para la respuesta del canal verde del escáner.

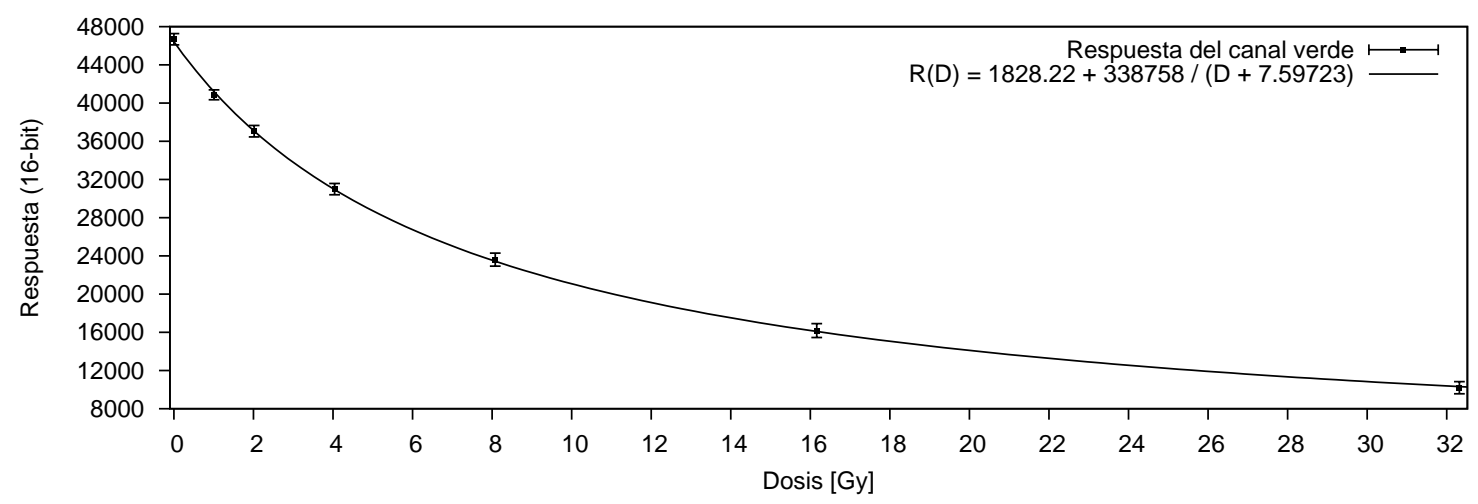

Figura 2. Curva patrón de la respuesta del canal verde del escáner contra dosis. 


\section{BiBLIOGRAFÍA}

[1] Organización Mundial de la Salud. Cáncer, febrero 2017. Nota descriptiva No. 297.

[2] Instituto Nacional del Cáncer (EE. UU.). Diccionario de cáncer: tumor sólido, marzo 2017.

[3] Secretaría de Salud. Informe sobre la Salud de los Mexicanos 2015, 2015.

[4] Stewart y Wild. World Cancer Report 2014. Technical report, International Agency for Research on Cancer, 2014.

[5] Luis Alberto Medina. Inmunoliposomas cargados con cisplatino y radiomarcados con emisores de partículas cargadas: estudios preclínicos de caracterización y respuesta terapéutica. Protocolo de investigación, 2016.

[6] Kostarelos, Emfietzoglou, y Stamatelou. Liposome-mediated delivery of radionuclides to tumor models for cancer radiotherapy: a quantitative analysis. Journal of Liposome Research, 9:407-424, 1999.

[7] Emfietzoglou, Kostarelos, y Sgouros. An analytic dosimetry study for the use of radionuclide-liposome conjugates in internal radiotherapy. Journal of Nuclear Medicine, 42:499-504, 2001.

[8] Luis A. Medina, Beth Goins, Mercedes Rodríguez-Villafuerte, Ande Bao, et al. Spatial dose distributions in solid tumours from ${ }^{186}$ Re transported by liposomes using HS radiochromic media. European Journal of Nuclear Medicine and Molecular Imaging, 34:1039-1049, 2007.

[9] Emfietzoglou, Kostarelos, Papakostas, Yang, et al. Liposome-mediated radiotherapeutics within avascular tumor spheroids: Comparative dosimetry study for various radionuclides, liposome systems, and a targeting antibody. Journal of Nuclear Medicine, 46:89-97, 2005.

[10] Allard, Hindré, Passirani, Lemaire, et al. ${ }^{188}$ Re-loaded lipid nanocapsules as a promising radiopharmaceutical carrier for internal radiotherapy of malignant gliomas. European Journal of Nuclear Medicine and Molecular Imaging, 35:1838-1846, 2008.

[11] Chang, Hsu, Chang, Lan, et al. Therapeutic efficacy of ${ }^{188}$ Re-liposome in a C26 murine colon carcinoma solid tumor model. Investigational New Drugs, 31:801-811, 2013.

[12] Phillips, Goins, y Bao. Radioactive liposomes. Wiley Interdisciplinary Reviews: Nanomedicine and Nanobiotechnology, 1:69-83, 2009.

[13] Lambert, Bacher, y Defreyne. Rhenium-188 based radiopharmaceuticals for treatment of liver tumours. Quarterly Journal of Nuclear Medicine and Molecular Imaging, 53:305-310, 2009.

[14] F. F. Knapp Jr. Rhenium-188 - A generator-derived radioisotope for cancer therapy. Cancer Biotherapy Radiopharmaceuticals, 13(5):337-349, 1998.

[15] Comisión Internacional de Protección Radiológica. Nuclear decay data for dosimetric calculations. Annals of the ICRP, 38(3), 2008. Publicación ICRP 107.

[16] Joshua Grimes. Patient-specific internal dose calculation techniques for clinical use in targeted radionuclide therapy. $\mathrm{PhD}$ thesis, University of British Columbia, 2013.

[17] Alice Petitguillaume. Dosimétrie Monte Carlo personnalisée pour la planification et l'évaluation des traitements de radiothérapie interne: développement et application à la radiothérapie interne sélective (SIRT). PhD thesis, Université Paris-Sud, 2014.

[18] Frank Herbert Attix. Introduction to Radiological Physics and Radiation Dosimetry. John Wiley \& Sons, 1986.

[19] Ervin B. Podgoršak. Radiation Physics for Medical Physicists. Springer, 2006.

[20] Yuri A. Berezhnoy. The Quantum World of Nuclear Physics. World Scientific, 2005.

[21] Habib Zaidi y George Sgouros, editors. Therapeutic Applications of Monte Carlo Calculations in Nuclear Medicine. Institute of Physics, 2003.

[22] Evelyn E. Watson, Michael G. Stabin, y Jeffry A. Siegel. MIRD formulation. Medical Physics, 20(2):511-514, 1993.

[23] Bolch, Eckerman, Sgouros, y Thomas. MIRD Pamphlet No. 21: A generalized schema for radiopharmaceutical dosimetry - Standarization of nomenclature. Journal of Nuclear Medicine, 50:477-484, 2009.

[24] Ivar Stakgold y Michael J. Holst. Green's Functions and Boundary Value Problems. John Wiley \& Sons, 2011.

[25] Walter S. Snyder, Mary R. Ford, y Gordon G. Warner. MIRD Pamphlet No. 5, revised: Estimates of specific absorbed fractions for photon sources uniformly distributed in various organs of a heterogeneous phantom. Technical report, Society of Nuclear Medicine, 1978.

[26] Bolch, Bouchet, Robertson, et al. MIRD Pamphlet No. 17: The dosimetry of nonuniform activity distributions - Radionuclide S values at the voxel level. Journal of Nuclear Medicine, 40:11S-36S, 1999.

[27] Giap, Macey, Bayouth, y Boyer. Validation of a dose-point kernel convolution technique for internal dosimetry. Physics in Medicine and Biology, 40:365-381, 1995.

[28] Curtis R. Vogel. Computational Methods for Inverse Problems. SIAM, 2002.

[29] Simon Cherry, James Sorenson, y Michael Phelps. Physics in Nuclear Medicine. Elsevier Saunders, 4 edition, 2012. 
[30] Jerrold T. Bushberg, J. Anthony Seibert, Edwin M. Leidholdt Jr, y John M. Boone. The Essential Physics of Medical Imaging. Lippincott Williams \& Wilkins, 2012.

[31] Albert Tarantola. Inverse Problem Theory and Model Parameter Estimation. SIAM, 2005.

[32] Charles L. Epstein. Introduction to the Mathematics of Medical Imaging. Society for Industrial and Applied Mathematics, 2 edition, 2008.

[33] Alex F. Bielajew. Fundamentals of the Monte Carlo method for neutral and charged particle transport. University of Michigan, 2001.

[34] Stephen A. Dupree y Stanley K. Fraley. A Monte Carlo Primer. A Practical Approach to Radiation Transport. Springer, 2002.

[35] Jun S. Liu. Monte Carlo Strategies in Scientific Computing. Springer, 2004.

[36] Alireza Haghighat. Monte Carlo Methods for Particle Transport. CRC Press, 2015.

[37] Forrest B. Brown. Fundamentals of Monte Carlo particle transport. Technical Report LA-UR-05-4983, Los Alamos National Laboratory, 2005. Notas de un curso sobre el método de Monte Carlo aplicado al transporte de partículas.

[38] Theodore M. Jenkins, R. Nelson, Walter, y Alessandro Rindi, editors. Monte Carlo Transport of Electrons and Photons. Plenum Press, 1988. Actas de la 8va Escuela Internacional de Daño y Protección Radiológicos.

[39] I. Kawrakow, E. Mainegra-Hing, D.W.O. Rogers, F. Tessier, y B.R.B. Walters. The EGSnrc code system: Monte Carlo simulation of electron and photon transport. Technical Report PIRS-701, National Research Council Canada, 2015.

[40] B. Walters, I. Kawrakow, y D.W.O. Rogers. DOSXYZnrc users manual. Technical Report PIRS-794revB, National Research Council Canada, 2013.

[41] D.W.O. Rogers, B. Walters, y I. Kawrakow. BEAMnrc users manual. Technical Report PIRS-0509(A)revL, National Research Council Canada, 2013.

[42] F. Sánchez, A. Orero, A. Soriano, C. Correcher, et al. ALBIRA: A small animal PET/SPECT/CT imaging system. Medical Physics, 40(5), 2013.

[43] Sébastien Ourselin, A Roche, G Subsol, Xavier Pennec, y Nicholas Ayache. Reconstructing a 3D structure from serial histological sections. Image and Vision Computing, 19:25-31, 2001.

[44] Sébastien Ourselin, Radu Stefanescu, y Xavier Pennec. Robust registration of multi-modal images: Towards real-time clinical applications. In Takeyoshi Dohi y Ron Kikinis, editors, Medical Image Computing and Computer-Assisted Intervention - MICCAI 2002, volume 2489 of Lecture Notes in Computer Science, pages 140-147, 2002.

[45] Marc Modat. README.txt, 2009. Archivo parte de la distribución del código fuente del software NiftyReg 1.3.9.

[46] National Institute of Standards y Technology (NIST). 2014 CODATA recommended values: elementary charge, 2015.

[47] Matteo Frigo y Steven G. Johnson. The design and implementation of FFTW3. Proceedings of the IEEE, 93(2):216-231, 2005.

[48] J. Sorriaux, A. Kacperek, S. Rossomme, J.A. Lee, D. Bertrand, S. Vynckier, y E. Sterpin. Evaluation of Gafchromic ${ }^{\circledR}$ EBT3 films characteristics in therapy photon, electron and proton beams. Physica Medica, pages 1-10, 2012.

[49] Martin J. Butson, Peter K.N. Yu, Tsang Cheung, y Peter Metcalfe. Radiochromic film for medical radiation dosimetry. Materials Science and Engineering R, 41:61-120, 2003.

[50] David F. Lewis. Practical guide to radiochromic film EBT2/EBT3, 2012.

[51] International Specialty Products. Gafchromic EBT3, 2011. Folleto de producto.

[52] Ole Tange. GNU Parallel - the command-line power tool. ;login: The USENIX Magazine, pages 42-47, 2011.

[53] H. Brönnimann, J. Iacono, J. Katajainen, P. Morin, et al. Space-efficient planar convex hull algorithms. Theoretical Computer Science, 321(1):25-40, 2004.

[54] Kenneth Moreland. Diverging color maps for scientific visualization. In G. Bebis et al., editors, ISVC 2009: Advances in Visual Computing, volume 5876 of Lecture Notes in Computer Science, pages 92-103. Springer, 2009.

[55] William Kahan. Pracniques: further remarks on reducing truncation errors. Communications of the ACM, 8(1):40, 1965.

[56] Yuni K. Dewaraja. Quantitative SPECT for dosimetry, 2008. Diapositivas para el SNM 2008 Annual Meeting.

[57] Yuni K. Dewaraja, Eric C. Frey, George Sgouros, et al. MIRD Pamphlet No. 23: Quantitative SPECT for patient-specific 3-dimensional dosimetry in internal radionuclide therapy. Journal of Nuclear Medicine, 53:1310-1325, 2012.

[58] M.S. Rosenthal, J. Cullom, W. Hawkins, S.C. Moore, B.M.W. Tsui, y M. Yester. Quantitative SPECT imaging: a review and recommendations by the Focus Committee of the Society of Nuclear Medicine Computer and Instrumentation Council. Journal of Nuclear Medicine, 36:1489-1513, 1995.

[59] Benjamin M.W. Tsui, Xide Zhao, Eric C. Frey, y William H. McCartney. Quantitative Single-Photon Emission Computed Tomography: Basics and clinical considerations. Seminars in Nuclear Medicine, 24(1):38-65, 1994.

[60] Panagiotis Papadimitroulas, George Loudos, George C. Nikiforidis, y George C. Kagadis. A dose point kernel database using GATE Monte Carlo simulation toolkit for nuclear medicine applications: comparison with other Monte Carlo codes. Medical Physics, 39(8):5238-5247, 2012.

[61] N. Lanconelli, M. Pacilio, S. Lo Meo, F. Botta, et al. A free database of radionuclide voxel S values for the dosimetry of nonuniform activity distributions. Physics in Medicine and Biology, 57:517-533, 2012.

[62] Michael G. Stabin, Richard B. Sparks, y Eric Crowe. OLINDA/EXM: The second-generation personal computer software for internal dose assessment in nuclear medicine. Journal of Nuclear Medicine, 46:1023-1027, 2005.

[63] H. Alva, H. Mercado-Uribe, M. Rodríguez-Villafuerte, y M. E. Brandan. The use of a reflective scanner to study radiochromic film response. Physics in Medicine and Biology, pages 2925-2933, 2002.

[64] Ashland Inc. Gafchromic ${ }^{\mathrm{TM}}$ dosimetry media, type EBT-3, 2016. 
ESTIMACIÓN COMPUTACIONAL DE LA DISTRIBUCIÓN INTERNA DE DOSIS ABSORBIDA EN UN TUMOR SOLIDO A PARTIR DE IMÁGENES TOMOGRAFICAS

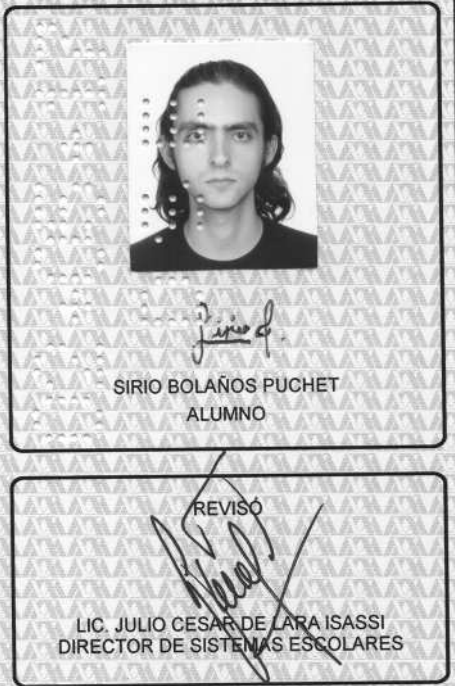

Bajo la Presidencia del primero y con carácter de Secretario el último, se reunieron para proceder al Examen de Grado cuya denominación aparece al margen, para la obtención del grado de:

MAESTRO EN CIENCIAS (MATEMATICAS APLICADAS E INDUSTRIALES) DE: SIRIO BOLANOS PUCHET

y de acuerdo con el articulo 78 fracción III del Reglamento de Estudios Superiores de la Universidad Autónoma Metropolitana, los miembros del jurado resolvieron:

$$
\text { Aprobar }
$$

Acto continuo, el presidente del jurado comunicó a interesado el resultado de la evaluación y, en caso aprobatorio, le fue tomada la protesta.

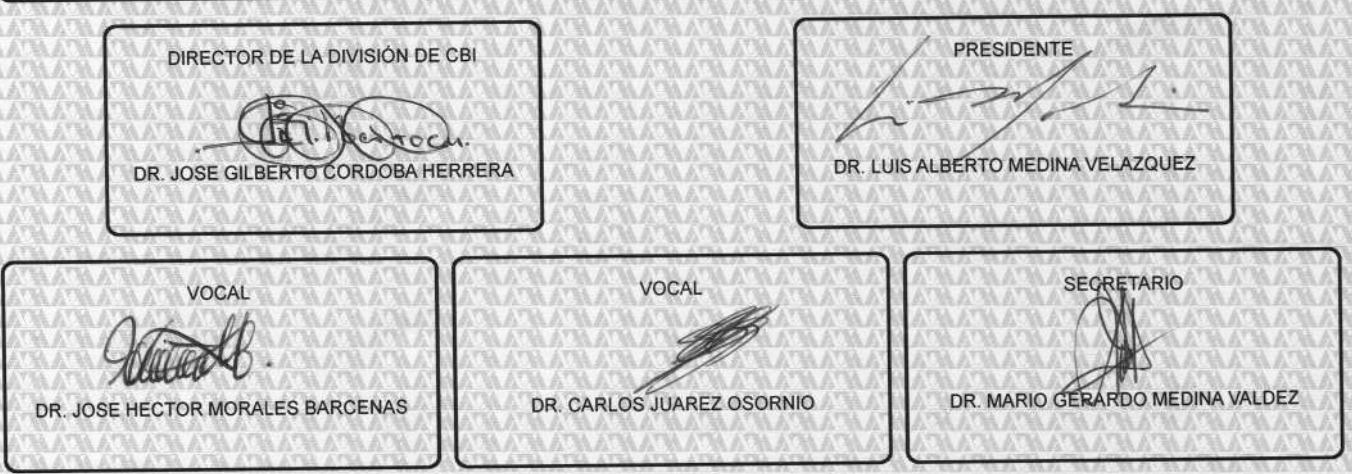

